\title{
Review \\ Pharmacokinetics and Pharmacodynamics of Intranasal Solid Lipid Nanoparticles and Nanostructured Lipid Carriers for Nose-to-Brain Delivery
}

\author{
Thi-Thao-Linh Nguyen (D) and Han-Joo Maeng *
}

check for updates

Citation: Nguyen, T.-T.-L.; Maeng,

H.-J. Pharmacokinetics and Pharmacodynamics of Intranasal Solid Lipid Nanoparticles and Nanostructured Lipid Carriers for Nose-to-Brain Delivery. Pharmaceutics 2022, 14, 572. https://doi.org/ 10.3390/pharmaceutics14030572

Academic Editors: Giuseppe Trapani and Massimo Conese

Received: 10 February 2022

Accepted: 3 March 2022

Published: 5 March 2022

Publisher's Note: MDPI stays neutral with regard to jurisdictional claims in published maps and institutional affiliations.

Copyright: (C) 2022 by the authors. Licensee MDPI, Basel, Switzerland. This article is an open access article distributed under the terms and conditions of the Creative Commons Attribution (CC BY) license (https:// creativecommons.org/licenses/by/ $4.0 /)$.
College of Pharmacy, Gachon University, 191 Hambakmoe-ro, Yeonsu-gu, Incheon 21936, Korea; linh.nguyen@gachon.ac.kr

* Correspondence: hjmaeng@gachon.ac.kr; Tel.: +82-32-820-4935

\begin{abstract}
Nose-to-brain drug delivery has been of great interest for the treatment of many central nervous system (CNS) diseases and psychiatric disorders over past decades. Several nasally administered formulations have been developed to circumvent the blood-brain barrier and directly deliver drugs to the CNS through the olfactory and trigeminal pathways. However, the nasal mucosa's drug absorption is insufficient and the volume of the nasal cavity is small, which, in combination, make nose-to-brain drug delivery challenging. These problems could be minimized using formulations based on solid lipid nanoparticles (SLNs) or nanostructured lipid carriers (NLCs), which are effective nose-to-brain drug delivery systems that improve drug bioavailability by increasing drug solubility and permeation, extending drug action, and reducing enzymatic degradation. Various research groups have reported in vivo pharmacokinetics and pharmacodynamics of SLNs and NLCs nose-to-brain delivery systems. This review was undertaken to provide an overview of these studies and highlight research performed on SLN and NLC-based formulations aimed at improving the treatment of CNS diseases such neurodegenerative diseases, epilepsy, and schizophrenia. We discuss the efficacies and brain targeting efficiencies of these formulations based on considerations of their pharmacokinetic parameters and toxicities, point out some gaps in current knowledge, and propose future developmental targets.
\end{abstract}

Keywords: nose-to-brain; drug delivery; SLNs; NLCs; central nervous system; blood-brain barrier; brain targeting; pharmacokinetics; pharmacodynamics

\section{Introduction}

Drug development for central nervous system (CNS) diseases and psychiatric disorders is challenging due to the side effects of drugs, the complexity of the brain, and notably, the lack of efficient strategies to deliver drugs across the blood-brain barrier (BBB) $[1,2]$. The BBB is composed of tightly connected endothelial capillary cells and plays a critical role in protecting the CNS from pathogens and solutes in blood [3]. Solute molecules can cross the BBB via different mechanisms. Several lipid-soluble molecules can enter the brain by passive diffusion. In this mechanism, the molecule lipophilicity generally defines the penetration rate and extent into the brain. However, many of these molecules are usually pumped back to the circulatory system by some efflux pumps expressed in the BBB. Small polar molecules, such as amino acids, glucose, nucleosides, and organic anions and cations, are transported by carrier-mediated transport. Another mechanism is receptor-mediated transcytosis, which transports large molecules, such as iron, insulin, and leptin [4]. Similar to Lipinski's rule of five, the permeation of a molecule across the BBB depends on its molecular weight, lipophilicity, $\mathrm{H}$ bond donors and acceptors, charge, and polar surface area $[5,6]$. Thus, only a small number of hydrophobic and low molecular weight molecules can cross the BBB, whereas others are restricted by the barrier characteristics of the BBB, which makes it difficult to develop drugs that target the brain [7]. 
During recent years, intranasal (IN) administration, a non-invasive drug delivery approach for local or systemic effects, has been used to provide direct nose-to-brain transport. Due to the presence of direct anatomical connection between the CNS and the nasal cavity, IN administration can provide the access of drugs to the CNS [8-11]. As compared to parenteral administration, IN delivery can overcome the BBB, provide faster brain delivery, and enhance drug targeting and drug bioavailability. Furthermore, IN administration avoids gastrointestinal and hepatic metabolisms, decreases drug accumulation in non-targeted organs, and reduces systemic side effects [12-14]. Therefore, nose-to-brain delivery is an effective approach to manage CNS diseases and psychiatric disorders.

Despite these advantages, IN administration for nose-to-brain transport has several limitations that must be overcome during the development of novel formulations. First, the administration volume for each nostril is limited $(<200 \mu \mathrm{L})$ in humans, making this route challenging for drugs requiring high doses. Second, administered samples are easily lost due to mucociliary clearance, a primary defense mechanism that prevents pathogens, toxins, and particles from entering the body [15]. Thus, formulations may have short residence times (15-30 $\mathrm{min}$ ) in the nasal cavity, which confines the drug absorption. Third, enzymes in the nasal cavity can metabolize a number of drugs, and thus, these drugs need to be protected from enzymatic degradation [16,17]. Forth, IN formulations must not cause irritation in the nasal cavity, i.e., these formulations need to have $\mathrm{pH}$ values and viscosities compatible with nasal mucosa and their components do not induce destruction or inflammation of the nasal epithelium [18]. In recent years, many formulation approaches including liposomes, emulsions, polymeric nanoparticles, inorganic nanoparticles, solid lipid nanoparticles (SLNs), and nanostructured lipid carriers (NLCs) have been developed to address these issues [19-25]. In particular, formulations based on SLNs and NLCs provide effective nose-to-brain transport to improve drug bioavailability by increasing drug solubility, drug permeation, and stability, extending the drug action, and reducing enzymatic degradation. SLNs and NLCs can also be loaded into hydrogel systems $[26,27]$ or coated with mucoadhesive polymers to improve these effects [28,29].

Many research groups have successfully developed formulations based on SLNs and NLCs for nose-to-brain delivery with in vivo pharmacokinetic (PK) and pharmacodynamic (PD) studies. However, many reports did not calculate all PK parameters for the brain targeting and considerably evaluated them. Several reviews on SLNs and NLCs intranasal formulations have been published [30-33], which summarized results from some selected studies to highlight the efficacy of these formulations. However, none are systematic reviews to address the efficacy of nose-to-brain formulations based on in vivo PK and PD data. Therefore, in this review, we aimed to summarize these preclinical studies with an emphasis on the evaluation of brain targeting efficacy. We conducted a systematic review on in vivo nose-to-brain delivery of SLN and NLC-based formulations. We collected reported data or re-calculated data derived from PK studies to evaluate the brain targeting efficacies of formulations. By analysis of PK parameters, this review provides an insight into the brain targeting efficacies of SLN and NLC-based formulations and identifies their limitations. In addition, we present our perspectives for future development of these formulations.

\section{Nose-to-Brain Delivery Pathways and Feasibilities of SLNs and NLCs for Nose-to-Brain Drug Delivery}

\subsection{Nose-to-Brain Delivery Pathways}

Nose-to-brain delivery pathways have been extensively investigated and reported in many studies. As shown in Figure 1a, following the IN administration of a drug formulation, drug molecules or drug-loaded particles transport directly from the nose to the brain via olfactory and trigeminal nerves and indirectly into the systemic circulation before crossing the $\mathrm{BBB}$ to reach the brain [34-36].

When a drug enters the nasal cavity, it is distributed to the olfactory and respiratory regions. The olfactory region has olfactory nerves that begin at the olfactory epithelia and end at the olfactory bulb [37]. Drugs in the olfactory region can be transported to the brain 
by four different routes: (1) an extraneuronal route along olfactory neurons, (2) an intraneuronal route by olfactory neuron endocytosis, (3) through supporting cells by endocytosis, and (4) through the intercellular space by passing tight junctions (Figure 1b) $[38,39]$. The extraneuronal route (route 1) is the major direct pathway for drug transport from the nose to the brain, which may take up to $30 \mathrm{~min}$. The intraneuronal route (route 2) involves drug endocytosis by olfactory neurons and release in the olfactory bulb before distributing to different brain regions, and this process may take several hours or days [7]. The drug transport through or along supporting cells (routes 3 and 4) is less important [39]. The olfactory pathway has been indicated in some studies. For example, fluorescence response to IN administered Cyanine7 NHS ester-loaded SLNs (Cys7-SLNs) was clearly observed in olfactory bulb, cerebellum, and striatum [12]. Furthermore, a proportion of drugs entering the respiratory region can be transported directly to the brain through the trigeminal nerve pathway via extraneuronal or intraneuronal routes although this pathway is less important than the olfactory pathway [7].
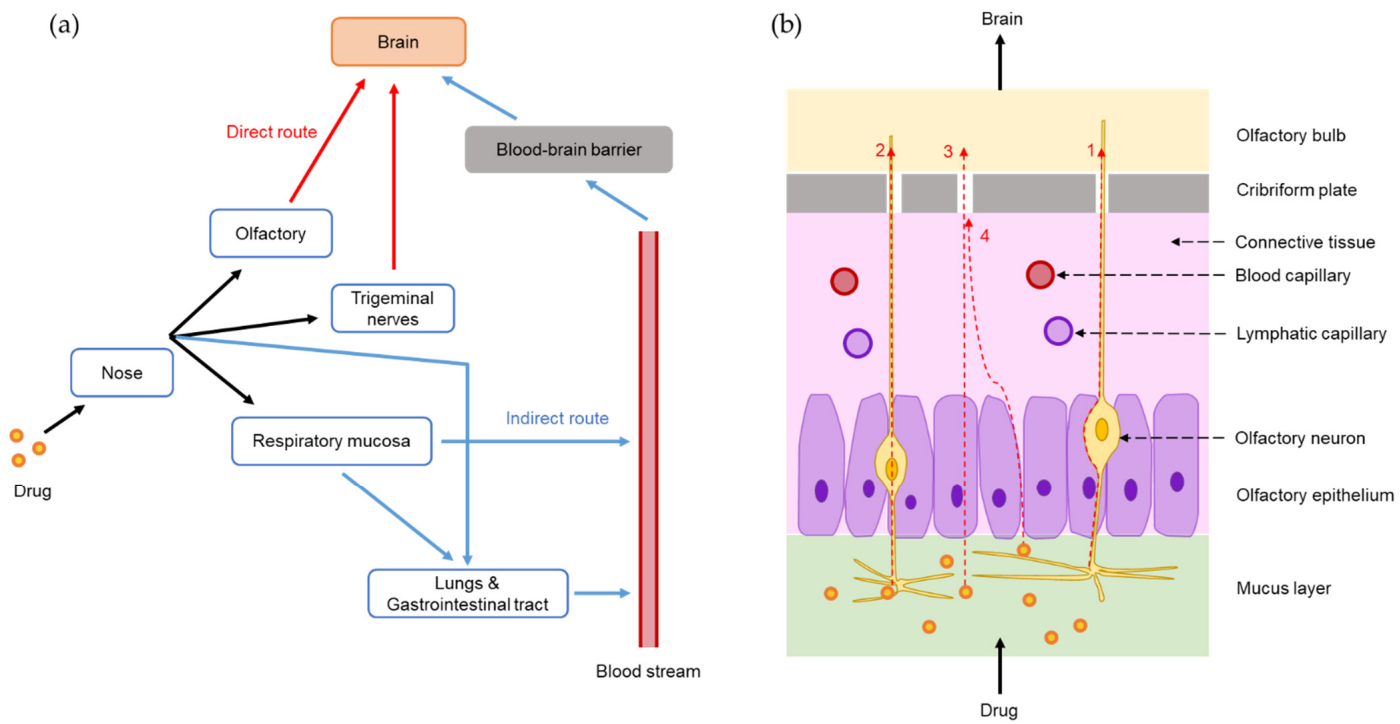

Figure 1. Pathways for nose-to-brain delivery of intranasal formulation: (a) Drug transports from the nose to the brain by direct route (olfactory and trigeminal pathways) and indirect (entering systemic circulation and crossing the blood-brain barrier). (b) Olfactory pathway for nose-to-brain delivery of drugs: (1) extraneuronal route, (2) intraneuronal route, (3) through supporting cells, and (4) along supporting cells.

Drugs in the respiratory region are also absorbed into the bloodstream by respiratory epithelia. However, this process is only suitable for lipophilic drugs with low molecular weights and high BBB permeability. Drugs not absorbed in the nasal cavity can reach the lungs and gastrointestinal tract and subsequently be absorbed into the systemic circulation $[7,40]$. The drug may cross the BBB from the blood to reach the brain. However, this indirect pathway is less remarkable since the BBB prevents most drugs from reaching the brain, which is similar to any drug administered systemically [38].

\subsection{Feasibilities of SLNs and NLCs for Nose-to-Brain Drug Delivery}

SLNs and NLCs have been continuously developed over the last two decades. Both are colloidal nanoparticles with solid lipid matrices, which can be produced from solid lipids (SLNs) or mixtures of solid and liquid lipids (NLCs) [41-43]. SLNs and NLCs are alternatives to micelles, emulsions, liposomes, and polymeric nanoparticles in drug delivery. They have some distinct advantages that facilitate their wider applications for oral, parenteral, intranasal, ocular, transdermal, and pulmonary drug delivery [44-46]. The components of SLNs and NLCs are physiologically biocompatible and biodegradable lipids and other excipients that are generally recognized as safe (GRAS), making them safe nano-drug delivery 
systems $[47,48]$. SLNs and NLCs are more stable than micelles, emulsions, or liposomes because their solid matrices can protect incorporated drugs more efficiently [49]. Furthermore, SLNs and NLCs can encapsulate hydrophilic or hydrophobic drugs with higher entrapment efficiencies than liposomes [50,51]. Their lipid components can be modified to alter drug release [52,53]. NLCs have higher drug loadings and better drug stabilities during storage than SLNs because of their imperfect or amorphous structures, which provide more space to accommodate drugs [54-56].

SLNs and NLCs have several distinct advantages for nose-to-brain delivery. First, they can improve drug solubility and permeability, and the partition of nanoparticles into the lipid bilayer of the nasal epithelial cell membrane is greater than that of free drugs due to the lipophilic natures of SLNs and NLCs [57]. The nanosized particles with sufficient lipophilicity can easily squeeze through intercellular spaces between olfactory cells [58]. In addition, the use of surfactants (e.g., Tween 80 , Tween 20 , and sodium lauryl sulfate) can open tight junctions between epithelial cells and enhance drug permeability [59]. Second, incorporating drugs into SLNs and NLCs increases drug retention in the nasal cavity [60], and this retention can be improved by loading SLNs and NLCs into gel or coating them with suitable materials. Poloxamer 407, Poloxamer 188, methylcellulose, and hydroxypropyl methylcellulose (HPMC) are typically used for gel preparation. They also augment the nasal absorption of drugs [61,62]. Poloxamer can reduce mucus viscosity and elasticity, and, thereby, increase the transcellular transport of SLNs and NLCs [61]. Some mucoadhesive polymers, such as chitosan (CS) [63], trimethylchitosan [64], and glycol chitosan [29], can prolong the residence times of SLNs and NLCs in the nasal cavity. It was demonstrated in one study that a coating layer of polyethylene glycol 25 stearate inhibited P-glycoprotein efflux at cerebrovascular endothelial cell membranes, and thereby increased brain drug concentration [65]. Third, SLNs and NLCs can reduce the enzymatic degradation of drugs within nasal mucus better than solution-based dosage forms (e.g., solution, suspension, and gel) [58]. Finally, the safety of SLNs and NLCs well supports their feasibilities for nose-to-brain delivery [57].

\section{In Vivo Evaluation of Intranasal Formulations for Nose-to-Brain Delivery}

\subsection{PK and Biodistribution Studies}

Several different experimental designs have been used for PK studies to evaluate the IN administration of SLNs and NLCs for brain targeting. Generally, formulations (dispersions or gels) of SLNs or NLCs (administered IN) have been compared with free drug solutions or suspensions (IN), free drug solutions or suspensions (IV), and SLNs or NLCs (IV) in PK studies $[65,66]$. In some cases, oral administrations of free drug solutions or suspensions $[67,68]$ or a marketed product [69] have also been used. However, the appropriate approach is to compare SLNs or NLCs (IN) with free drug solution or suspension (IN and IV) [15]. In PK and biodistribution studies, drug concentrations in blood and brain are determined at different time points, and areas under the curve for blood $\left(\mathrm{AUC}_{\mathrm{blood}}\right)$ and brain $\left(\mathrm{AUC}_{\text {brain }}\right)$ are calculated for each formulation. In addition, maximum drug concentrations $\left(\mathrm{C}_{\max }\right)$ and times taken to reach these concentrations $\left(\mathrm{T}_{\max }\right)$ are also determined from PK profiles.

Different parameters can be compared among formulations to evaluate the brain targeting of an SLN and NLC-based formulation, such as $\mathrm{AUC}_{\text {brain, }}, \mathrm{C}_{\text {max,brain, }} \mathrm{T}_{\text {max,brain, }}$ drug targeting efficiency (DTE), drug transport percentage (DTP) [65], brain: blood ratios at each time point [70], and drug concentration in the brain at the final time point [71]. DTE and DTP are critical parameters of the brain targeting efficacies of nose-to-brain delivery systems. DTE\% is a measure of drug accumulation in the brain following IN administration relative to IV administration, and is defined by:

$$
\mathrm{DTE} \%=\frac{\left(\mathrm{AUC}_{\text {brain,IN }}\right) /\left(\mathrm{AUC}_{\text {blood,IN }}\right)}{\left(\mathrm{AUC}_{\mathrm{brain}, \mathrm{IV}}\right) /\left(\mathrm{AUC}_{\text {blood,IV }}\right)} \times 100
$$

where AUC is determined over the study duration $\left(\mathrm{AUC}_{0-\mathrm{t}}\right)$. DTE\% values can range from 0 to $\infty$. A DTE $\%$ value of $>$ or $<100$ suggests efficient or ineffective brain targeting, respectively. $\log _{10}(\mathrm{DTE} \%)$ values are also used [15]. 
$\mathrm{DTP} \%$ is the percentage of a drug that enters the brain via direct routes (through the olfactory and trigeminal pathways), and is defined by:

$$
\mathrm{DTP} \%=\frac{\mathrm{AUC}_{\text {brain,IN }}-\left(\frac{\mathrm{AUC}_{\text {brain,IV }}}{\mathrm{AUC}_{\text {blood,IV }}} \times \mathrm{AUC}_{\mathrm{blood}, \mathrm{IN}}\right)}{\mathrm{AUC} C_{\text {brain, } \mathrm{IN}}} \times 100
$$

The subtraction indicates the amount of drug entering the brain via the indirect route (from blood to the brain through the BBB). Equation (2) can be re-arranged and expressed as:

$$
\mathrm{DTP} \%=\left(1-\frac{100}{\mathrm{DTE} \%}\right) \times 100
$$

DTP\% values can range theoretically from $-\infty$ to 100 . When no drug is transported via direct routes, $\mathrm{DTP} \%=0$. However, in some cases, $\mathrm{DTP} \%$ values are $<0$ because DTE $\%$ values are $<100$. Positive DTP\% values indicate drug delivery via direct routes contributes significantly to overall brain delivery. Drugs that do not easily cross the BBB have a high $\mathrm{DTP} \%$ value, and a DTP\% value of 100 indicates a drug cannot cross the BBB (AUC $\mathrm{brain}_{\text {,IV }}$ $=0)[15]$.

DTE\% and DTP\% values of drug-loaded SLNs and NLCs (IN) can be compared with those of the free drug solutions or suspensions (IN) using relative DTE\% (logRDTE\%) and relative DTP\% $(\log \mathrm{RDTP} \%)$ as follows:

$$
\begin{aligned}
& \operatorname{LogRDTE} \%=\log _{10}\left(\frac{\text { DTE\% } \%_{\text {IN SLNs or NLCs }}}{\text { DTE\% }{ }_{\text {IN free drug }}} \times 100\right) \\
& \operatorname{LogRDTP\% }=\log _{10}\left(\frac{\text { DTP\% } \%_{\text {IN SLNs or NLCs }}}{\text { DTP\% } \text { IN free drug }_{\text {IN }}} \times 100\right)
\end{aligned}
$$

LogRDTE\% and $\log R D T P \%$ values of $>2$ indicate SLNs and NLCs (IN) have better brain targeting efficiencies than free drugs (IN) [15].

DTE $\%$ and DTP\% are usually calculated using the AUC values of free drugs (IN), but in some cases, the AUC values of SLNs or NLCs (IN) have been used to calculate DTE\% and $\mathrm{DTP} \%$ values. To eliminate this inconsistency, we recalculated DTE\% and DTP\% values mentioned in these studies.

$\mathrm{DTE} \%$ and DTP\% are effective parameters for evaluating brain targeting by IN formulations, but if $\mathrm{AUC}_{\text {blood,IN }}$ is very low, $\mathrm{DTE} \%$ and $\mathrm{DTP} \%$ can be high despite a low $\mathrm{AUC}_{\text {brain,IN }}$. Therefore, other parameters are also used. $\mathrm{B}_{\mathrm{IN} / \mathrm{IV}}$ is the ratio of drug accumulation in the brain following IN administration over that following IV administration, and is calculated using:

$$
\mathrm{B} \%_{\mathrm{IN} / \mathrm{IV}}=\frac{\mathrm{AUC}_{\text {brain,IN }}}{\mathrm{AUC}_{\text {brain,IV }}} \times 100
$$

A B $\%$ IN/IV value of $>100$ indicates that IN administration results in greater accumulation of drug in brain than IV administration.

$\mathrm{RB} \%$ is the ratio of drug accumulation in the brain for SLNs and NLCs (IN) versus that of the free drug (IN), and is also used to evaluate the effectiveness of brain targeting of SLNs and NLCs.

$$
\mathrm{RB} \%=\frac{\mathrm{AUC}_{\text {brain,SLNs and NLCs (IN) }}}{\mathrm{AUC}_{\text {brain,free drug }(\mathrm{IN})}} \times 100
$$

An $\mathrm{RB} \%$ value of $>100$ indicates brain drug accumulation is higher for SLNs and NLCs (IN) than for the free drug (IN) [15].

Drug accumulation in the brain can be observed using gamma scintigraphy images after labeling the drug, SLNs, or NLCs with ${ }^{99 \mathrm{~m}} \mathrm{Tc}[66,72]$. This technique is also used in PK studies to quantify drug accumulation in blood and the brain [73-75]. Fluorescence imaging is also used for the DiR DiIC18-labeled CS-NLCs [76]. SLNs and NLCs can be 
labeled with coumarin 6 , or rhodamine-123 and visualized in brain tissue by confocal laser scanning microscopy $[77,78]$.

\subsection{Pharmacodynamic Studies}

PD studies are performed to evaluate the efficacies of SLNs and NLCs (IN) in animals. Depending on drug and disease studies, appropriate animal models are selected to compare SLN or NLC candidates with free drugs or commercial products (administered IN, IV, or orally). For example, Plasmodium berghei ANKA-injected mice are used to evaluate the anti-cerebral malarial effects of artesunate [57], artemether, and lumefantrine [64]. In epilepsy, the maximal electroshock seizure model [79-81] or pentylenetetrazole-induced epilepsy rat model [82-84] are used. Treatment effects on Alzheimer's disease and dementia are assessed using animals with scopolamine-induced amnesia [85-89] or streptozocin-induced Alzheimer's disease [90]. Tests used for assessing depression include the tail suspension, the forced swimming [91], the locomotor activity [92], and the marble-burying tests [93]. Models used for Parkinson's disease include 1-methyl-4-phenyl-1,2,3,6-tetrahydropyridine-induced Parkinson's disease [94], 6-hydroxydopamine partially lesioned rats [95], chlorpromazine-induced Parkinsonism-like signs [96], haloperidol-induced catalepsy [97], and rotenone-induced Parkinson's disease [98].

\subsection{Toxicity Studies}

Histopathological examinations are usually used to evaluate the nasomucosal toxicities of SLNs and NLCs. After IN administration, fresh nasal mucosa is carefully removed and stored in formalin solution. Samples are stained with hematoxylin and eosin and then examined under a light microscope to detect nasal tissue damage [99]. Biomarkers are also used to investigate toxicity. For example, total protein, lactate dehydrogenase, alkaline phosphatase, and immuno-globulin E levels in nostril fluid are used to study nasomucosal toxicity [99]. Hematological [75] and hepatic biomarkers [100] have also been used in some studies.

\section{Nose-to-Brain Delivery of SLN and NLC-Based Formulations: Summary of a Literature Search for In Vivo Studies}

We searched three electronic databases, including (i) MEDLINE (PubMed), (ii) Scopus, and (iii) Web of Science, for original studies published up to 20 January 2022. The search method is described in Supplementary Material.

The processes used to search and screen articles were in accord with PRISMA 2020 guidelines [101]. As shown in Figure 2, after identification and screening steps, 86 articles were included to conduct this systematic review.

Some of these articles performed in vivo studies on the same SLN or NLC formulations, and thus, these articles were based on the results of 81 studies. In detail, the same duloxetineloaded NLCs were used for two PK and one PD studies in three different articles [73,92,102]. Two articles used haloperidol-loaded NLCs and reported the same PK results [103,104], and an NLC formulation containing resveratrol was used for PK and PD studies in two different reports $[85,86]$. Two articles used the same olanzapine-loaded NLCs for PK studies in mice [26] and rats [75].

All 86 articles included in this review were published from 2011 to 2021, and half of them were published in the last three years (2019-2021) (Figure S1a). Interest in the nose-tobrain delivery of drugs using SLNs and NLCs and in vivo brain targeting evaluations is increasing. Three types of animals have been used in these studies, including mice, rabbits, and rats. Among them, rat is the most predominant model (Figure S1b). Six studies used two types of animals. SLNs and NLCs were used in suspension form in 48 studies for in vivo evaluation (Figure S1b). Gelling systems and surface modifications were reported in 22 and 11 studies, respectively. NLCs are the second generation of SLNs with more advantages; therefore, 51 studies investigated NLCs and 30 investigated SLNs (Figure S1b). Various production methods were used to prepare SLNs and NLCs in these studies, including high-speed homogenization and ultrasonication, solvent diffusion, solvent evaporation, high-pressure homogenization, solvent injection, microemulsion, and double emulsion. 
High-speed homogenization and ultrasonication was the most frequently used method in these studies (47\%) (Figure S1c). There were 66 PK and biodistribution studies and 30 PD studies. Fifteen studies reported both in vivo PK and PD results (Figure S1d).

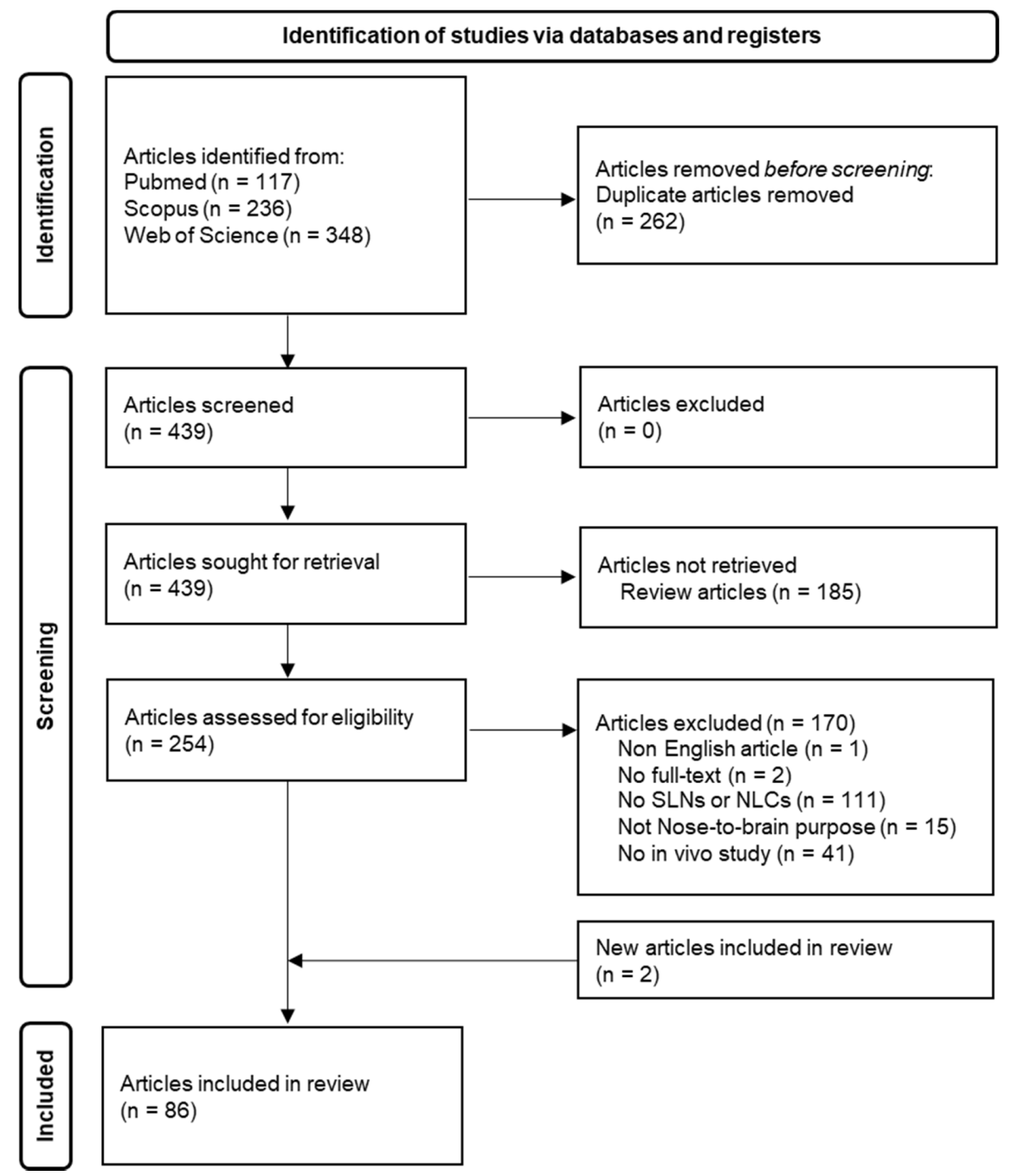

Figure 2. PRISMA 2020 flow diagram explaining the process of searching and screening articles to include in the review.

Reported particle sizes, polydispersity indices, and zeta potentials of SLNs and NLCs are summarized in this review. Particle size is a pivotal factor determining total surface area and physical stability of SLNs and NLCs. As shown in Figure 3a, most of the SLNs and NLCs described had a particle size of $<200 \mathrm{~nm}(78 \%)$ and the median particle size was $151.6 \mathrm{~nm}$. Polydispersity index is also a critical parameter, and a value of $<0.5 \mathrm{im}-$ plies a monodispersed and homogenous dispersion of SLNs or NLCs [105]. As shown in Figure 3b, approximately $70 \%$ of the SLNs and NLCs had a polydispersity index of $<0.3$, which is considered an optimum value that indicates a dispersion with a satisfactory size distribution [106]. Three studies reported polydispersity indices of $>0.5$, indicating non-homogeneity and polydispersity [105]. The median polydispersity index was 0.272.

Zeta potential is the surface charge of a particle, and values were reported in 67 studies with 45 cases of negatively charged and 22 cases of positively charged nanoparticles. Most of the reported zeta potential values (79\%) were between -30 and $30 \mathrm{mV}$ (Figure 3c). A dispersion with an absolute zeta potential value of $>30 \mathrm{mV}$ is generally considered physically stable. However, in many cases, the stabilities of SLNs and NLCs are maintained by stabilizers even though the zeta potential value was not high [107]. 

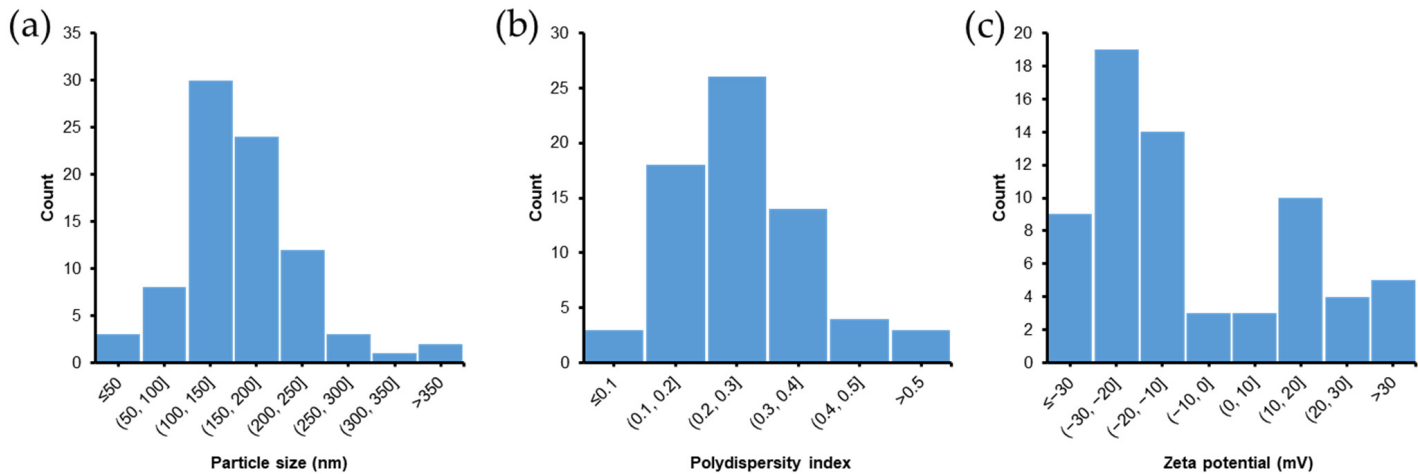

Figure 3. Summary of (a) particle size, (b) polydispersity index, and (c) zeta potential of SLNs and NLCs reported in articles included in the review. $n=83$ for (a), $n=68$ for (b), and $n=67$ for (c).

\section{In Vivo Evaluations of SLN and NLC-Based Formulations for Nose-to-Brain Delivery}

This section discusses the efficacy of SLNs and NLCs for nose-to-brain delivery using the in vivo results of previous studies. SLNs and NLCs have been used in suspension forms (plain SLNs and NLCs) or loaded into gels (SLN or NLC gel), and several drugs have been incorporated into SLNs and NLCs to treat a wide range of CNS diseases.

\subsection{PK Studies with DTE\% and DTP\% Values}

PK and biodistribution evaluations were reported in 66 of the 81 studies. These studies aimed to show SLNs and NLCs (IN) better target the brain than other formulations, such as free drugs (IN, IV, or oral) or IV administered SLNs or NLCs. DTE\% and DTP\% values were provided in 26 studies. The DTE\% and DTP\% values were sometimes calculated from raw data when they were not reported in the original articles. When DTE\% and DTP\% values were incorrectly reported, we recalculated these values. In most cases, DTE $\%$ and DTP\% values showed SLNs and NLCs (IN) more effectively targeted the brain than free drugs (IN).

Youssef et al. developed SLNs loaded with almotriptan, a second-generation triptan with high selectivity for $5-\mathrm{HT}_{1 \mathrm{~B} / 1 \mathrm{D}}$ receptor used to treat acute migraine [99]. The optimized SLN formulation was dispersed in an in situ nasal mucoadhesive gel composed of Poloxamer 407 and sodium carboxymethyl cellulose (Na-CMC). In rats, SLN gel (IN) exhibited a rapid onset brain targeting $\left(\mathrm{T}_{\max , \text { brain }}=10 \mathrm{~min}\right)$. $\mathrm{DTE} \%$ values were 335.7 and 255.1, and DTP\% values were 70.21 and 60.80 for SLN gel (IN) and free drug-loaded gel (IN), respectively, which confirmed good targeting efficiencies for both formulations. However, the SLN gel was superior to free drug-loaded gel, as indicated by logRDTE\%, logRDTP\%, and $\mathrm{RB} \%$ values of $2.12,2.06$, and 125.9 , respectively. In addition, the safety of SLN gel was confirmed through biomarkers' evaluation and histopathological examination results.

Agomelatine, an antidepressant, was loaded into SLNs for nose-to-brain delivery [67]. The brain targeting efficacy of SLNs (IN) was demonstrated by DTE\% and DTP\% results of 47.379 and 190.02, respectively. However, the B\% $\mathrm{IN} / \mathrm{IV}$ value was 83.26 , which indicated the IN administration of SLNs was not superior to IV administration of the free drug. This research group later loaded the optimized SLNs into an in situ nasal gel composed of $16 \%$ Poloxamer 407 and 0.4\% HPMC [60]. Interestingly, SLN gel (IN) had lower DTE\% (141.42), DTP\% (29.29), and B\% IN/IV (52.6) values than SLNs (IN). Unfortunately, this issue was not discussed in the original article.

Jain et al. developed NLCs loaded with artemether for the treatment of cerebral malaria [108]. PK studies in rats showed that the brain:blood concentration ratio of NLCs (IN) was higher than those of a drug solution (IN and IV) at all times. DTE\% and DTP\% values of NLCs (IN) were 278.2 and 64.02, respectively, and logRDTE\% (2.07), logRDTP\% (2.05), and $\mathrm{RB} \%$ (254.5) values indicated better brain targeting for NLCs than the drug solution (IN). The B\% IN/IV value of 444.8 signified the higher brain bioavailability of the NLCs (IN) over the drug solution (IV). 
Asenapine, an antipsychotic drug, was incorporated into NLCs for the treatment of schizophrenia and bipolar disorders via IN administration [28]. In rats, the $C_{\text {max,brain }}$ value of NLCs (IN) was 1.4- and 1.8-fold higher than those of IN and IV drug solution, respectively. DTP\% values were not reported in this study, and thus we calculated them from raw data. NLCs (IN) showed DTE\% and DTP\% values of 207.2 and 51.7, respectively, which were higher than those of the drug solution (IN). In addition, B\% IN/IV (276.7) and $\mathrm{RB} \%$ (267.8) values indicated that the brain bioavailability of NLCs (IN) was greater than those of IN and IV drug solution. Moreover, an animal behavioral study using catalepsyinduced rats showed that NLCs (IN) had better therapeutic and safety profiles than the drug solution (IN). Later, this group coated the optimized NLC formulation with glycol

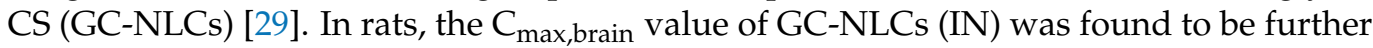
increased (by 1.8- and 2.3-fold higher than those of IN and IV drug solution, respectively). We calculated DTP\% from raw data since it was not reported. DTE\% (288.3), DTP\% (65.31), $\operatorname{logRDTE} \%$ (2.22), $\log$ RDTP\% (2.18), B\% IN/IV (407.9), and RB\% (394.8) values of GC-NLCs (IN) were higher than those for NLCs (IN) in the previous report [28], which indicated that the glycol CS coating increased the brain targeting ability of uncoated NLCs.

Yasir et al. developed donepezil-loaded SLNs for nose-to-brain delivery for the treatment of Alzheimer's disease [109]. PK studies in rats revealed that $\mathrm{C}_{\text {max,brain }}$ of SLNs (IN) was 4.1- and 5.4-fold higher than those of IN and IV drug solution, respectively. DTE\% and DTP\% values of SLNs (IN) were 288.75 and 65.37, higher than those of the drug solution (IN) (156.94 and 36.28, respectively. RB\% value of 197.6 showed that SLNs (IN) exhibited better brain targeting than the free drug (IN). In addition, the B\% IN/IV value (163.4) indicated that the brain bioavailability of SLNs (IN) was greater than that of drug solution (IV). These results demonstrated the potential merits of using SLNs (IN) to deliver donepezil to the brain.

In another study, donepezil-loaded SLNs produced similar results [110]. The $C_{\text {max,brain }}$ of SLNs (IN) was 5.5- and 7.6-fold higher than those of IN and IV drug solution, respectively. The DTE\% and DTP\% values of SLNs (IN) were 533.95 and 81.94, higher than those of drug solution (IN) (243.78 and 58.84, respectively. Furthermore, RB\% (290.9) and B\% IN/IV (300.9) values indicated greater brain bioavailability of SLNs (IN) than drug solution (IN or IV). Gamma scintigraphy images of rabbits after IN administration confirmed higher SLNs uptake by brain than drug solution.

Duloxetine, a drug used to treat major depressive disorders, was loaded NLCs for nose-to-brain delivery [92]. NLCs (IN) improved locomotor activity, total swimming, and climbing times, and reduced the duration of immobility period as compared with drug solution (IN or IV). Duloxetine brain concentration for NLCs (IN) was 3.8-fold higher than that for the drug solution (IN). This research group used the same NLC formulation for IN administration in rats and found a 2.39-fold increase in brain concentration for NLCs (IN) as compared with the drug solution (IN) [102]. Later, the authors carried out biodistribution studies in rabbits using ${ }^{99 \mathrm{~m}}$ Tc-labeled duloxetine [73]. The DTE\% and DTP\% values of NLCs (IN) were 758.1 and 86.81, respectively, which were higher than those of the drug solution (IN) (287.3 and 65.12, respectively). The logRDTE\% (2.42), $\log$ RDTP\% (2.12), and RB\% (984.9) values indicated better brain targeting by NLCs than the drug

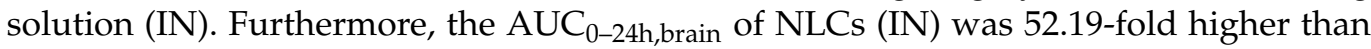
that of drug solution $(\mathrm{IV})(\mathrm{B} \% \mathrm{IN} / \mathrm{IV}=5219)$, which represented a dramatic improvement in brain bioavailability.

Pokharkar et al. developed NLCs loaded with efavirenz, a potent non-nucleoside reverse transcriptase inhibitor used for the treatment of human immunodeficiency virus (HIV) [65]. IN delivery of the optimized NLCs was employed to target HIV in CNS. PK studies in rats revealed that NLCs (IN) had a 2.5-fold higher $\mathrm{C}_{\text {max,brain }}$ value than a drug dispersion (IN), while brain bioavailability was $\sim 18$-fold higher $(\mathrm{RB} \%=1782.5)$. In addition, reported DTE\% and DTP\% values of NLCs (IN) were 487.4 and 88.2. After recalculation using raw data, these values were 1205 and 91.7; whereas for drug dispersion (IN), they were 48.4 and <0, respectively. In addition, NLCs (IN) remarkably increased 
brain bioavailability as compared with the pure drug (IV) $\left(\mathrm{B}_{\mathrm{IN} / \mathrm{IV}}=1272.5 \%\right)$. For the same optimized NLCs, the IN administration showed a 3.73-fold increase in brain bioavailability, as compared with IV administration.

In a recent study, escitalopram and paroxetine were co-loaded into NLCs for the treatment of depression [111]. The optimized NLC formulation was incorporated into a thermoreversible Poloxamer 407 and Carbopol 974P gel. The developed NLC gel was IN administrated to mice, resulting in the different brain targeting efficacies of escitalopram and paroxetine. For paroxetine, the $\mathrm{C}_{\text {max,brain }}$ of NLC gel (IN) was 4.8- and 5.9-fold higher than those of the free drug (IN and IV, respectively). DTE\% and DTP\% values of the NLC gel (IN) were 388 and 74.2, respectively, which were also higher than those of the free drug (IN) (232 and 56.9, respectively). B\% IN/IV and RB\% values (272.5 and 138.3, respectively) showed that the NLC gel (IN) increased brain bioavailability as compared with free paroxetine (IV and IN). Surprisingly, escitalopram had poor brain targeting efficacy (DTE\% $=25.4$, $\mathrm{DTP} \%=-294, \mathrm{~B} \% \mathrm{IN} / \mathrm{IV}=10.5$, and $\mathrm{RB} \%=23.9)$. The authors suggested that hydrophilic drugs (like escitalopram) were unlikely to exhibit benefits when incorporated into NLC gels (IN). However, several hydrophilic drugs have been successfully delivered to the brain by SLNs and NLCs (IN) $[109,110,112]$. We found that the drug loadings of escitalopram and paroxetine in NLCs were 1.8 and $4.0 \%$, respectively. This meant it was impossible to use the same doses of these drugs $(2.38 \mathrm{mg} / \mathrm{kg})$ in PK studies as was reported. Thus, the dose of escitalopram in NLC gel (IN) was probably lower than that of the free drug (IN and IV) and reported DTE\%, DTP\%, B\% IN/IV, and RB\% values were incorrect.

Yasir et al. performed PK studies in rats on haloperidol-loaded SLNs (IN) and drug solutions (IN and IV) $[103,104]$. The drug concentrations in the brain were higher for SLNs (IN) than for drug solution (IN and IV). Notably, $\mathrm{C}_{\text {max,brain }}$ of SLNs (IN) was 3.7and 4.3-fold higher than those of drug solutions (IN and IV, respectively). As a result, the

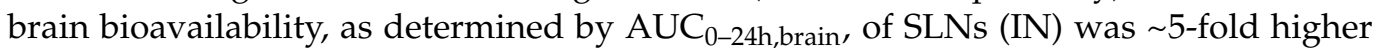
than that of the drug solution (IV) $(\mathrm{B} \%$ IN $/ \mathrm{IV}=500.9)$. DTE\% and DTP\% values of the drug solution (IN) were 1128.6 and 91.14, respectively. The higher values of SLNs (IN) (DTE\% $=2362.4$ and DTP\% $=95.77)$ and other parameters $(\log \mathrm{RDTE} \%=2.32, \log \mathrm{RDTP} \%=2.02$, $\mathrm{RB} \%=349.7$ ) suggested better brain targeting efficiency for SLNs than the drug solution following IN administration.

Levofloxacin and doxycycline were co-loaded into SLNs for meningitis treatment [112]. HPMC gel of the optimized SLNs was prepared to increase drug residence in the nasal cavity. In PK studies using rats, the DTE\% (149.8 and 161.9) and DTP\% (33.28 and 38.26 (corrected)) of levofloxacin and doxycycline for SLN gel (IN) indicated effective brain targeting. LogRDTE\% values (2.19 for levofloxacin and 2.21 for doxycycline) suggested better brain targeting by the SLN gel (IN) over the drug solution (IN). However, the $\mathrm{C}_{\text {max,brain }}$ and $\mathrm{AUC}_{0-360 \mathrm{~min}, \text { brain }}$ of levofloxacin and doxycycline of drug solution (IV) were higher than those of the SLN gel (IN). This was attributed to passive diffusion of drugs across the BBB when initial drug concentrations in rat plasma were boosted following IV administration. Thus, although the SLN gel exhibited effective brain targeting, absolute drug accumulations in the brain of the SLN gel (IN) were lower than those of the drug solution (IV). Abourehab et al. developed NLCs loaded with nicergoline for the treatment of dementia [58]. In PK studies using rats, the DTE\% value of the NLC gel (IN) (187.3) was based on the AUC of the NLC dispersion (IV), and the DTP\% value of the drug solution (IN) was incorrectly reported (180.6). After recalculating using Equations (1) and (2), we found DTE\% values of 92.2 and 237.3 and DTP\% values of -8.4 and 57.87 for the drug solution (IN) and NLCs (IN), respectively. LogRDTE\% (2.41) and RB\% (417.6) values indicated

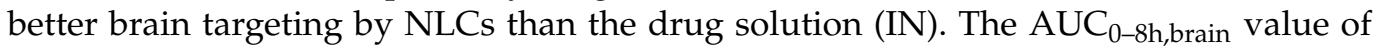
NLCs (IN) was 2.66- and 1.44-fold higher than those of the drug solution (IV) and NLCs (IV), respectively.

Ondansetron was loaded into NLCs for the management of chemotherapy-induced postoperative nausea and vomiting [113]. In PK studies in rats, the $C_{\text {max,brain }}$ and $\mathrm{AUC}_{0-330 \mathrm{~min}, \text { brain }}$ values of the NLCs (IN) were 4.1- and 34.3-fold higher than those of 
the drug solution (IV), respectively. DTE\% and DTP\% values of NLCs (IN) were reported to be 506 and 97.14, respectively. However, based on the AUC reported, these values were corrected to 5062 and 98.02, respectively.

Nair et al. developed two types of phenytoin-loaded NLCs with different particle sizes: NLC1 (<50 nm) and NLC2 (>100 nm) [36]. In PK studies using rats, DTE\% and DTP\% values were not calculated. After calculation from raw data, NLC1 and NLC2 (IN) had DTE $\%$ values of $\sim 150,000$ and $~ 72,600$ and DTP\% values of 99.93 and 99.86 , respectively. Thus, the drug had low BBB permeability, and phenytoin predominantly accumulated in brain via direct routes. NLC1 and NLC2 (IN) increased $\mathrm{AUC}_{0-1 \mathrm{~h} \text {,brain }}$ 48.7- and 36.3fold $(\mathrm{B} \% \mathrm{IN} / \mathrm{IV}=4873$ and 3629$)$, respectively, as compared with a phenytoin marketed formulation (IV) and 30.2- and 22.5-fold, respectively, compared with a drug solution (IN).

Uppuluri et al. developed SLNs containing piribedil, an anti-Parkinson's disease drug, and then loaded optimized SLNs in a thermoresponsive methylcellulose in situ gel [27]. PK studies in rats showed that the SLN gel (IN) and SLN suspension (IN) increased the $\mathrm{AUC}_{0-6 \mathrm{~h} \text {,brain }}$ by 4 - and 3.1-fold $(\mathrm{RB} \%=404.5$ and 312.6), respectively as compared with the drug suspension (IN). DTE\% values of the SLN gel (IN) and SLN suspension (IN) were 137.5 and 119.9, respectively, higher than that of the IN drug suspension (54.25). Furthermore, DTP\% values (27.29 and 16.59 for SLN gel (IN) and SLN suspension (IN), respectively) revealed efficient direct nose-to-brain delivery, whereas the drug suspension (IN) had a DTP\% value below 0.

Risperidone, an atypical antipsychotic, was loaded into SLNs and NLCs in two studies. For risperidone-loaded SLNs, in mouse PK studies, the brain:blood ratio at $1 \mathrm{~h}$ of SLNs (IN) was 10- and 5-fold higher than those of drug solution (IV) and SLNs (IV), respectively. The brain targeting of SLNs (IN) was further confirmed by gamma scintigraphy imaging. $\mathrm{DTE} \%, \mathrm{DTP} \%$, and B\% $\%$ /NV values for SLNs (IN) were not reported, but calculation from raw data revealed them to be 830.9, 87.97, and 2278.6, respectively, indicating SLNs (IN) achieved effective nose-to-brain delivery. The pharmacodynamic study (paw test with Perspex platform) was conducted using SLNs (IV) and drug solution (IV), but not SLNs (IN) [66].

In another study, risperidone was loaded into CS-coated NLCs [63]. In an in vivo behavioral study using haloperidol-treated rats, CS-NLCs showed greater bio-efficacy with respect to catalepsy and locomotor activity than the drug suspension (IN or IV).

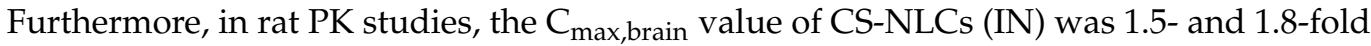
higher than those of the drug suspension (IN and IV, respectively). DTE\% and DTP\% values were not reported, but calculation produced DTE $\%=252.7$ and DTP $\%=60.4$ for CS-NLCs (IN). They were higher than those of the drug suspension (IN) $(\log R D T E \%=$ 2.37 and $\log \mathrm{RDTP} \%=2.98)$, indicating better brain targeting. The brain bioavailability of CS-NLCs (IN) was greater than those of the drug suspension (IN and IV), as evidenced by $\mathrm{B} \% \mathrm{IN} / \mathrm{IV}=440.3$ and $\mathrm{RB} \%=308.9$.

Gabal et al. developed anionic and cationic NLCs loaded with ropinirole, a drug used to treat Parkinson's disease [61]. Two types of NLCs were loaded into in situ gels composed of $15 \%$ Poloxamer $407,12 \%$ Poloxamer 188, and 1\% HPMC. Since ropinirole is a hydrophilic drug with low membrane permeability, its nasal absorption was limited, as evidenced by $\mathrm{DTE} \%=23.2$ and DTP\% $=-330.2$. Following IN administration, the $\mathrm{AUC}_{0-6 \mathrm{~h} \text {,brain }}$ of the cationic NLC gel was 1.4-fold higher than that of the anionic NLC gel. Cationic and anionic NLC gels both increased the brain bioavailability of ropinirole ( $\mathrm{RB} \%=4087.9$ and 5820.3 ,

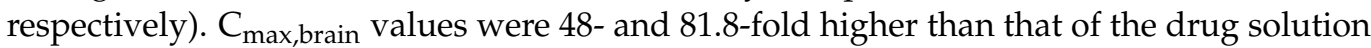
(IN). In addition, both gels had higher half-lives (5- and 8.8-fold, respectively) and mean residence times (MRT) (7.7- and 9.0-fold, respectively) in the brain than a drug solution (IN). DTE $\%$ and DTP\% values of the anionic NLC gel were 158.5 and 36.9, respectively, higher than those of the cationic NLC gel (128.6 and 22.3, respectively). However, the B\% IN/IV values of both NLC gels were $<100$, indicated that the absolute brain bioavailability of NLC gels (IN) was lower than that of the drug solution (IV).

Sesamol, a potential candidate for the treatment of glial cancer, was incorporated into SLNs for nose-to-brain delivery [114]. SLNs (IN) had a shorter $T_{\text {max,brain }}$ (10 min versus 
$30 \mathrm{~min}$ ) and a higher $\mathrm{C}_{\text {max,brain }}$ (13.2-fold) than the free drug (IV). DTE\% (764), DTP\% (86.1), and B\% $\%$ IN (590.4) values indicated effective brain targeting by the SLNs (IN) over the free drug (IV).

Masjedi et al. developed NLCs loaded with sumatriptan, a selective $5-\mathrm{HT}_{1 \mathrm{~B}}$ and $5-\mathrm{HT}_{1 \mathrm{D}}$ receptor agonist used for relieving migraine and cluster headache [115]. PK studies in rats showed that the $C_{\text {max,brain }}$ of the NLCs (IN) was 5.6-, 7.3-, and 9.4-fold higher than those of drug solution (IN), drug solution (IV), and NLCs (IV), respectively. The authors reported DTE $\%=258$ and $\mathrm{DTP} \%=61.23 \%$ for NLCs (IN), but these values were based on a comparison with NLCs (IV). When recalculated using Equations (1) and (2), actual values were 2416 and 95.86, respectively. The $\log$ RDTE\% (2.60), $\log$ RDTP\% (2.06), and RB\% (744.6) values indicated better brain targeting for the NLCs than the drug solution (IN). Furthermore, the $\mathrm{AUC}_{0-4 h, \text { brain }}$ value of the NLCs (IN) was 12.95- and 7.70-fold higher than those of the drug solution (IV) and NLCs (IV), respectively.

Tarenflurbil, a potential candidate for treating Alzheimer's disease, was loaded into SLNs for nose-to-brain delivery [68]. In rat PK studies, after a single dose, $\mathrm{C}_{\text {max,brain }}$ for SLNs (IN) was 1.5-, 1.7-, and 4.1-fold higher than those for drug solution (IV), drug solution (IN), and drug suspension (oral), respectively. DTE\% and DTP\% values were 183.2 and 45.4, respectively. $\operatorname{LogRDTE} \%$ (2.20), $\log \mathrm{RDTP} \%$ (2.55), and RB\% (182.1) indicated higher brain targeting for SLNs (IN) than the drug solution (IN). Furthermore, the brain bioavailability of SLNs (IN) was 1.42- and 3.83-fold higher than those of the drug solution (IV) and drug suspension (oral). In a multiple-dose study, drug concentrations in the brain after 5 and 10 days for SLNs (IN) were approximately 2-fold higher than those for the drug solution (IV) and drug suspension (oral).

Khan et al. prepared NLCs loaded with temozolomide, an effective antineoplastic drug used to treat metastatic melanoma and glioma [116]. In rat PK studies, the optimized NLCs (IN) had a DTE\% value of 457, which was 4-fold higher than that of the drug dispersion (IN). However, the reported DTE\% value for the drug dispersion (IN) was incorrect (169.7\%), and the corrected value was 113.3. DTP\% values were not reported. When calculated from the raw data, DTP\%, logRDTE\%, logRDTP\%, B\% ${ }_{\mathrm{IN} / \mathrm{IV}}$, and RB\% values of the NLCs (IN) were 78.16, 2.61, 2.82, 588.1, and 282.7, respectively, indicating effective brain targeting by IN administration of the NLCs. The accumulation of NLCs in the brain was confirmed using gamma scintigraphy images.

Sarma et al. developed NLCs loaded with tenofovir for the treatment of HIV in the brain [78]. In rat PK studies, optimized NLCs had a 3.2, 5.8, and 6.5-fold higher $C_{\text {max,brain }}$ than NLCs (IV), drug solution (IV), and drug solution (IN), respectively. DTE\% and DTP\% values were not reported, and calculation from raw data produced values of 481.9 and 79.25, respectively for the NLCs (IV). LogRDTE\% (2.22), logRDTP\% (2.08), and RB\% (402.7) values indicated higher brain targeting for the NLCs than the drug solution (IN). Furthermore, the brain bioavailability of NLCs (IN) was 12.0- and 3.6-fold higher than those of drug solution (IV) and NLCs (IV), respectively. Confocal microscopic images of rat brain tissue showed coumarin 6-labeled NLCs accumulated until $24 \mathrm{~h}$ after IN administration, whereas accumulation following IV administration was negligible for the same formulation.

Ziprasidone was loaded into NLCs for the management of schizophrenia via nose-tobrain delivery [117]. In rat PK studies, NLCs (IN) showed higher brain:blood concentration ratios at all time points and a faster onset $(10 \mathrm{~min})$ than drug solution (IV). DTE\% value was 476.8 , but DTP\% value was incorrectly reported $(89.85 \%)$. Recalculation from raw data produced DTP\% = 79.0, indicating brain targeting by NLCs (IN).

Major features of SLN and NLC-based formulations for nose-to-brain delivery in these studies are summarized in Table 1. 
Table 1. Major features of SLN and NLC-based formulations for nose-to-brain delivery: PK studies with DTE\% and DTP\%.

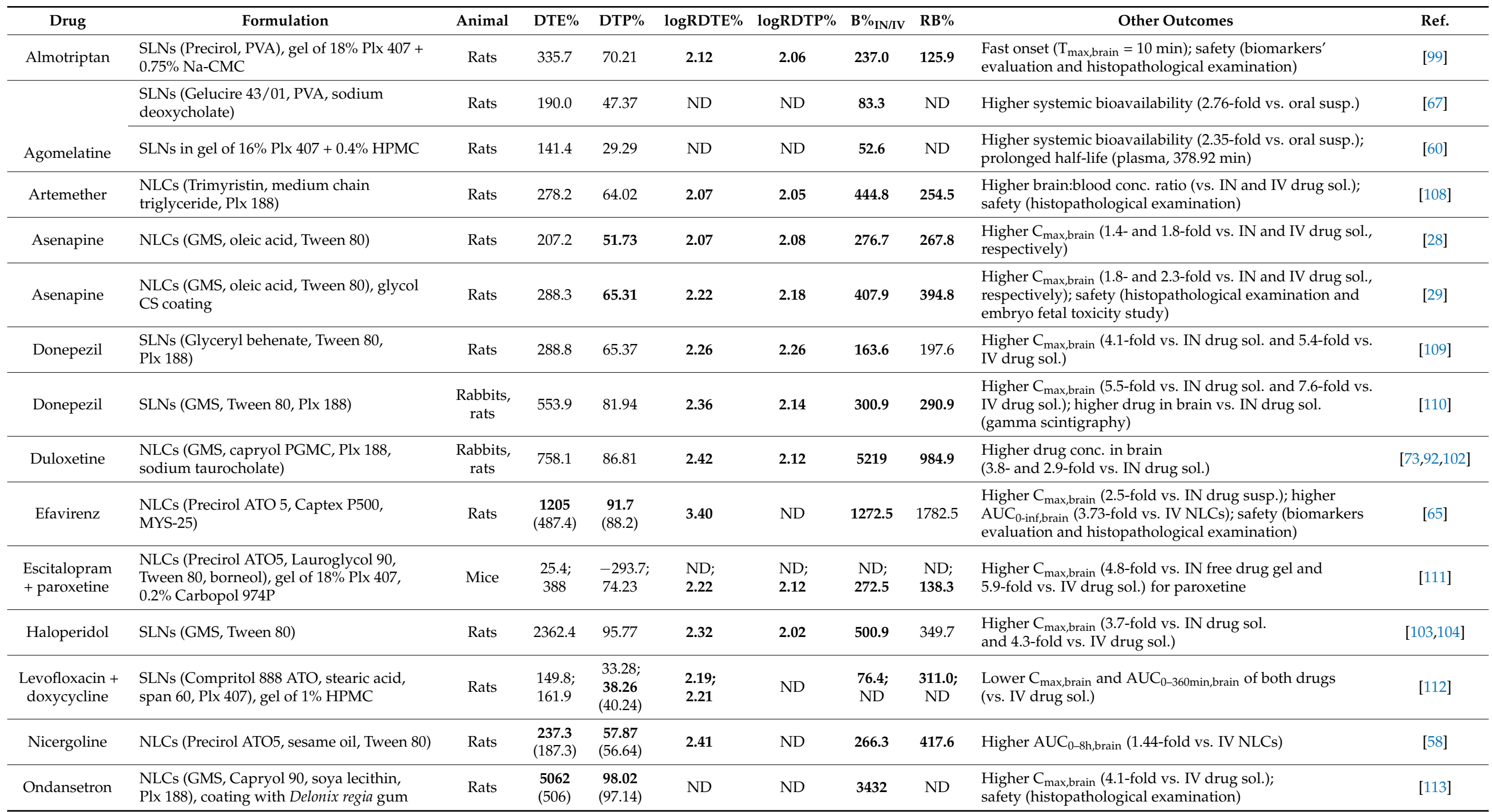


Table 1. Cont.

\begin{tabular}{|c|c|c|c|c|c|c|c|c|c|c|}
\hline Drug & Formulation & Animal & DTE\% & DTP\% & $\operatorname{logRDTE} \%$ & $\operatorname{logRDTP} \%$ & B\% $\%_{I N / I V}$ & RB\% & Other Outcomes & Ref. \\
\hline \multirow{2}{*}{ Phenytoin } & \multirow{2}{*}{ NLCs (Cholesterol, oleic acid, Plx 188) } & Rats & 149,952 & 99.93 & 5.18 & ND & 4873 & 3025 & \multirow{2}{*}{ Safety (histopathological examination) } & \multirow{2}{*}{ [36] } \\
\hline & & Rats & 72,615 & 99.86 & 4.87 & ND & 3629 & 2252 & & \\
\hline \multirow[b]{2}{*}{ Piribedil } & SLNs (Palmitic acid, polyvinyl alcohol) & \multirow{2}{*}{ Rats } & 119.9 & 16.59 & 2.34 & ND & 112.3 & 312.6 & \multirow{2}{*}{ Reduced $C_{\text {max,plasma }}$ vs. IN drug susp. } & \multirow{2}{*}{ [27] } \\
\hline & SLNs in gel of $1.5 \%$ methyl cellulose & & 137.5 & 27.29 & 2.40 & ND & 145.3 & 404.5 & & \\
\hline Risperidone & SLNs (Compritol 888 ATO, Plx 407) & Mice & 830.9 & 87.97 & ND & ND & 2278.6 & ND & $\begin{array}{l}\text { Higher brain:blood ratio at } 1 \mathrm{~h} \text { (10-fold vs. IV drug sol. } \\
\text { and } 5 \text {-fold vs. IV SLNs); brain targeting confirmed by } \\
\text { gamma scintigraphy images }\end{array}$ & [66] \\
\hline \multirow[b]{2}{*}{ Ropinirole } & $\begin{array}{l}\text { Anionic NLCs (Compritol } 888 \text { ATO, } \\
\text { Labrafac, PC, Plx 188, Tween 80, SDS), } \\
\text { gel of 15\% Plx 407, 12\% Plx 188, 1\% HPMC }\end{array}$ & Rats & 158.5 & 36.9 & 2.83 & ND & 69.8 & 4087.9 & \multirow{2}{*}{$\begin{array}{l}\text { Higher } \mathrm{C}_{\max , \text { brain }}(48 \text { - and } 81.8 \text {-fold) and half-life (5-and } \\
\text { 8.8-fold) for cationic and anionic NLC gels vs. IN drug } \\
\text { sol., respectively; safety (histopathological examination) }\end{array}$} & \multirow[t]{2}{*}{ [61] } \\
\hline & $\begin{array}{l}\text { Cationic NLCs (+stearic acid), gel of } 15 \% \\
\text { Plx } 407,12 \% \text { Plx 188, } 1 \% \text { HPMC }\end{array}$ & Rats & 128.6 & 22.3 & 2.74 & ND & 99.4 & 5820.3 & & \\
\hline Sesamol & SLNs (GMS, Tween 80) & Rats & 764 & 86.1 & ND & ND & 590.4 & ND & $\begin{array}{l}\text { Shorter } \mathrm{T}_{\max } \text {,brain }(10 \mathrm{~min} \text { vs. } 30 \mathrm{~min} \text { for IV drug sol.); } \\
\text { higher } \mathrm{C}_{\max , \text { brain }}(13.2 \text {-fold vs. IV drug sol.) }\end{array}$ & [114] \\
\hline Sumatriptan & $\begin{array}{l}\text { NLCs (Stearic acid, cholesterol, triolein, } \\
\text { Brij 35, Brij 72) }\end{array}$ & Rats & $\begin{array}{l}2416 \\
(258.0)\end{array}$ & $\begin{array}{l}95.86 \\
(61.23)\end{array}$ & 2.60 & 2.06 & 1295 & 744.6 & $\begin{array}{l}\text { Higher } \mathrm{C}_{\mathrm{max}, \text { brain }}(5.6-, 7.3-\text {, and } 9.4 \text {-fold vs. IN drug sol., } \\
\text { IV drug sol., and IV NLCs, respectively); higher } \\
\text { AUC }_{0-4 h, \text { brain }}(7.70 \text {-fold vs. IV NLCs) }\end{array}$ & [115] \\
\hline Tarenflurbil & $\begin{array}{l}\text { SLNs (GMS, stearic acid, soya lecithin, } \\
\text { Tween 20) }\end{array}$ & Rats & 183.2 & 45.4 & 2.20 & 2.55 & 142.3 & 182.1 & $\begin{array}{l}\text { Higher } \mathrm{C}_{\text {max,brain }}(1.5-, 1.7-\text {, and } 4.1 \text {-fold vs. IV drug sol., } \\
\text { IN drug sol,, and oral drug susp., respectively); higher } \\
\text { drug level in brain (multiple-dose, } \sim 2 \text {-fold vs. IV drug sol. } \\
\text { and oral drug susp.) }\end{array}$ & [68] \\
\hline Temozolomide & $\begin{array}{l}\text { NLCs (Gelucire } 44 / 14, \alpha \text { tocopherol, } \\
\text { Tween } 80 \text { ) }\end{array}$ & Rats & 457.8 & 78.16 & 2.61 & 2.82 & 588.1 & 282.7 & $\begin{array}{l}\text { Gamma scintigraphy images confirmed the brain } \\
\text { accumulation of NLCs }\end{array}$ & [116] \\
\hline Tenofovir & $\begin{array}{l}\text { NLCs (Compretol } 888 \text { ATO, oleic acid, } \\
\text { Tween 80, Plx 188) }\end{array}$ & Rats & 481.9 & 79.25 & 2.23 & 2.08 & 1204 & 402.7 & $\begin{array}{l}\text { Higher } \mathrm{C}_{\mathrm{max}, \text { brain }}(3.2,5.8 \text { - and } 6.5 \text {-fold vs. IV NLCs, IV } \\
\text { drug sol., and IN drug sol., respectively); higher } \\
\text { AUC }_{0 \text {-inf,brain }}(3.6 \text {-fold vs. IV NLCs); higher brain } \\
\text { accumulation (confocal microscopic image, vs. IV NLCs); } \\
\text { safety (histopathological examination) }\end{array}$ & {$[78]$} \\
\hline Ziprasidone & $\begin{array}{l}\text { NLCs (Gelucire } 43 / 01 \text {, Capmul MCM, } \\
\text { Labrasol, Transcutol P) }\end{array}$ & Rats & 476.8 & $\begin{array}{c}79.0 \\
(89.85)\end{array}$ & ND & ND & ND & ND & $\begin{array}{l}\text { Higher brain:blood conc. ratios and faster onset (10 } \mathrm{min}) \\
\text { vs. IV drug sol. }\end{array}$ & [117] \\
\hline
\end{tabular}




\subsection{PK and Biodistribution Studies without DTE\% and DTP\% Values}

In the remaining $40 \mathrm{PK}$ and biodistribution studies, DTE\% and DTP\% values were unavailable and thus, the brain targeting efficiencies of SLNs and NLCs (IN) were evaluated using other parameters.

\subsubsection{Comparisons Using Brain Bioavailability}

In some studies, the brain bioavailabilities of SLNs and NLCs (IN) were compared with free drug solution (IN, IV, or oral) or with SLNs and NLCs (IV). For example, the $\mathrm{AUC}_{0-8 \mathrm{~h} \text {,brain }}$ of almotriptan-loaded CS-coated NLCs (CS-NLCs) following IN administration to rabbits was 4.56- and 8.06-fold higher than those of Migrostop tablets (oral) and

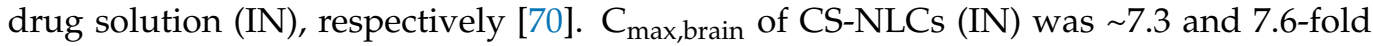
higher than those of Migrostop tablets (oral) and drug solution (IN), respectively. $\mathrm{T}_{\text {max,brain }}$ was observed at 10 min for CS-NLCs (IN), whereas values for Migrostop tablets (oral) and drug solution (IN) were 60 and $20 \mathrm{~min}$, respectively. The brain:blood concentration ratios of CS-NLCs (IN) were in the range 1.4-2.2, whereas the ranges of Migrostop tablet (oral) and drug solution (IN) were $0.41-0.89$ and $1.0-1.92$, respectively. These results indicated effective brain targeting by CS-NLCs (IN).

Singh et al. developed SLNs loaded with alprazolam, an antianxiety drug [38]. SLNs and drug solution were labeled with ${ }^{99} \mathrm{~m}$ Tc for biodistribution studies using rats. DTE\% and DTP\% values of SLNs (IN) and drug solution (IN) were based on the AUC of SLNs (IV). Recalculation was not possible because there was no drug solution (IV) group. SLNs (IN) had higher DTE\% and DTP\% values than the drug solution (IN). Likewise, AUC $_{0-8 h, b r a i n}$ of SLNs (IN) was 2- and 1.33-fold higher than those of drug solution (IN) and SLNs (IV), respectively. Biodistribution studies also revealed that the IN route caused less drug accumulation in liver, spleen, intestine, and kidney than the IV route. Scintigraphy images taken in rabbits revealed more drug deposition in the brain for SLNs (IN) than for SLNs (IV).

In a recent study, astaxanthin-loaded NLCs were developed to improve the treatment of Parkinson's disease [97]. The optimized NLC formulation was incorporated in an in situ gel composed of $20 \%$ Poloxamer 407 and $0.5 \%$ CS. In rats, the NLC gel (IN) had higher $\mathrm{C}_{\text {max,brain }}$ (9.5-fold) and $\mathrm{AUC}_{\text {brain }}$ (7.79-fold) values than the free drug gel (IN). The reported DTP\% value of 99.75 was calculated using data for NLCs (IV). In haloperidol-treated rats, the NLC gel (IN) improved rat behaviors in the rotarod test and akinesia measurements as compared with the free drug gel (IN).

Buspirone, an anxiolytic agent, was loaded into SLNs [77]. In rats, the $\mathrm{C}_{\text {max,brain }}$ of SLNs (IN) was 1.7- and 2.3-fold higher than those of drug solution (IN) and SLNs (IV). DTE\% (882.6) and DTP\% (88.67) values were based on the AUC of SLNs (IV). This research group later developed CS-coated NLCs loaded with buspirone [118]. CS-NLCs (IN) had higher $\mathrm{C}_{\max \text {,brain }}$ (1.5- and 2.6-fold) and $\mathrm{AUC}_{0-12 \mathrm{~h}, \text { brain }}$ (2.2- and 3.1-fold) values than the drug solution (IN) and NLCs (IV), respectively. DTE\% and DTP\% values of CS-NLCs (IN) were 1462.5 and 93.16, respectively, which were higher than those of the drug solution (IN) (544.4 and 81.63, respectively). However, these values were based on the AUC of CS-NLCs (IV).

Tripathi et al. developed cinnarizine-loaded NLCs and incorporated them in in situ gel for the treatment of migraine [119]. In rats, the optimized NLC gel (IN) showed higher $\mathrm{C}_{\text {max,brain }}$ (2.07-fold) and $\mathrm{AUC}_{0-4 \mathrm{~h} \text {,brain }}$ (2.23-fold) values than the drug solution (IN). In formalin-induced acute nociception rat model, the NLC gel (IN) exhibited higher antinociceptive activity for neurogenic pain and inflammatory pain than the free drug solution (IN). In a recent study, clozapine-loaded NLCs were developed to enhance the

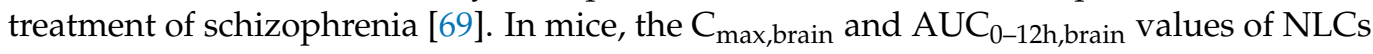
(IN) were 11.8- and 6.15-fold higher than those of clozapine tablets (oral). Curcumin was loaded into NLCs to target brain tumors via IN administration [120]. In rats, $C_{\text {max,brain }}$

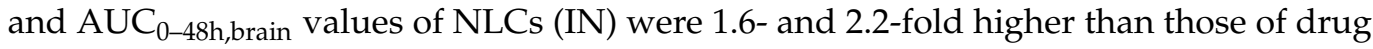
suspension (IN), respectively.

Butani et al. developed donepezil-loaded NLCs and incorporated the optimized NLCs

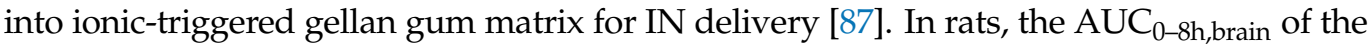


NLC gel (IN) was 1.26-fold higher than that of a tablet (oral). This slight increase indicated that the NLC gel was not highly potential for brain targeting. No PK data were provided for IV or IN administrations of the free drug. In a rat model of scopolamine-induced amnesia, the NLC gel (IN) improved cognitive function as compared with a marketed tablet (oral). Recently, flibanserin-loaded NLCs were developed for the treatment of hypoactive sexual desire disorder in premenopausal women [121]. The optimized NLC formulation was incorporated into in situ gel of $0.6 \%$ gellan gum. In rats, the NLC gel (IN) had higher $C_{\text {max,brain }}$ (3.5-fold) and $\mathrm{AUC}_{0 \text {-inf,brain }}$ (6.3-fold) values than the flibanserin gel (IN). Lurasidone-loaded NLCs were developed to improve the treatment of schizophrenia and bipolar disorder [122]. In rats, NLCs (IN) had higher $\mathrm{C}_{\text {max,brain }}$ (1.9- and 7.9-fold) and $\mathrm{AUC}_{0-24 h \text {,brain }}$ (2.96- and 9.3-fold) values than the drug solution (IN) and drug suspension (oral), respectively.

Gadhave et al. developed olanzapine-loaded NLCs and incorporated the optimized NLCs into Poloxamer 407-HPMC gel [26]. PK studies were performed using NLC gel and NLC dispersion with radiolabeled olanzapine $\left({ }^{99 \mathrm{~m}} \mathrm{Tc}\right) . \mathrm{C}_{\mathrm{max} \text {,brain }}$ and $\mathrm{AUC}_{0-6 \mathrm{~h} \text {,brain values }}$ of NLC gel (IN) were 3.98- and 3.81-fold higher than those of the NLC dispersion (IV). The same group later reported that this NLC gel had DTE\% and DTP\% values of 54,550 and 99.81, respectively [75], but these values were based on AUC of NLCs (IV). Notably, the NLC gel (IN) showed higher brain bioavailability than a microemulsion gel (IN) and NLCs (IV). Furthermore, the NLC gel did not show any evidence of hematological or liver toxicity following IN administration.

Palagati et al. developed oleuropein-loaded NLCs for the treatment of meningitis [123]. In rats, the $\mathrm{AUC}_{0-6 \mathrm{~h} \text {,brain }}$ of the optimized NLCs (IN) was 2.23-fold higher than that of the NLCs (IV). Although a DTP\% value of 83.07 was reported, data was insufficient to enable recalculation. In a previous study, borneol-stearic acid (Bo-SA) conjugate was prepared to enhance the brain targeting of Pueraria flavones-loaded SLNs [124]. In rats, the $\mathrm{AUC}_{0-8 \mathrm{~h} \text {,brain }}$ and $\mathrm{C}_{\mathrm{max} \text {,brain }}$ values of Bo-SA-SLNs (IN) were 8.31- and 8.29-fold higher than those of SLNs (IN), respectively.

Sivadasu et al. developed NLCs loaded with quetiapine, one of the most effective schizophrenia drugs [125]. IN administration of the optimized NLCs showed 4.15- and 3.57-fold increases in the $\mathrm{C}_{\text {max, brain }}$ and $\mathrm{AUC}_{0-6 \mathrm{~h} \text {,brain }}$ values, respectively, as compared with IV administration. The authors also reported DTE\% and DTP\% values of 485.76 and 90.26, respectively. However, these values were based on AUC of NLCs (IV). A previous study reported the development of a gellan gum and xanthan gum in situ gel containing resveratrol-loaded NLCs for the treatment of Alzheimer's disease [85]. PD studies (Morris Water Maze test) of a scopolamine-induced amnesia rat model showed that the NLC gel (IN) significantly improved memory function compared with a drug suspension (oral). This group later used the same gel to perform PK studies in rats [86]. The NLC gel (IN) showed higher $C_{\text {max,brain }}$ (2.6-fold) and $\mathrm{AUC}_{0-8 h \text {,brain }}$ (1.4-fold) values than the drug suspension (oral).

Rizatriptan-loaded SLNs were developed to improve the management of migraine [126].

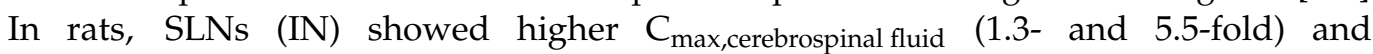

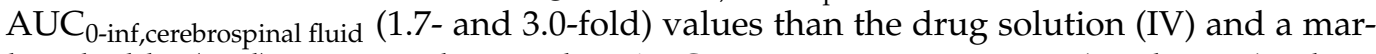

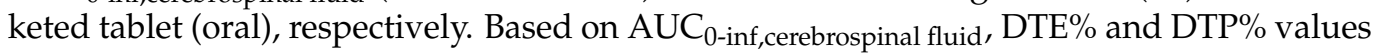
for the SLNs (IN) were 263.6 and 62.1, respectively. Recently, Pardeshi et al. incorporated ropinirole-dextran sulfate conjugation into NLCs, which were then coated with $\mathrm{N}, \mathrm{N}, \mathrm{N}$ trimethyl CS [127]. In mice, NLCs (IN) had a higher $C_{\text {max,brain }}$ than NLCs (IV) and drug conjugate solution (IN) (1.7- and 17.4-fold, respectively). No PK data were provided for the drug conjugate solution (IV) to enable DTE\% and DTP\% calculations. Nevertheless, the brain targeting of NLCs (IN) was confirmed based on brain bioavailability as the NLCs

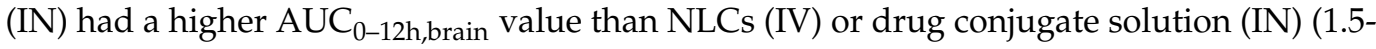
and 13.7-fold, respectively).

Kumar et al. developed SLNs loaded with streptomycin to treat cerebral tuberculosis [72]. In vivo studies were carried out using ${ }^{99 \mathrm{~m}} \mathrm{Tc}-$ labeled streptomycin. In a mouse biodistribution study, the brain concentrations of streptomycin for SLNs (IN) were higher 
than those for the drug solution (IN) (4.57-fold at $0.5 \mathrm{~h}$ and 6.0 -fold at $24 \mathrm{~h}$ ). Likewise,

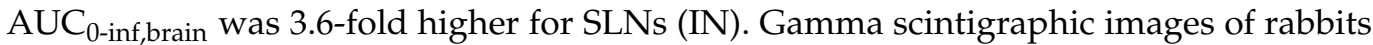
confirmed the higher deposition of ${ }^{99 \mathrm{~m}} \mathrm{Tc}-$ labeled streptomycin in the brain for SLNs (IN).

In a recent study, ${ }^{99 \mathrm{~m}} \mathrm{Tc}$ radiolabeled teriflunomide was loaded into NLC gellan gumcarbopol 974P gel [74]. In mice, the brain:blood concentration ratios of the NLC gel (IN) were approximately 2-3- and 8-10-fold higher than those of the NLC dispersion (IN and IV, respectively). DTE\% values of the NLC gel (IN) and NLC dispersion (IN) (1500 and 92, respectively) were based on the AUC for the NLC dispersion (IV). DTP\% values of the NLC gel (IN) and NLC dispersion (IN) were incorrectly reported (283 and 42.5, respectively), whereas they should have been 93.3 and -8.7 , respectively, based on the AUC for the NLC dispersion (IV). The $\mathrm{AUC}_{0 \text {-inf,brain }}$ of the NLC gel (IN) was 1.34-fold higher than that of

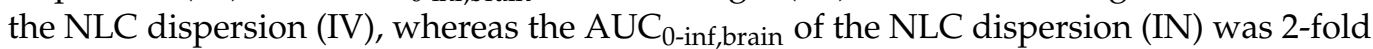
lower than that of the NLC dispersion (IV). Thus, the incorporation of NLCs into gellan gum-carbopol $974 \mathrm{P}$ gel critically increased brain targeting.

Table 2 summarizes major features of SLN and NLC-based formulations for nose-tobrain delivery in these studies.

\subsubsection{Comparison Using Brain: Blood Concentration Ratios}

In some cases, brain bioavailability was unavailable, and thus, brain:blood concentration ratios were used instead. For example, Gupte et al. developed efavirenz-loaded SLNs. The brain:blood concentration ratio at $24 \mathrm{~h}$ in rats of SLNs (IN) was approximately 150-fold higher than that of a marketed tablet (oral) [128]. Pioglitazone, a drug used to manage Alzheimer's disease, was incorporated into NLCs for IN administration [129]. In in vivo biodistribution studies using rats, the optimized NLCs (IN) had a 1.9- and 10.7-fold higher brain:blood concentration ratio than drug solution (IN and IV, respectively).

Rimonabant, a cannabinoid antagonist used to treat many CNS diseases, was loaded into NLCs [130]. In rats, the brain:blood concentration ratio at $6 \mathrm{~h}$ after administration of NLCs (IN) was 17.11, higher than that of the drug solution (IN) (11.74). However, we found that drug concentration in the brain at $6 \mathrm{~h}$ was $5.8 \mu \mathrm{g} / \mathrm{g}$ for the NLCs (IN), which was slightly higher than that $(5.1 \mu \mathrm{g} / \mathrm{g})$ of the drug solution (IN). Eskandari et al. prepared NLCs loaded with valproic acid, a drug widely used to treat migraine, bipolar disorder, epilepsy, and cancer [80]. In rats, the brain:plasma concentration ratio at $60 \mathrm{~min}$ after administration was 8.4 for optimized NLCs (IN), which was 5.09-fold higher than that for NLCs (intraperitoneal, IP). In addition, NLCs (IN) provided the same protective effect against seizure in rats (maximal electroshock seizure model) as IP administration of the drug solution, but at a 37.5-fold lower dose.

Table 3 summarizes the major features of SLN and NLC-based formulations for noseto-brain delivery in these studies. 
Table 2. Major features of SLN and NLC-based formulations for nose-to-brain delivery: Comparison using brain bioavailability from PK studies (without DTE\% and $\mathrm{DTP} \%)$.

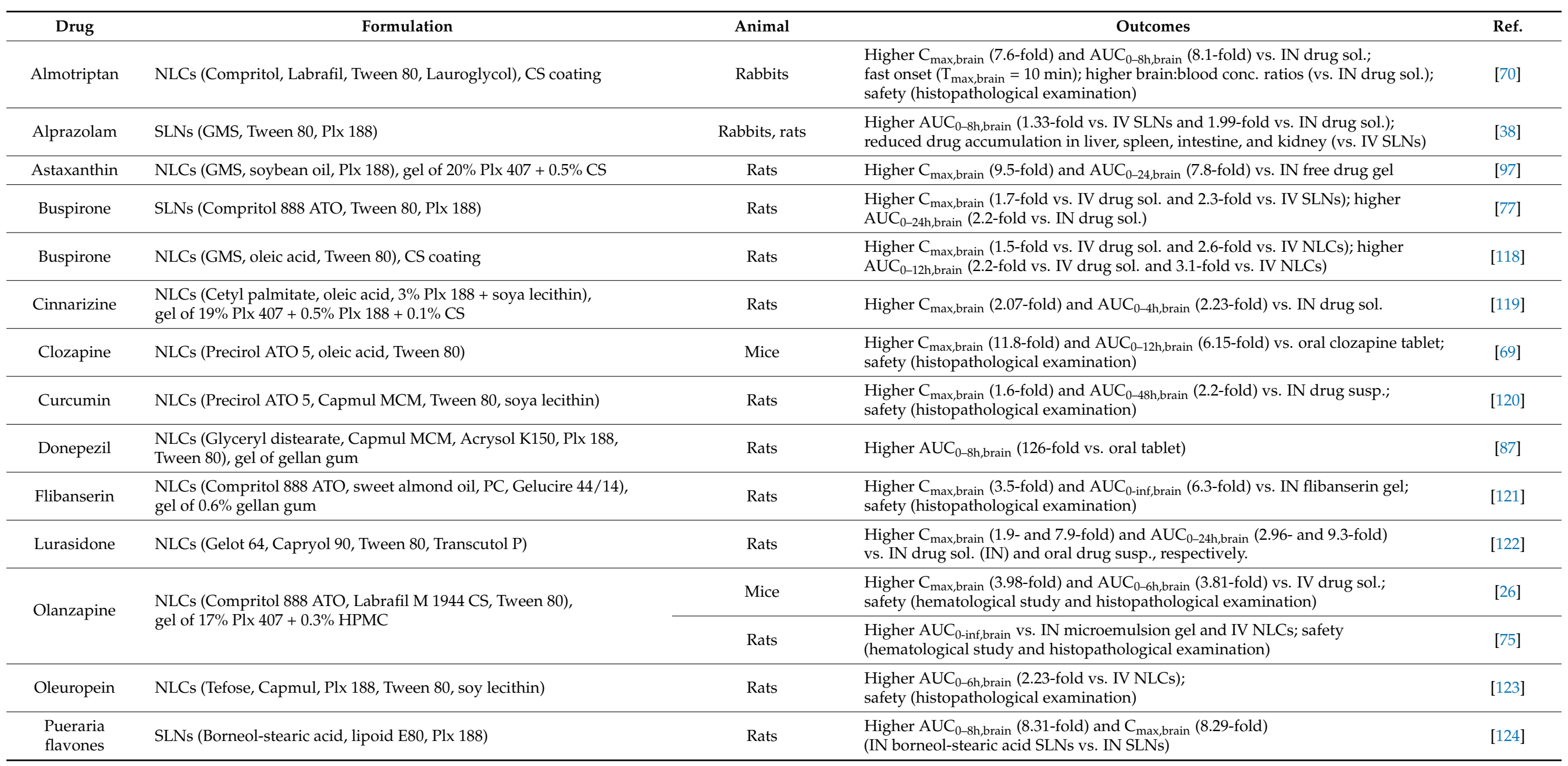


Table 2. Cont.

\begin{tabular}{|c|c|c|c|c|}
\hline Drug & Formulation & Animal & Outcomes & Ref. \\
\hline Quetiapine & NLCs (Gelucire 44/14, oleic acid, Tween 80, Transcutol P) & Rats & $\begin{array}{l}\text { Higher } C_{\max , \text { brain }}\left(4.15 \text {-fold) and } \mathrm{AUC}_{0-6 h, b r a i n}(3.57 \text {-fold) vs. IV NLCs; }\right. \\
\text { safety (histopathological examination) }\end{array}$ & [125] \\
\hline Resveratrol & $\begin{array}{l}\text { NLCs (Cetyl palmitate, Capmul MCM, Acrysol, Tween 80, Plx 188), } \\
\text { gel of gellan and xanthan gum }\end{array}$ & Rats & $\begin{array}{l}\text { Higher } \mathrm{C}_{\max , \text { brain }}\left(2.6 \text {-fold) and } \mathrm{AUC}_{0-8 \mathrm{~g} \text {,brain }}(1.4 \text {-fold) vs. oral drug susp.; }\right. \\
\text { safety (histopathological examination) }\end{array}$ & {$[85,86]$} \\
\hline Rizatriptan & SLNs (Glycerol monostearate, lecithin, Plx 407) & Rats & $\begin{array}{l}\text { Higher } C_{\max , \text { cerebrospinal fluid }}\left(1.3 \text { - and } 5.5 \text {-fold) and } \mathrm{AUC}_{0 \text {-inf,cerebrospinal fluid }}\right. \\
\text { (1.7- and 3.0-fold) vs. IV drug sol. and oral tablet, respectively }\end{array}$ & [126] \\
\hline Ropinirole & NLCs (Tristearin, flaxseed oil, TPGS, Lipoid S100), TMC coating & Mice & $\begin{array}{l}\text { Higher } \mathrm{C}_{\max , \text { brain }}(1.7-\text {-fold vs. IV NLCs and } 17.4-\text {-fold vs. IN drug sol.); } \\
\text { higher AUC } \mathrm{C}_{0-12 \mathrm{~h} \text {,brain }}(1.5 \text {-fold vs. IV NLCs and } 13.7 \text {-fold vs. IN drug sol.); } \\
\text { safety (histopathological examination) }\end{array}$ & [127] \\
\hline Streptomycin & SLNs (Compritol 888 ATO, Tween 80, soy lecithin) & Rabbits; mice & $\begin{array}{l}\text { Higher brain conc. ( } 4.57 \text {-fold at } 0.5 \mathrm{~h} \text { and } 6.0 \text {-fold at } 24 \mathrm{~h} \text { ) and } \mathrm{AUC}_{0 \text {-inf,brain }} \\
\text { (3.6-fold) vs. drug sol. in mice; higher brain conc. in rabbits (gamma scintigraphy) }\end{array}$ & [72] \\
\hline Teriflunomide & $\begin{array}{l}\text { NLCs (Glyceryl dibehenate, glyceryl mono-linoleate, Gelucire } 44 / 14 \text { ), } \\
\text { gel of } 0.2 \% \text { carbopol } 974 \mathrm{P}+0.2 \% \text { gellan gum }\end{array}$ & Mice & $\begin{array}{l}\text { Higher } \mathrm{AUC}_{0-8, \text { brain }}(1.34 \text {-fold vs. IV NLCs); higher brain:blood conc. ratios } \\
\text { ( } 2-3-\text { and } 8-10 \text {-fold vs. IN and IV NLCs, respectively); safety (histopathological } \\
\text { examination and biochemical markers) }\end{array}$ & [74] \\
\hline
\end{tabular}

Table 3. Major features of SLN and NLC-based formulations for nose-to-brain delivery: Comparison using brain:blood concentration ratios from PK studies.

\begin{tabular}{|c|c|c|c|c|}
\hline Drug & Formulation & Animal & Outcomes & Ref. \\
\hline Efavirenz & SLNs (Tripalmitin, Plx 188) & Rats & Higher brain:blood conc. ratio at $24 \mathrm{~h}$ (150-fold vs. oral tablet) & [128] \\
\hline Pioglitazone & NLCs (Tripalmitin, Capmul MCM, stearyl amine, Tween 80, Plx 188) & Rats & $\begin{array}{l}\text { Higher brain:blood conc. ratio (1.9- and } 10.7 \text {-fold vs. IN and IV } \\
\text { drug sol., respectively); safety (histopathological examination); }\end{array}$ & [129] \\
\hline Rimonabant & NLCs (Tristearin, Miglyol 812N, Plx 188) & Rats & Higher brain:blood conc. ratio (vs. IN drug sol.) & [130] \\
\hline Valproic acid & NLCs (Cetyl palmitate, soy lecithin, octyldodecanol, Plx 188) & Rats & Higher brain:plasma conc. ratio at $60 \mathrm{~min}$ (5.09-fold vs. IP NLCs) & [80] \\
\hline
\end{tabular}




\subsubsection{Drug Accumulation in the Brain}

Some studies used drug concentrations in the brain for comparison purposes. For example, artemether and lumefantrine were co-loaded in N,N,N-trimethyl chitosan-coated NLCs (TMC-NLCs) for the treatment of cerebral malaria [64]. In mice, TMC-NLCs (IN) produced higher drug concentrations in the brain than the drug suspension (IN and oral). In parasite-infected mice, parasite suppression on day 7 for TMC-NLCs (IN) was $95 \%$ higher than that for IN NLCs (82.5\%), IN drug suspension (79.1\%), and oral drug suspension (46.3\%). In another study, ${ }^{99 \mathrm{~m}} \mathrm{Tc}$ radiolabeled astaxanthin-loaded SLNs were developed for the management of neurological disorders [71]. SLNs (IN) achieved $\sim 2$-fold higher drug concentrations in brain than IV administration (at $1 \mathrm{~h}$ ). This finding was confirmed by gamma scintigraphy imaging.

Esposito et al. developed SLNs loaded with dimethyl fumarate for the treatment of multiple sclerosis [131]. SLNs were labeled with indocyanine green for fluorescent luminescent imaging. SLNs (IN) showed the brain accumulation similar to that of SLNs (IP), but at a 10fold lower dose. A previous study reported the development of NLCs loaded with embelin for the treatment of epilepsy [82]. Optimized NLCs (IN) resulted in higher drug concentrations in the brain than the drug solution (IN) and a marketed formulation (IV). However, there was insufficient data to calculate DTE $\%$ and DTP\% values. In pentylenetetrazole-treated rats, NLCs (IN) reduced malondialdehyde and nitrite levels and increased glutathione levels as compared with drug solution (IN) and a marketed formulation (IV).

Saini et al. developed CS-coated SLNs containing ferulic acid for the treatment of Alzheimer's disease [90]. The drug concentrations in rat brain for CS-SLNs (IN) and SLNs (IN) were 6.91- and 5.42-fold higher than that for a drug suspension (IN), respectively. In rat model of Alzheimer's disease (induced by streptozocin), both CS-SLNs (IN) and SLNs (IN) improved cognitive ability and biochemical parameters (lipid peroxidation, nitrite, superoxide dismutase, acetylcholinesterase, glutathione, and protein levels in cortex and hippocampus) as compared with a drug suspension (IN, oral) and SLNs (oral). CS-SLNs (IN) were more effective than SLNs (IN).

Lamotrigine-loaded NLCs were developed to improve the treatment of epilepsy [81]. Gamma scintigraphy studies showed that drug accumulated in the brain until $6 \mathrm{~h}$ after IN administration of NLCs. At $24 \mathrm{~h}$ after administrations, drug concentration in the brain for NLCs (IN) was 1.4- and 5.1-fold higher than those for drug solutions (IN and oral, respectively). Likewise, in rats with seizures, NLCs (IN) improved behavioral abnormalities, decreased malondialdehyde, and increased glutathione in the brain as compared with drug solution (IN and oral). Hasan et al. developed SLNs loaded with naloxone, an opioid receptor antagonist used to treat opioid overdose [132]. The drug was radiolabeled with ${ }^{99 \mathrm{~m}} \mathrm{Tc}$, and gamma scintigraphy and biodistribution studies in rats showed better deposition of naloxone in the brain for SLNs (IN) than for drug solution (IN). The PK and biodistribution studies were conducted in rabbits on only SLNs (IN), and thus, DTE\% and DTP $\%$ values could not be calculated.

Sun et al. developed a paeonol-loaded SLN gel ( $0.4 \%$ deacetylated gellan gum and $0.3 \%$ HPMC) [12]. The authors found that brain accumulation was better for a cyanine7 NHS ester-loaded SLN gel (IN) than cyanine7 NHS ester-loaded SLNs (IV). Li et al. prepared a quetiapine-loaded SLN gel and evaluated it in a rat model of schizophrenia [133]. It was found that drug concentrations in the prefrontal cortex, cerebellum, hippocampus, and pituitary after SLN gel (IN) administration were similar to those of the drug solution (IV) and significantly higher than those of the drug solution (oral) at all time points. Furthermore, the SLN gel (IN) improved hippocampal morphology more than drug solution (IV and oral) in a rat schizophrenia model.

Wavikar et al. developed rivastigmine-loaded NLCs for the treatment of Alzheimer's disease [88]. The optimized NLC formulation was incorporated into an in situ gel (15\% Poloxamer 407 and $0.8 \%$ gellan gum). Biodistribution studies in rats showed 4.6-, 8.6-, and 1.6-fold higher drug concentration in the brain at $1 \mathrm{~h}$ for the NLCs gel (IN) than for the drug solution (IN), drug solution (IV), and NLCs (IV), respectively. Furthermore, in 
scopolamine-induced amnesic mice, the NLC gel (IN) exhibited faster regain of memory loss than the drug solution (IN and IV).

Some studies reported drug accumulations in the brain for SLNs and NLCs (IN) without using a reference (control) formulation, which was insufficient to demonstrate brain targeting efficiencies as compared with other formulations. For example, when NLCs loaded with a geraniol-ursodeoxycholic acid conjugate were developed for the management of Parkinson's disease [134], NLCs (IN) were found to deliver drug from the nose to the brain in rats without causing mucosal irritation, and the drug was detected in cerebrospinal fluid until $3 \mathrm{~h}$ after administration. However, the authors did not perform PK studies on drug solutions (IN and IV) for comparison. Gartziandia et al. developed CS-coated NLCs containing human insulin-like growth factor-I (hIGF-I)) [76]. Fluorescence imaging revealed that DiR DiIC18-labeled CS-NLCs presented in the nasal cavity until $24 \mathrm{~h}$ and rapidly distributed in the olfactory tract and brain after IN administration. However, no other formulations (e.g., IV and IN drug solutions) were examined.

Khanna et al. developed SLNs loaded with nalbuphine for the management of pain [135]. SLNs were radiolabeled with ${ }^{99 \mathrm{~m}} \mathrm{Tc}$. Biodistribution and gamma scintigraphy studies revealed their presence in the brain $10 \mathrm{~min}$ after administration and their retention until $8 \mathrm{~h}$. SLNs (IN) produced better analgesic effects and had early action onsets than the drug solution (intramuscular injection) in thermal allodynia-induced rats. In another study, the ${ }^{99 \mathrm{~m}}$ Tc-SLNs (IN) loaded with ondansetron exhibited rapid accumulation (1 h post-administration) in rabbit brains as determined by gamma scintigraphy [136].

Bhatt et al. developed SLNs loaded with rosmarinic acid for the management of Huntington's disease [137]. Rat PK studies showed drug accumulation amount in the brain of $5.69 \mu \mathrm{g}$; but unfortunately, no detailed data were provided. In 3-nitropropionic acidtreated rats, SLNs (IN) improved behavioral abnormalities and attenuated oxidative stress (by decreasing malondialdehyde and nitrite levels and increasing catalase and glutathione levels in the brain) as compared with SLNs (IV) or free rosmarinic acid (IN). In a recent study, zolmitriptan-loaded SLNs were incorporated into HPMC gel [138]. Histopathological examination of brain tissues showed that SLNs accumulated in the brain cells until $24 \mathrm{~h}$ after IN administration.

Major features of SLN and NLC-based formulations for nose-to-brain delivery in these studies are summarized in Table 4.

\subsection{PD Studies}

Among the 30 studies that reported PD evaluations, 15 performed PK or biodistribution studies and these have been mentioned above. The remaining 15 articles were as follows.

Agbo et al. developed NLCs loaded with artesunate for the treatment of severe cerebral malaria [57]. In mice infected with Plasmodium berghei ANKA, activity and parasitemia reduction for NLCs (IN) (54.70 and 33.28\%, respectively) were comparable to those for intramuscular administration (58.80 and $42.18 \%$, respectively). These results suggested that artesunate-loaded NLCs (IN) might be a satisfactory alternative to conventional intramuscular administration, which can be problematic in remote areas. In a recent study, Matarazzo et al. developed NLCs containing cannabidiol, a phytocannabinoid used to treat chemotherapy-induced peripheral neuropathy in cancer patients [139]. Cetylpyridinium chloride was used as a surfactant to produce positively charged NLCs. In mice with paclitaxel-induced neuropathic pain, the NLC dispersion (IN) had greater antinociceptive effects than the drug solution (IN and oral). 
Table 4. Major features of SLN and NLC-based formulations for nose-to-brain delivery: Comparison using drug accumulation in the brain from PK studies.

\begin{tabular}{|c|c|c|c|c|}
\hline Drug & Formulation & Animal & Outcomes & Ref. \\
\hline Artemether + lumefantrine & $\begin{array}{l}\text { NLCs (Gelucire 50/13, Lipoid S75, oleic acid, Capmul MCM, } \\
\text { Tween 80), TMC coating }\end{array}$ & Mice & Higher drug conc. in mice brain (vs. IN and oral drug susp.) & [64] \\
\hline Astaxanthin & SLNs (Stearic acid, Plx 188, lecithin) & Rats & Higher drug conc. in the brain ( $\sim 2$-fold vs. IV SLNs) & [71] \\
\hline Embelin & NLCs (Cetyl palmitate, octyldodecanol, Plx 188) & Rats & Higher drug conc. in the brain (vs. IN drug sol. and IV marketed formulation) & [82] \\
\hline Ferulic acid & SLNs (Compritol, Plx 188), CS coating & Rats & $\begin{array}{l}\text { Higher drug conc. in brain (6.91-fold for IN CS-SLNs and 5.42-fold for IN } \\
\text { SLNs vs. IN drug susp.); safety (histopathological examination) }\end{array}$ & [90] \\
\hline Naloxone & SLNs (GMS, Plx 407, Tween 80) & Rabbits, rats & $\begin{array}{l}\text { Better brain deposition via gamma scintigraphy and biodistribution studies } \\
\text { (vs. IN drug sol.); safety (weight variation, histopathological examination) }\end{array}$ & [132] \\
\hline Paeonol & $\begin{array}{l}\text { SLNs (GMS, soybean lecithin, Plx 407, Tween } 80 \text { ), gel of } 0.4 \% \\
\text { deacetylated gellan gum }+0.3 \% \text { HPMC }\end{array}$ & Rats & Higher brain accumulation (vs. IV SLNs) & [12] \\
\hline Quetiapine & SLNs (GMS, span-80, butanol), gel of 21\% Plx $407+5.6 \%$ Plx 188 & Rats & $\begin{array}{l}\text { Drug conc. in the brain: similar to those for IV drug sol. and higher than those } \\
\text { for oral drug sol.; better effect in improving hippocampal morphology change }\end{array}$ & [133] \\
\hline Rivastigmine & $\begin{array}{l}\text { NLCs (GMS, Capmul MCM C8, Lecithin and Tween } 80 \text { ), gel of } 15 \% \\
\text { Plx } 407+0.8 \% \text { gellan gum }\end{array}$ & Rats, mice & $\begin{array}{l}\text { Higher drug concentration in the brain at } 1 \mathrm{~h}(4.6-, 8.6-\text {-, and } 1.6-\text { fold vs. IN } \\
\text { drug sol., IV drug sol., and IV NLCs, respectively); safety (hematology and } \\
\text { histopathological examination) }\end{array}$ & [88] \\
\hline hIGF-1 & NLCs (Precirol ATO5, Miglyol, Tween 80, Plx 188), CS coating & Mice & $\begin{array}{l}\text { Brain accumulation (via fluorescence imaging); } \\
\text { safety (histopathological examination) }\end{array}$ & [76] \\
\hline Nalbuphine & SLNs (Phosphatidylcholine, Tween 80, Plx 407) & Rats & Detection of drug in brain from $10 \mathrm{~min}$ to $8 \mathrm{~h}$ & [135] \\
\hline Ondansetron & SLNs (GMS, Plx 188, lecithin) & Rabbits & $\begin{array}{l}\text { Rapid drug localization in brain ( } 1 \mathrm{~h} \text {, gamma scintigraphy); } \\
\text { safety (histopathological examination) }\end{array}$ & [136] \\
\hline Rosmarinic acid & SLNs (GMS, Tween 80, hydrogenated soya phosphatidyl choline) & Rats & Drug amount in brain $(5.69 \mu \mathrm{g})$ & [137] \\
\hline Zolmitriptan & SLNs (Steari acid, cholesterol, lecithin), gel of 3\% HPMC & Rats & Accumulation of SLNs in brain until $24 \mathrm{~h}$ & [138] \\
\hline
\end{tabular}

IM, intramuscular; hIGF-1, human insulin-like growth factor-1. 
Deshkar et al. developed NLCs containing carbamazepine, an anticonvulsant and antiepileptic [79]. The NLCs were loaded into in situ gel (20\% Poloxamer $407,5 \%$ Poloxamer 188 , and $0.2 \%$ CS). The NLC gel (IN) improved in vivo anticonvulsant activity in rats with maximal electroshock seizure as compared with a carbamazepine dispersion (oral) or carbamazepine in situ gel (IN). In a previous study, superparamagnetic iron oxideloaded NLCs (SPION-NLCs) containing clonazepam were developed for the treatment of epilepsy [83]. SPION was used to increase drug targeting with the help of an external magnetic field. The optimized formulation was incorporated into in situ gel (15\% Poloxamer 407 and $0.75 \%$ sodium alginate). In pentylenetetrazole-induced convulsion mouse model, the SPION-NLC gel (IN) and NLC gel (IN) prolonged the onset of convulsion (7.5- and 1.5-fold) and death (14- and 5-fold), respectively, as compared with the non-treated controls.

Vitorino et al. developed NLCs loaded with fluoxetine for the treatment of depression [93], and examined its effects in mice using marble-burying and forced swimming tests. The results obtained showed that NLCs (IN) had more potent anti-depressive and anxiolytic effects than the drug solution (oral). Gartziandia et al. loaded glial cell-derived neurotrophic factor (GDNF) into CS-NLCs for nose-to-brain delivery [95]. In 6-hydroxydopamine partially lesioned rats, IN administration of CS-NLCs induced greater behavioral improvements and had more potent neuroprotective and neurorestorative effects than the oral drug solution. Hernando et al. also incorporated GDNF into NLCs coated with CS (CS-NLCs) or a transactivator of transcription (TAT) peptide-CS conjugate (TAT-CS-NLCs) [94]. In a 1-methyl-4-phenyl-1,2,3,6-tetrahydropyridine-treated mouse model of Parkinson's disease, CS-NLCs (IN) and TAT-CS-NLCs (IN) improved motor recovery and increased numbers of tyrosine hydroxylase fibers in striatum and tyrosine hydroxylase neuron levels in substantia nigra more than GDNF solution (IN).

Ketononazole was loaded into NLCs to improve the treatment of cryptococcal meningoencephalitis [140]. In mice infected with fungal cells, NLCs (IN) reduced the fungal burden in the brain more than free ketononazole (IN). Taymouri et al. developed NLCs containing lorazepam, a drug used to treat epilepsy [84]. The optimized NLC formulation was loaded into an in situ gel of CS and $\beta$-glycerol phosphate for nose-to-brain delivery. In pentylenetetrazoletreated rats, the NLC gel (IN) reduced seizure occurrence versus the NLC dispersion (IN) and lorazepam solution (IP). A previous study reported the development of NLCs loaded with rivastigmine for the treatment of dementia [89]. The optimized NLCs (IN) showed noticeable improvements in escape and transfer latencies (using the Morris water maze test and the elevated plus maze test) in scopolamine-treated rats as compared with drug solution (IN).

Pardeshi et al. developed SLNs loaded with ropinirole [96]. In chlorpromazine-treated mice exhibiting Parkinsonism-like signs, the optimized SLNs (IN) showed better anti-tremor activity than a marketed tablet (oral) at a 3.3-fold lower dose. Another study reported the development of NLCs loaded with selegiline for the treatment of Parkinson's disease [98]. In rotenone-treated rats, the NLCs (IN) restored behavior and malondialdehyde, nitrite, and glutathione levels better than free selegiline (IN). Hangargekar et al. developed SLNs loaded with sertraline and evaluated the antidepressant effects of the optimized SLNs on rats using the tail suspension and forced swimming tests [91]. SLN (IN) and the free drug (IN) reduced immobility duration in both tests, but SLN (IN) did so at a 2.5-fold higher dose.

Gadhave et al. developed NLCs loaded with teriflunomide for the treatment of multiple sclerosis [100]. The optimized NLC formulation was incorporated into in situ gel $(17 \%$ Poloxamer 407 and $0.3 \%$ HPMC). In a cuprizone-induced rat model of microglia activation and demyelination, the NLC gel (IN) induced more rapid remyelination and behavior improvements than NLCs (oral). Esposito et al. developed SLNs loaded with URB597, an endocannabinoid hydrolysis inhibitor, for the treatment of depression [141]. The SLNs (IN) induced behavioral effects similar to those induced by URB597 solution (IP).

Table 5 summarizes the major features of SLN and NLC-based formulations for noseto-brain delivery in the 30 PD studies. 
Table 5. Major features of SLN and NLC-based formulations for nose-to-brain delivery: PD studies.

\begin{tabular}{|c|c|c|c|c|}
\hline Drug & Formulation & Animal Model & Outcomes & Ref. \\
\hline $\begin{array}{l}\text { Artemether }+ \\
\text { lumefantrine }\end{array}$ & $\begin{array}{l}\text { NLCs (Gelucire 50/13, Lipoid S75, oleic acid, Capmul } \\
\text { MCM, Tween 80), TMC coating }\end{array}$ & Plasmodium berghei ANKA-injected mice & $\begin{array}{l}\text { Higher parasite suppression ( } 95 \% \text { vs. } 82.5 \% \text { (IN NLCs), } \\
79.1 \% \text { (IN drug susp.), and } 46.3 \% \text { (oral drug susp.)) }\end{array}$ & {$[64]^{*}$} \\
\hline Artesunate & $\begin{array}{l}\text { NLCs (Compritol HD5 ATO, Phospholipon 90H, Miglyol } \\
812 \text { N, Transcutol HP, Tween 80, Plx 188) }\end{array}$ & Plasmodium berghei ANKA-injected mice & $\begin{array}{l}\text { Similar activity ( } 54.70 \% \text { vs. } 58.80 \%) \text { and reduction in } \\
\text { parasitaemia ( } 33.28 \% \text { vs. } 42.18 \% \text { ) vs. IM NLCs }\end{array}$ & [57] \\
\hline Asenapine & NLCs (GMS, oleic acid, Tween 80) & Rats with L-dopa and carbidopa-induced catalepsy & Better therapeutic and safety profiles (vs. IN drug sol.) & {$[28]^{*}$} \\
\hline Astaxanthin & $\begin{array}{l}\text { NLCs (GMS, soybean oil, Plx 188), } \\
\text { gel of } 20 \% \text { Plx } 407+0.5 \% \text { CS }\end{array}$ & Rats with haloperidol-induced catalepsy & $\begin{array}{l}\text { Improved behaviors in rotarod test and akinesia } \\
\text { measurement (vs. IN free drug gel) }\end{array}$ & [97] * \\
\hline Cannabidiol & $\begin{array}{l}\text { NLCs (Stearic acid, oleic acid, Span 20, cetylpyridinium } \\
\text { chloride), gel of } 17 \% \text { Plx } 407+3 \% \text { Plx } 188\end{array}$ & Mice with paclitaxel-induced neuropathic pain & Increased antinociceptive effects (vs. IN and oral drug sol.) & [139] \\
\hline Carbamazepine & $\begin{array}{l}\text { NLCs (Precirol, Capmul MCM, Tween 80, Span 20), gel of } \\
20 \% \text { Plx } 407,5 \% \text { Plx 188, 0.2\% CS }\end{array}$ & Rats with MES & $\begin{array}{l}\text { Higher protection efficacy against seizure } \\
\text { (vs. IN plain drug gel) }\end{array}$ & [79] \\
\hline Cinnarizine & $\begin{array}{l}\text { NLCs (Cetyl palmitate, oleic acid, } 3 \% \text { Plx } 188+\text { soya } \\
\text { lecithin), gel of } 19 \% \text { Plx } 407+0.5 \% \text { Plx } 188+0.1 \% \text { CS }\end{array}$ & Formalin-induced acute nociception rats & $\begin{array}{l}\text { Higher antinociceptive activity in neurogenic pain and } \\
\text { inflammatory pain (vs. IN drug sol.) }\end{array}$ & [119] * \\
\hline Clonazepam & $\begin{array}{l}\text { SLNs (GMS, stearic acid, compritol, oleic acid, glycerol } \\
\text { oleate), gel of } 15 \% \text { Plx } 407+0.75 \% \text { sodium alginate }\end{array}$ & Mice with pentylenetetrazole-induced epilepsy & $\begin{array}{l}\text { Prolonged onset times for convulsion (7.5- and } 1.5 \text {-fold) and } \\
\text { death (14- and 5-fold) for IN SPION-NLC gel and IN NLC } \\
\text { gel vs. control }\end{array}$ & [83] \\
\hline Donepezil & $\begin{array}{l}\text { NLCs (Glyceryl distearate, Capmul MCM, Acrysol K150, } \\
\text { Plx 188, Tween 80), gel of gellan gum }\end{array}$ & Rats with scopolamine-induced amnesia & Improved cognitive function (vs. oral tablet) & {$[87]^{*}$} \\
\hline Duloxetine & NLCs (GMS, capryol PGMC, Plx 188, sodium taurocholate) & Rats, locomotor activity and forced swimming tests & $\begin{array}{l}\text { Improved locomotor activity, increased swimming and } \\
\text { climbing time, reduced immobility period vs. drug sol. } \\
\text { (IN and IV); }\end{array}$ & {$[73,92,102] *$} \\
\hline Embelin & NLCs (Cetyl palmitate, octyldodecanol, Plx 188) & Rats with pentylenetetrazole-induced epilepsy & $\begin{array}{l}\text { Reduced malondialdehyde and nitrite and increased } \\
\text { glutathione (vs. IN drug sol. and IV marketed formulation) }\end{array}$ & {$[82]^{*}$} \\
\hline Ferulic acid & SLNs (Compritol, Plx 188), CS coating & $\begin{array}{l}\text { Rats with streptozocin-induced } \\
\text { Alzheimer's disease }\end{array}$ & $\begin{array}{l}\text { Improved cognitive ability and biochemical parameters } \\
\text { (IN CS-SLNs > IN SLNs > IN, oral drug susp., oral SLNs) }\end{array}$ & {$[90]^{*}$} \\
\hline Fluoxetine & NLCs (Precirol ATO5, Lauroglycol 90, Tween 80) & Mice, marble-burying and forced swimming tests & $\begin{array}{l}\text { Reduced depressive and anxiety-like behaviors } \\
\text { (better than oral drug solution) }\end{array}$ & [93] \\
\hline GDNF & $\begin{array}{l}\text { NLCs (Precirol ATO5, Miglyol, Tween 80, Plx 188), } \\
\text { CS coating }\end{array}$ & 6-hydroxydopamine partially lesioned rats & $\begin{array}{l}\text { Increased behavioral improvement, neuroprotective, and } \\
\text { neuro-restorative effects (vs. oral drug sol.) }\end{array}$ & [95] \\
\hline GDNF & $\begin{array}{l}\text { NLCs (Precirol ATO5, Mygliol, Tween 80, Plx 188), } \\
\text { coating with transactivator of transcription (TAT) } \\
\text { peptide-CS conjugate }\end{array}$ & $\begin{array}{l}\text { Mice with 1-methyl-4-phenyl-1,2,3,6- } \\
\text { tetrahydropyridine-induced } \\
\text { Parkinson's disease }\end{array}$ & $\begin{array}{l}\text { Better motor recovery and immunohistochemistry data } \\
\text { (vs. IN GDNF sol.) }\end{array}$ & [94] \\
\hline Ketoconazole & $\begin{array}{l}\text { NLCs (Compritol } 888 \text { ATO, Miglyol } 812 \text { N, Solutol HS15, } \\
\text { Tween 80) }\end{array}$ & Mice infected with fungal cells & Reduced fungal burden in brain (vs. IN drug sol.) & [140] \\
\hline
\end{tabular}


Table 5. Cont.

\begin{tabular}{|c|c|c|c|c|}
\hline Drug & Formulation & Animal Model & Outcomes & Ref. \\
\hline Lamotrigine & NLCs (GMS, oleic acid, Tween 80, Plx 188) & Rats with MES & $\begin{array}{l}\text { Improved behavioral abnormalities, decreased } \\
\text { malondialdehyde, and increased glutathione } \\
\text { (vs. IN and oral drug sol.) }\end{array}$ & {$[81]^{*}$} \\
\hline Lorazepam & $\begin{array}{l}\text { SLNs (GMS, oleic acid, Plx 407), gel of CS and } \\
\beta \text {-glycerol phosphate }\end{array}$ & Rats with pentylenetetrazole-induced epilepsy & $\begin{array}{l}\text { Reduced occurrence seizures } \\
\text { (vs. IN NLC dispersion and IP drug sol.) }\end{array}$ & [84] \\
\hline Nalbuphine & SLNs (Phosphatidylcholine, Tween 80, Plx 407) & Thermal allodynia induced rats & $\begin{array}{l}\text { Better analgesic effect and early onset of action } \\
\text { (vs. IM drug sol.) }\end{array}$ & {$[135]^{*}$} \\
\hline Resveratrol & $\begin{array}{l}\text { NLCs (Cetyl palmitate, Capmul MCM, Acrysol, } \\
\text { Tween 80, Plx 188), gel of gellan and xanthan gum }\end{array}$ & Rats scopolamine-induced amnesia & Improved memory function (vs. oral drug sol.) & {$[85,86]^{*}$} \\
\hline Risperidone & NLCs (Stearic acid, oleic acid, Tween 80), CS coating & Rats with haloperidol-induced catalepsy & Greater bio-efficacy (vs. IN and IV drug susp.) & {$[63]^{*}$} \\
\hline Rivastigmine & NLCs (Compritol 888 ATO, triacetin, sucrose acetate, Plx) & Rats with scopolamine-induced amnesia & $\begin{array}{l}\text { Improve escape latency and transfer latency } \\
\text { (vs. IN drug sol.) }\end{array}$ & [89] \\
\hline Rivastigmine & $\begin{array}{l}\text { NLCs (GMS, Capmul MCM C8, Lecithin and Tween } 80 \text { ), } \\
\text { gel of } 15 \% \text { Plx } 407+0.8 \% \text { gellan gum }\end{array}$ & Mice with scopolamine-induced amnesia & Faster regain of memory loss (vs. IN and IV drug sol.) & {$[88]^{*}$} \\
\hline Ropinirole & SLNs (Dynasan 114, stearylamine, Plx 188, soy lecithin) & $\begin{array}{l}\text { Mice with chlorpromazine-induced } \\
\text { Parkinsonism-like signs }\end{array}$ & $\begin{array}{l}\text { Better anti-tremor activity with a 3.3-fold lower dose } \\
\text { (vs. oral tablet); safety (histopathological examination) }\end{array}$ & [96] \\
\hline Rosmarinic acid & $\begin{array}{l}\text { SLNs (GMS, Tween } 80 \text {, hydrogenated soya } \\
\text { phosphatidyl choline) }\end{array}$ & $\begin{array}{l}\text { Rats with 3-nitropropionic acid-induced } \\
\text { neurotoxicity }\end{array}$ & $\begin{array}{l}\text { Increased protection against striatal oxidative stress } \\
\text { (vs. IV SLNs) }\end{array}$ & {$[137]^{*}$} \\
\hline Selegiline & NLCs (Stearylamine, olive oil, Tween 80, Plx 188) & Rats with rotenone-induced Parkinson's disease & $\begin{array}{l}\text { Better restored behavior (vs. IN drug sol.); reduced } \\
\text { malondialdehyde and nitrite and increased glutathione } \\
\text { (vs. IN drug sol.) }\end{array}$ & [98] \\
\hline Sertraline & SLNs (GMS, Plx 188, Tween 80) & Rats, tail suspension test and forced swimming test & $\begin{array}{l}\text { Similar reduction in immobility duration (vs. IN free drug) } \\
\text { but at a 2.5-fold higher dose. }\end{array}$ & [91] \\
\hline Teriflunomide & $\begin{array}{l}\text { NLCs (Compritol } 888 \text { ATO, maisine } 35-1 \text {, Gelucire 44/14); } \\
\text { gel of } 17 \% \text { Plx } 407+0.3 \% \text { HPMC }\end{array}$ & Rats with cuprizone-induced demyelination & $\begin{array}{l}\text { Rapid remyelination and improved behaviors } \\
\text { (vs. oral NLCs); safety (microscopic examination, } \\
\text { hepatic biomarkers) }\end{array}$ & [100] \\
\hline URB597 & SLNs (Tristearin, Plx 188) & Rats, social behavioural study & Similar behavioral effects (vs. IP drug sol.) & [141] \\
\hline Valproic acid & $\begin{array}{l}\text { NLCs (Cetyl palmitate, soy lecithin, } \\
\text { octyldodecanol, Plx 188) }\end{array}$ & Rats with MES & $\begin{array}{l}\text { Similar protective effects (vs. IP drug sol.) } \\
\text { with a } 37.5 \text {-fold lower dose }\end{array}$ & {$[80]^{*}$} \\
\hline
\end{tabular}

GDNF, glial cell-derived neurotrophic factor; MES, maximal electroshock-induced seizure; *, studies with PK studies that were presented in Tables 1-4. 


\subsection{Toxicity Studies}

Toxicity studies were performed in 30 of the studies. In most cases, SLN and NLCbased formulations were reported to be safe, as demonstrated by histopathological and biomarker examinations. For example, in rats, an almotriptan-SLN gel did not show any signs of mucosal damage, cilia loss, or cell necrosis, while total protein, lactate dehydrogenase, alkaline phosphatase, or immunoglobulin $\mathrm{E}$ in notril lavage fluids were in safe levels [99]. An in situ Poloxamer 407-HPMC gel of olanzapine-loaded NLCs did not increase the risk of hematological or liver toxicity following IN administration [75]. In another study, teriflunomide-loaded NLCs reduced the risk of hepatotoxicity as compared with the free drug [100]. However, one study reported destruction of nasomucosal epithelium after the IN administration of cationic ropinirole-loaded NLCs to rats. Fortunately, the nasal irritation and inflammation disappeared when NLCs were incorporated into Poloxamer thermosensitive in situ gels [61].

\section{Evaluation of PK Parameters for Nose-to-Brain Delivery}

We analyzed the PK parameters collected from studies included in this review, including $\mathrm{DTE} \%, \mathrm{DTP} \%, \log \mathrm{RDTE} \%, \log \mathrm{RDTP} \%, \mathrm{~B} \% \mathrm{IN} / \mathrm{IV}, \mathrm{RB} \%$, and $\mathrm{AUC}_{\text {brain }} / \mathrm{AUC}_{\text {blood }}$ ratios. Statistical analysis was performed using $R$, version 3.6.1. The normality of variables distribution was evaluated using the Shapiro-Wilk's normality test. Differences between mean $\log \mathrm{DTE} \%, \mathrm{DTP} \%$, and $\log \mathrm{\%} \%$ IN/IV values of free drugs (IN) and SLN and NLC-based formulations (IN) were assessed using the $t$-test (for normal distributions). Differences between mean $\mathrm{AUC}_{\text {brain }} / \mathrm{AUC}_{\text {blood }}$ ratios of free drugs (IN), SLN and NLC-based formulations (IN), and free drugs (IV) were assessed by one-way analysis of variance (ANOVA) with a Tukey's Honestly Significant Difference (Tukey's HSD) post-hoc test for pairwise comparisons.

The DTE $\%$ and DTP\% values of free drugs (IN) and SLN and NLC-based formulations (IN) (Figure 4a,b) showed perfect correlations, as expressed by Equation (3). For free drugs (IN), $33.3 \%$ of studies had DTE $\%$ values of $<100$ and DTP\% values of $<0$ (Figure $4 a$ ), indicating insufficient brain targeting. It may have been due to some limitations of the IN administration [15,16]. All SLN and NLC-based formulations had DTE\% values $>100$ and DTP $\%$ values $>0$ (Figure $4 \mathrm{~b}$ ). Furthermore, mean values of $\operatorname{logDTE} \%$ and DTP\% (2.74 and 65.61, respectively) for SLN and NLC-based formulations were significantly greater than those of free drugs (2.18 and 7.72, respectively) (Figure 4c,d). When DTE\% and DTP\% values of SLN and NLC-based formulations (IN) and free drugs (IN) were compared in same studies, all $\log R D T E \%$ and $\log$ RDTP\% values were $>2$ (Figure $5 a, b)$. Mean values of $\log \mathrm{RDTE} \%$ and $\log \mathrm{RDTP} \%$ were 2.61 and 2.25 , respectively. These results show that SLN and NLC-based formulations (IN) improved brain targeting of drugs.

However, $\mathrm{B} \%$ IN/IV and RB\% values are also important when evaluating the efficacies

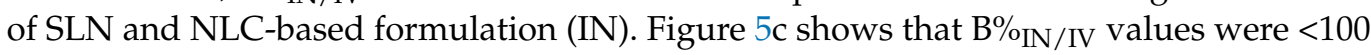
in 5 of 27 reported cases. They are agomelatine-loaded SLNs [67], agomelatine-loaded SLN gel [60], levofloxacin and doxycycline-loaded SLNs [112], ropinirole-loaded anionic and cationic NLCs [61]. In these cases, although DTE\% $(>100)$ and DTP\% $(>0)$ values suggested effective brain targeting of SLN and NLC-based formulation (IN), B\% $\%$ IN/IV values indicated that absolute brain bioavailabilities of SLN and NLC-based formulation (IN) were lower than those of the free drug (IV). Thus, in these cases, the therapeutic effects of SLN and NLC-based formulations (IN) are probably not greater than those of free drugs (IV). Low $\mathrm{B} \%$ IN/IV values could be due to substantial sample losses in the throat and gastrointestinal tract $[66,116]$, which would reduce $\mathrm{AUC}_{\text {brain }}$ and $\mathrm{AUC}_{\text {blood }}$ values of SLN and NLC-based

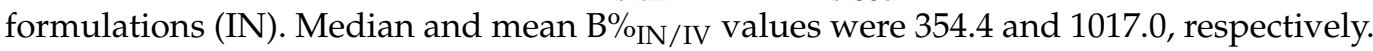

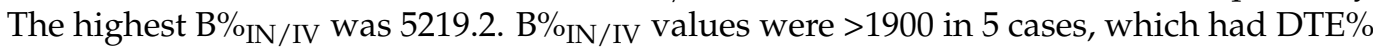
values of $>750$ and DTP $\%$ values of $>86$. Figure $5 \mathrm{~d}$ shows that RB\% values were $>100$ for all reported cases, indicating higher absolute brain bioavailabilities for SLN and NLC-based formulations (IN) than for free drugs (IN). Median and mean RB\% values were 353.7 and 882.6, respectively. 
(a)

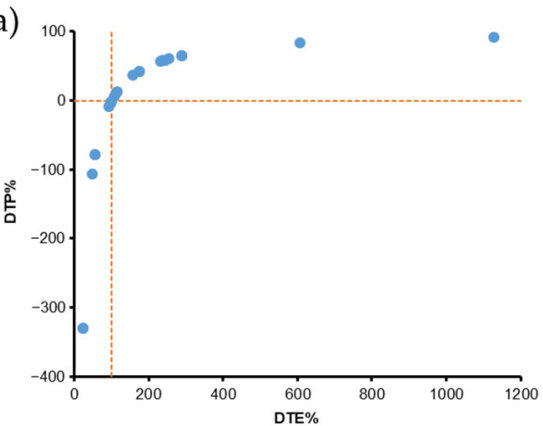

(c)

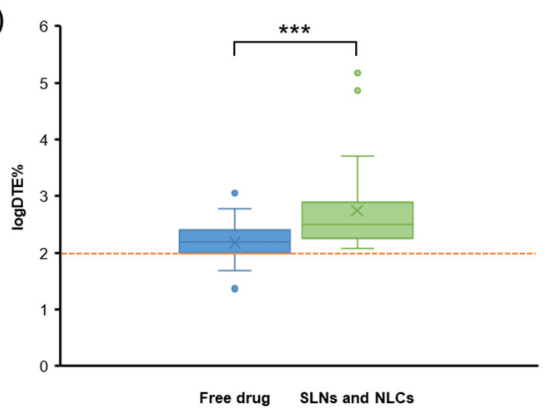

(b)

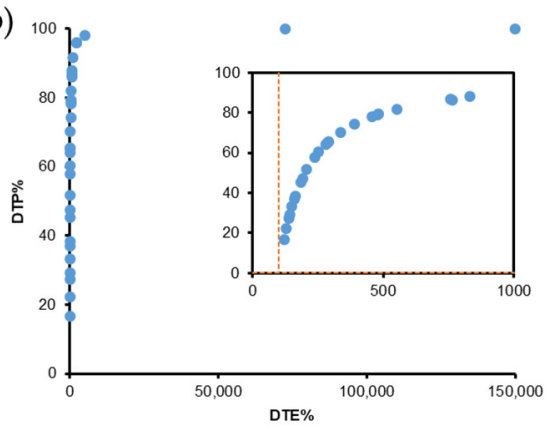

(d)

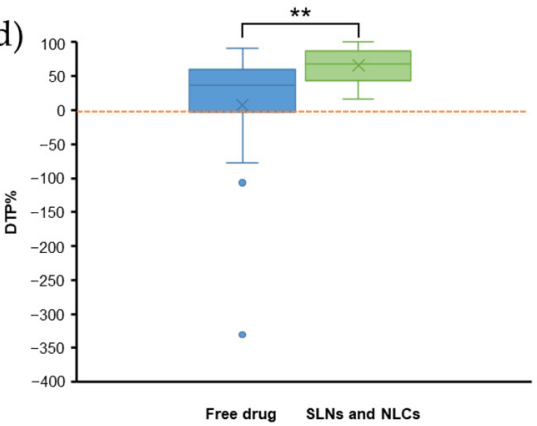

Figure 4. Summary of DTE\% and DTP\% for (a) free drug (IN) and (b) SLN and NLC-based formulation (IN). The inset in (b) shows data with DTE\% $<1000$. The vertical dot-lines in $(\mathbf{a}, \mathbf{b})$ are for DTE $\%=$ 100; the horizontal dot-line in (a) is for DTP\% $=0$. (c,, $\mathbf{d})$ Comparison of $\log \mathrm{DTE} \%$ and DTP\% between free drug (IN) and SLN and NLC-based formulation (IN) using boxplots. $\times$ indicates mean value. The horizontal dot-lines in (c) and (d) are for $\log \mathrm{DTE} \%=2$ and DTP $\%=0$, respectively. $n=21$ for free drug (IN) and $n=30$ for SLN and NLC-based formulation (IN). ${ }^{* *} p<0.01$ and ${ }^{* * *} p<0.001$ (t-test).

(a)

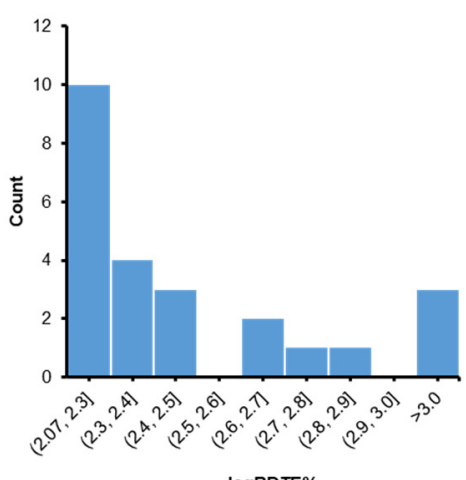

(c)

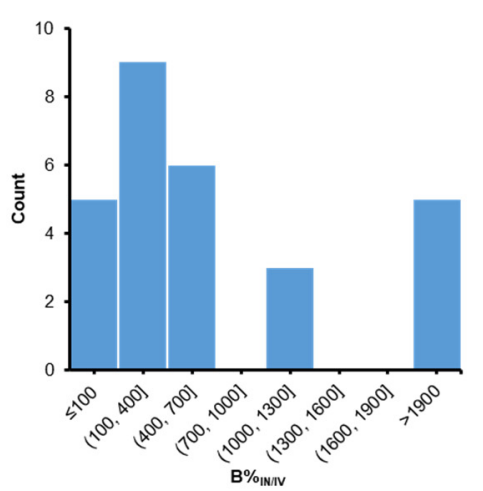

(b)

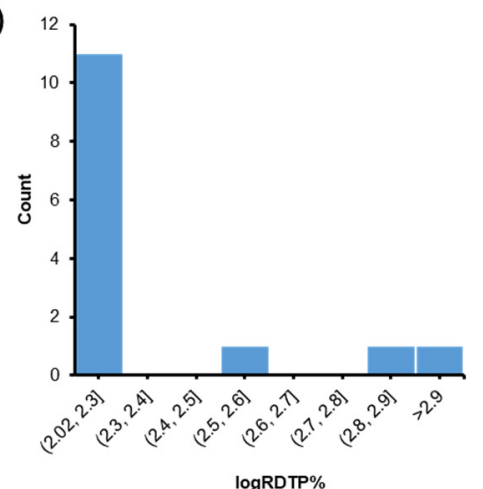

(d)

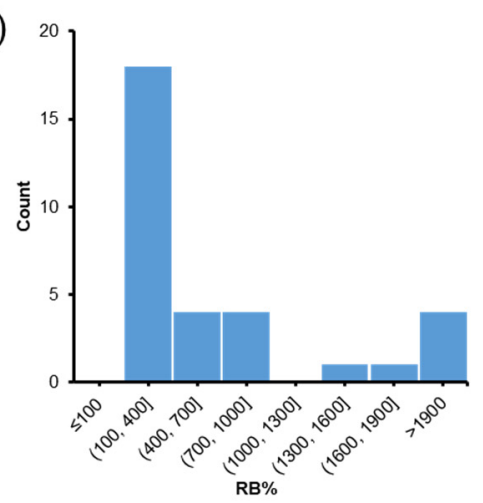

Figure 5. Summary of (a) $\operatorname{logRDTE} \%(n=24),(\mathbf{b}) \operatorname{logRDTP} \%(n=14),(\mathbf{c}) \mathrm{B} \% \mathrm{IN} / \mathrm{IV}(n=28)$, and (d) $\mathrm{RB} \%(n=32)$ for SLN and NLC-based formulation. 
In addition, we found that $\log \mathrm{B} \%$ IN/IV values of SLN and NLC-based formulations (IN) were always higher than those of free drugs (IN) in same studies (Figure 6a). Mean

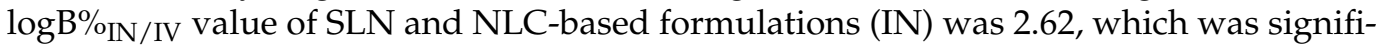
cantly higher than that (1.89) of free drugs (IN) (Figure 6b).

(a)

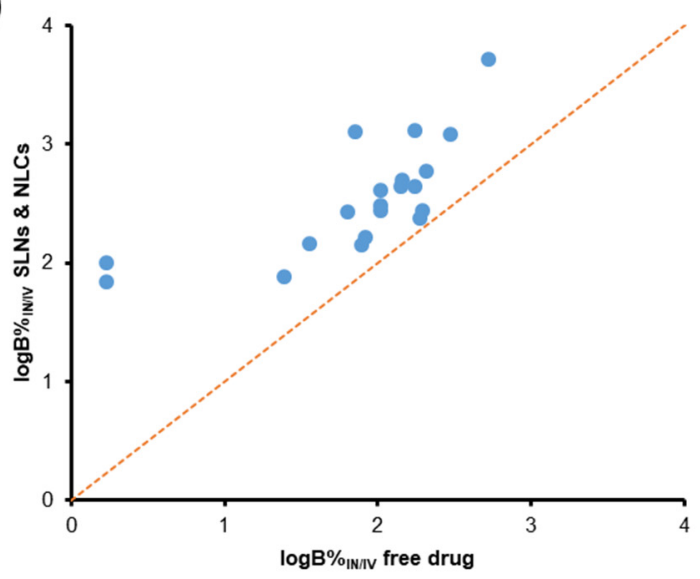

(b)

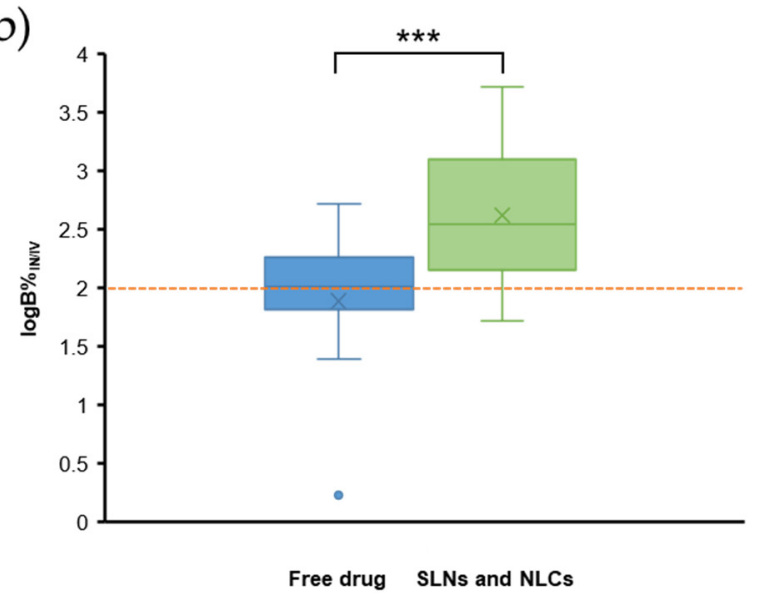

Figure 6. (a) Summary of paired $\log \%_{\mathrm{IN} / \mathrm{IV}}$ values for free drug (IN) and SLN and NLC-based formulation (IN) in the same studies $(n=20)$. The dot-line is for $y=x$. (b) Comparison of $\log \%_{\mathrm{oIN} / \mathrm{IV}}$ between free drug (IN) $(n=20)$ and SLN and NLC-based formulation (IN) $(n=28)$ using boxplots. $\times$ indicates mean value. The horizontal dot-line is for $\log \mathrm{B} \% \mathrm{IN} / \mathrm{IV}=2{ }^{* * *} p<0.001$ (t-test).

$\mathrm{AUC}_{\text {brain }} / \mathrm{AUC}_{\text {blood }}$ ratios of SLN and NLC-based formulation (IN) and free drugs (IN and IV) were compared. Regarding SLN and NLC-based formulations (IN) and free drugs (IN) (Figure 7a), only one of the 27 cases (streptomycin-loaded SLNs [72]) reported a higher $\mathrm{AUC}_{\text {brain }} / \mathrm{AUC}_{\text {blood }}$ ratio for the free drug (IN). Regarding free drugs (IN) and free drugs (IV) comparisons (Figure $7 \mathrm{~b}$ ), the IN route had a higher $\mathrm{AUC}_{\text {brain }} / \mathrm{AUC}_{\text {blood }}$ ratio in 14 of 19 cases. Five cases reported a higher $\mathrm{AUC} \mathrm{brain}_{\mathrm{b}} / \mathrm{AUC}_{\mathrm{blood}}$ ratio for free drugs (IV), which were piribedil-loaded SLN gel [27], efavirenz-loaded NLCs [65], ropinirole-loaded anionic NLC gel [61], nicergoline-loaded NLCs [58], and phenytoin-loaded NLCs (of particle size < $50 \mathrm{~nm}$ ) [36]. The $\mathrm{AUC}_{\text {brain }} / \mathrm{AUC}_{\text {blood }}$ ratios of SLN and NLC-based formulations (IN) were always higher than those of free drug (IV) in same studies (Figure 7c).

The boxplots in Figure $7 \mathrm{~d}$ show that $\log \left(\mathrm{AUC}_{\text {brain }} / \mathrm{AUC} \mathrm{C}_{\text {blood }}\right)$ values generally followed the order: SLN and NLC-based formulations (IN) $>$ free drugs (IN) $>$ free drugs (IV). The mean $\log \left(\mathrm{AUC}_{\mathrm{brain}} / \mathrm{AUC}_{\mathrm{blood}}\right)$ values of these systems were $0.32,-0.18$, and -0.44 , respectively, which were significantly different $\left(p=1.7 \times 10^{-7}\right.$, ANOVA). From post-hoc test results, we observed significant differences between SLN and NLC-based formulations (IN) and free drugs (IN) $(p<0.001)$ and between SLN and NLC-based formulations (IN) and free drugs (IV) $(p<0.0001)$, but the difference between mean $\log \left(\mathrm{AUC}_{\text {brain }} / \mathrm{AUC}_{\text {blood }}\right)$ values of free drugs (IN) and free drugs (IV) was not statistically significant $(p>0.05)$. Thus, $\mathrm{IN}$ administration increased $\mathrm{AUC}_{\text {brain }} / \mathrm{AUC}_{\text {blood }}$ ratios as compared with the IV route, and the incorporation of drugs in SLNs and NLCs further increased these ratios. Two SLN and NLC-based formulations (IN) reported exceptionally high $\mathrm{AUC}_{\text {brain }} / \mathrm{AUC}_{\text {blood }}$ ratios, which were phenytoin-loaded NLCs of different particle sizes $(<50 \mathrm{~nm}$ and $>100 \mathrm{~nm})$ [36]. The high $\mathrm{AUC} C_{\text {brain }} / \mathrm{AUC}_{\text {blood }}$ ratios observed in these cases was due to relatively low $A U C_{\text {blood }}$ values. We speculate that the developed NLC systems sufficiently transported phenytoin to the brain via direct routes (DTP\% $>99.8 \%$ ), and thus, only a small amount of the drug entered the bloodstream. 
(a)
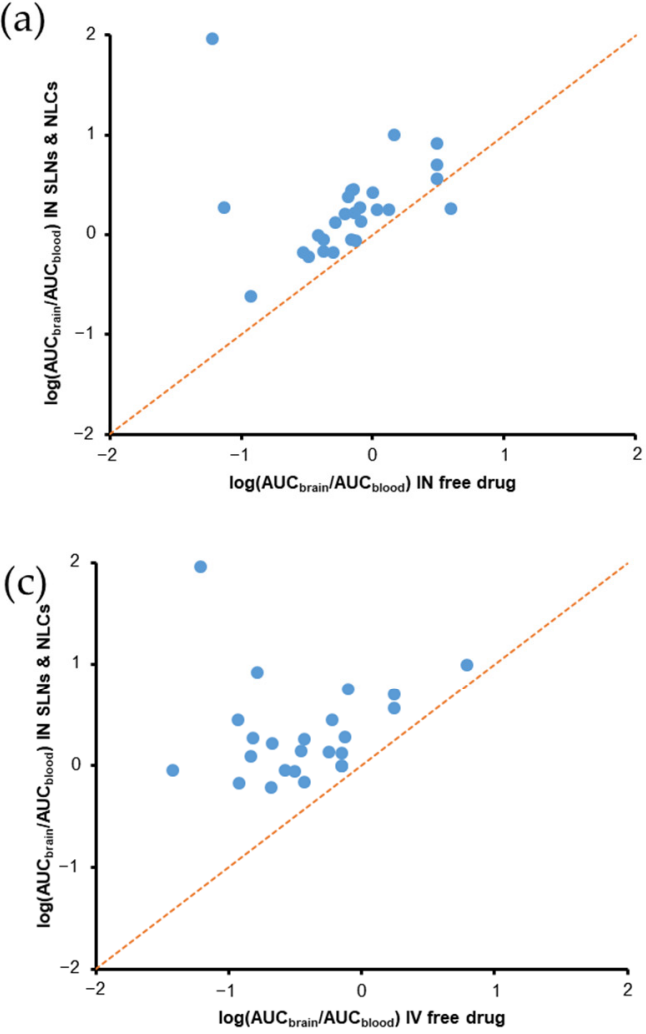

(b)

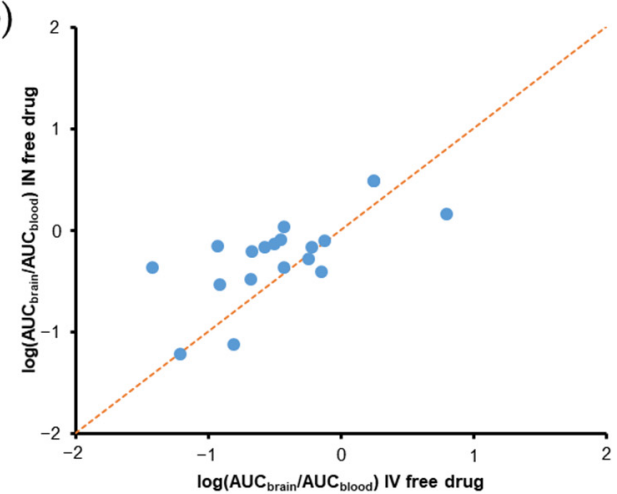

(d)

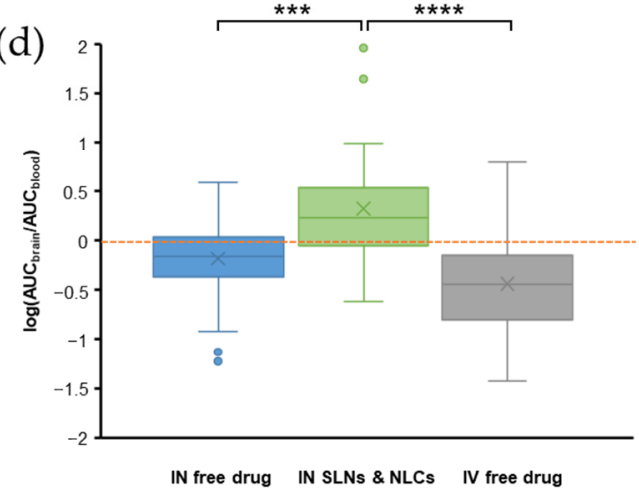

Figure 7. (a-c) Summary of paired $\mathrm{AUC}_{\text {brain }} / \mathrm{AUC}_{\mathrm{blood}}$ ratios for free drug (IN), SLN and NLC-based formulation (IN), and free drug (IN) in the same studies. The dot-line is for $\mathrm{y}=\mathrm{x} . n=27$ for $(\mathbf{a}), n=19$ for $(\mathbf{b})$, and $n=24$ for (c). (d) Comparison of $\mathrm{AUC}_{\text {brain }} / \mathrm{AUC}_{\text {blood }}$ ratios among free drug (IN) ( $\left.n=27\right)$, SLN and NLC-based formulation (IN) $(n=36)$, and free drug (IV) $(n=24)$ using boxplots. $\times$ indicates mean value. The horizontal dot-line is for $\log \mathrm{AUC}_{\mathrm{brain}} / \mathrm{AUC}_{\mathrm{blood}}=0$ (i.e, $\mathrm{AUC}_{\mathrm{brain}} / \mathrm{AUC}_{\mathrm{blood}}=1$ ). ${ }^{* * *} p<0.001$ and ${ }^{* * * *} p<0.0001$ (ANOVA with a Tukey's HSD post-hoc test).

\section{Effects of Gelling Systems and Surface Modifications of SLNs and NLCs}

\subsection{Effects of Gelling Systems}

Gelling systems can enhance drug nasal residence times and reduce enzymatic degradation and mucociliary clearance, and thus, improve nasal absorption and brain bioavailability of drugs [62]. In addition, mucoadhesive agents in gels can open tight junctions between epithelial cells and thereby enhance drug delivery to the brain [26]. Gelling systems are prepared using mucoadhesive polymers (e.g., HPMC or chitosan) and viscosity enhancers, which reduce mucociliary clearance and increase drug retention times in the nasal cavity [142]. Various biocompatible polymers have been used to prepare gelling systems for the IN route, such as Poloxamer 407, 188, methylcellulose, and HPMC [62]. These gelling systems can attenuate the nasal mucosal toxicities of nanosystems [143]. In the case of the cationic ropinirole-loaded NLCs, nasal mucosa toxicity disappeared after NLCs were loaded in Poloxamer thermosensitive in situ gels [61]. In most studies, SLNs and NLCs have been reported to be non-toxic to nasal mucosa, and thus, gelling systems would appear to primarily increase nasal residence times and minimize mucociliary clearance.

Gelling systems were used to improve the brain targeting efficiencies of SLNs and NLCs in 21 of the 81 studies. Most of these studies compared SLN and NLC gels (IN) with the free drug (IN and IV). In some studies, SLN and NLC gels (IN) were compared with SLN and NLC suspensions (IV) [26,74], which did not enable proper comparison of the efficacies of gelling systems over plain SLNs and NLCs.

Several studies compared SLN and NLC gels (IN) and plain SLN and NLC suspensions (IN). A recent study compared a piribedil-loaded SLN suspension and piribedil-loaded SLN gel, and found the brain bioavailability $\left(\mathrm{AUC}_{0-6 \mathrm{~h}, \mathrm{brain}}\right)$ and mean brain residence time 
$\left(\mathrm{MRT}_{\text {brain }}\right)$ of the SLN gel were 1.29- and 1.40-fold greater than those of the SLN suspension, respectively [27]. Furthermore, the DTE\%, DTP\%, logRDTE\%, B\% $\%$ IN $/$, and RB $\%$ values of the SLN gel (IN) were 137.5, 27.29, 2.40, 145.3, and 404.5, higher than those of the SLN suspension (IN) (119.9, 16.59, 2.34, 112.3, and 312.6, respectively). These findings indicate that the SLN gel (IN) better targeted brain than the SLN suspension (IN). Besides the longer nasal residence of gel ( 21.7 min versus $8 \mathrm{~min}$ ), the use of thermoresponsive in situ gel with rapid gelation may have reduced the spread of formulation from the olfactory region to respiratory epithelium, and therefore increased drug transport via direct routes [27]. In another study, the occurrence of seizures in pentylenetetrazole-treated rats was lower for lorazepam-loaded NLC gel (IN) than a lorazepam-loaded NLC suspension (IN) [84].

However, gelling systems are not always effective for SLNs and NLCs. In a previous study, agomelatine-loaded SLNs (IN) were found to have DTE\%, DTP\%, and B\% of 190.02, 47.379, and 83.26, respectively [67], and when incorporated into an in situ gel of Poloxamer 407 and $0.4 \%$ HPMC, these values reduced to 141.42, 29.29, and 52.6, respectively. A recent study reported that cannabidiol-loaded NLCs (IN) increased antinociceptive effects in mice with neuropathic pain [139]. However, NLC gel had no antinociceptive effect because the hydrophilic gel reduced the diffusion and nasal absorption of the lipophilic cannabidiol.

\subsection{Effects of Surface Modification of SLNs and NLCS}

Nasal formulations generally exploit mucoadhesive excipients to minimize mucociliary clearance and increase residence times of drugs [144]. These excipients are usually hydrophilic polymers, such as gums, alginates, starch, gelatin, chitosan, chitosan derivatives and conjugates, sodium hyaluronate, methylcellulose, HPMC, carboxymethylcellulose, polyacrylates, polymethacrylates, and crospovidone [145-149], which are able to interact with mucus by hydrophobic interactions, electrostatic attraction, hydrogen, and van der Waals bonds [150]. For SLNs and NLCs, these polymers are used to coat the surfaces of nanoparticles. Twelve of the 81 studies used a surface modification to improve the brain targeting efficiencies of SLNs and NLCs (IN). In 75\% of these studies, chitosan or its derivatives (glycol chitosan, TMC) were used, which can cause a change from negative to positive surface charge of SLNs and NLCs and increase electrostatic attractions between nanoparticles and mucus [151]. In addition, these excipients can induce opening of tight junctions between nasal epithelial cells to enhance drug transport [152].

Most of the 12 studies compared coated SLNs and NLCs (IN) with free drugs (IN and IV). Several studies clarified the efficacies of surface modification by comparing coated SLNs and NLCs (IN) with uncoated SLNs and NLCs (IN). A previous study reported that the mucoadhesive strength (as determined by detachment force) of ferulic acid-loaded SLNs increased from 6.88 to $8.55 \mathrm{~N}$ after coating with chitosan [90]. In addition, the drug concentration in the brain of CS-SLNs (IN) was 1.27-fold higher than that of SLNs (IN), suggesting the efficacy of chitosan surface modification in nose-to-brain delivery. Likewise, CS-SLNs (IN) improved cognitive ability and biochemical levels in the cortex and hippocampus better than the SLNs (IN) in the Alzheimer's disease-induced rats. In a previous study, asenapine-loaded NLCs were coated with glycol CS [29], and in rat PK studies, the $\mathrm{C}_{\text {max,brain }}$ of GC-NLCs (IN) was 1.3-fold higher than that of NLCs (IN). In addition, DTE $\%$, DTP $\%, \operatorname{logRDTE} \%, \operatorname{logRDTP} \%, \mathrm{~B} \%$ IN $/ \mathrm{IV}$, and RB\% values of GC-NLCs (IN) were higher than those for NLCs (IN) [28], which indicated that the glycol CS coating effectively increased brain targeting of NLCs. A recent study reported the efficacy of NLCs and TMC-NLCs co-loaded with artemether and lumefantrine [64]. It was found that TMC-NLCs (IN) exhibited greater parasite suppression than NLCs (IN) (95\% vs. 82.5\%) in parasite-injected mice.

\section{Challenges, Considerations, and Future Developments}

SLN and NLC-based formulations have been developed and evaluated for nose-tobrain delivery in various studies, because they increase nasal retention, reduce mucociliary 
clearance, improve drug solubility and permeability, minimize drug enzymatic degradation, and enhance nasomucosal biocompatibility [57-60]. Accumulating data demonstrates that SLNs and NLCs are effective drug delivery systems that can transport drugs to the brain via direct routes. However, some challenges need to be overcome since successful SLN and NLC-based formulations at the preclinical stage may fail to perform at the clinical stage for many reasons. First, the nasal cavities of humans and animal models differ anatomically. Nasal cavity length, surface areas volumes histology, and geometry are species-dependent and affect the retention and absorption of drugs $[7,40]$. The majority of studies included in this review used rats and mice in PK and PD studies due to their low cost and accessibility. However, their nasal cavities are very different from those of humans and other animals, such as rabbits, sheep, monkeys, and dogs. Rats and mice have small nasal orifices, which cause difficulties during intranasal administration, while those of rabbits, sheep, monkeys, and dogs are considerably larger [153]. The olfactory region comprises $\sim 10 \%$ of the nasal cavity in humans, rabbits, sheep, and monkeys, whereas, in mice, rats, and dogs, it occupies up to 50\% [33]. Second, volumes of IN administrations are also species dependent and vary from $\sim 10 \mu \mathrm{L}$ for mice, $40-50 \mu \mathrm{L}$ for rats, and greater amounts for other larger animals. Furthermore, the tools used for administration include micropipettes, syringes, nasal atomizers, sprays, and cannulas, which may affect the overall drug absorption and therapeutic effects [154]. Third, the experimental procedure for PK studies on nose-to-brain delivery via IN administration vary among research groups, and different approaches have been used to investigate the brain targeting efficiencies of developed formulations. Therefore, the methods used for PK studies on formulations intended for nose-to-brain delivery be standardized to some extent.

To develop SLN and NLC-based formulations for nose-to-brain delivery, some matters should be taken into consideration. In vivo PK studies on SLN and NLC-based formulations can be carried out on mice and rats during the initial stages, but rabbits, sheep, monkeys, or dogs should be used during later stages [154]. PK studies need to be performed using SLN and NLC-based formulations (IN) and free drugs (IN and IV) to determine relevant parameters such as DTE\%, DTP\%, B\% IN/IV, and RB\%. Some developed SLN and NLCbased formulations have $\mathrm{B} \% \mathrm{IN} / \mathrm{IV}$ values of $<100$ despite favorable DTE\% and DTP\% values $[60,61,67,112]$. Therefore, a formulation is deemed to have potential if it meets all required parameters. Furthermore, considerations of PK and PD data are critical in terms of predicting the feasibility of SLN and NLC-based formulations. The incorporation of gelling systems or surface modifications is favorable since they can improve drug nasal absorption and brain bioavailability. However, they are not always effective for SLNs and NLCs [67,139], and thus, investigations and comparisons of plain SLNs or NLCs and coated systems or gels are necessary. Another consideration is that the tools and techniques used for administration can affect drug absorption and therapeutic effects. Formulations should be administered to the posterior-most region of the nasal cavity (the olfactory region) to enable access to the olfactory pathway and minimize mucociliary clearance [142]. Regular nasal drops can increase drug exposure in the respiratory region, which results in more drugs entering the systemic circulation. Some delivery devices, such as syringeless needles and sprays, can deliver drug to the deeper, posterior region. Therefore, SLN and NLC-based formulations should be developed using appropriate delivery devices. Finally, an upward, tilted head position can maximize olfactory region exposure and enhance drug absorption [62]. Some transporters (e.g., organic anion transporter 3 and organic cation transporter 2) may contribute to the drug delivery from nose to brain and need to be considered during formulation development [155].

SLNs and NLCs for nose-to-brain drug delivery have been increasingly developed during recent years. The results summarized from 81 in vivo PK and PD studies demonstrate the efficacy of SLN and NLC-based formulations for nose-to-brain delivery and their potentials in clinical use. The transition from preclinical studies in animals to clinical studies is a great challenge that requires precise and accurate methods. Currently, some nasal formulations are in clinical trials or have been approved for medical use [33]. However, to 
the best of our knowledge, none of them are SLN and NLC-based formulations. Although SLN and NLC-based formulations have not been subjected to clinical studies, preclinical studies to date have demonstrated the undeniable potentials of these formulations. We believe that SLN and NLC-based formulations will be subjected to clinical trials soon and that they will enhance the management of different CNS diseases in the near future.

Supplementary Materials: The following supporting information can be downloaded at: https: / / www.mdpi.com/article/10.3390/pharmaceutics14030572/s1, Figure S1: Summary of articles included in the review.

Author Contributions: Conceptualization, T.-T.-L.N. and H.-J.M.; methodology, T.-T.-L.N.; validation, T.-T.-L.N. and H.-J.M.; formal analysis, T.-T.-L.N.; data curation, T.-T.-L.N. and H.-J.M.; writingoriginal draft preparation, T.-T.-L.N.; writing—review and editing, H.-J.M.; visualization, T.-T.-L.N.; supervision, H.-J.M.; project administration, T.-T.-L.N. and H.-J.M.; funding acquisition, H.-J.M. All authors have read and agreed to the published version of the manuscript.

Funding: This work was supported by the Basic Science Research Program of the National Research Foundation of Korea (NRF) funded by the Ministry of Science, ICT \& Future Planning (NRF-2021R1F1A1060378) and by the Ministry of Education (NRF-2020R1A6A1A03043708).

Institutional Review Board Statement: Not applicable.

Informed Consent Statement: Not applicable.

Data Availability Statement: The data presented in this study are available in this article.

Conflicts of Interest: The authors declare no conflict of interest.

\section{References}

1. Hong, S.-S.; Oh, K.T.; Choi, H.-G.; Lim, S.-J. Liposomal Formulations for Nose-to-Brain Delivery: Recent Advances and Future Perspectives. Pharmaceutics 2019, 11, 540. [CrossRef] [PubMed]

2. Md, S.; Bhattmisra, S.K.; Zeeshan, F.; Shahzad, N.; Mujtaba, M.A.; Srikanth Meka, V.; Radhakrishnan, A.; Kesharwani, P.; Baboota, S.; Ali, J. Nano-carrier enabled drug delivery systems for nose to brain targeting for the treatment of neurodegenerative disorders. J. Drug Deliv. Sci. Technol. 2018, 43, 295-310. [CrossRef]

3. Achar, A.; Myers, R.; Ghosh, C. Drug Delivery Challenges in Brain Disorders across the Blood-Brain Barrier: Novel Methods and Future Considerations for Improved Therapy. Biomedicines 2021, 9, 1834. [CrossRef] [PubMed]

4. Bellettato, C.M.; Scarpa, M. Possible strategies to cross the blood-brain barrier. Ital. J. Pediatrics 2018, 44, 131. [CrossRef] [PubMed]

5. Lipinski, C.A.; Lombardo, F.; Dominy, B.W.; Feeney, P.J. Experimental and computational approaches to estimate solubility and permeability in drug discovery and development settings1PII of original article: S0169-409X(96)00423-1. The article was originally published in Advanced Drug Delivery Reviews 23 (1997) 3-25.1. Adv. Drug Deliv. Rev. 2001, 46, 3-26. [CrossRef]

6. Brookes, A.; Ji, L.; Bradshaw, T.D.; Stocks, M.; Gray, D.; Butler, J.; Gershkovich, P. Is oral lipid-based delivery for drug targeting to the brain feasible? Eur. J. Pharm. Biopharm. 2022, 172, 112-122. [CrossRef]

7. Costa, C.; Moreira, J.N.; Amaral, M.H.; Sousa Lobo, J.M.; Silva, A.C. Nose-to-brain delivery of lipid-based nanosystems for epileptic seizures and anxiety crisis. J. Control. Release 2019, 295, 187-200. [CrossRef]

8. Bahadur, S.; Pardhi, D.M.; Rautio, J.; Rosenholm, J.M.; Pathak, K. Intranasal Nanoemulsions for Direct Nose-to-Brain Delivery of Actives for CNS Disorders. Pharmaceutics 2020, 12, 1230. [CrossRef]

9. Maaz, A.; Blagbrough, I.S.; De Bank, P.A. In Vitro Evaluation of Nasal Aerosol Depositions: An Insight for Direct Nose to Brain Drug Delivery. Pharmaceutics 2021, 13, 1079. [CrossRef]

10. Riccardi, C.; Napolitano, F.; Montesarchio, D.; Sampaolo, S.; Melone, M.A.B. Nanoparticle-Guided Brain Drug Delivery: Expanding the Therapeutic Approach to Neurodegenerative Diseases. Pharmaceutics 2021, 13, 1897. [CrossRef]

11. Lee, D.; Minko, T. Nanotherapeutics for Nose-to-Brain Drug Delivery: An Approach to Bypass the Blood Brain Barrier. Pharmaceutics 2021, 13, 2049. [CrossRef] [PubMed]

12. Sun, Y.; Li, L.; Xie, H.; Wang, Y.; Gao, S.; Zhang, L.; Bo, F.; Yang, S.; Feng, A. Primary Studies on Construction and Evaluation of Ion-Sensitive in situ Gel Loaded with Paeonol-Solid Lipid Nanoparticles for Intranasal Drug Delivery. Int. J. Nanomed. 2020, 15, 3137-3160. [CrossRef] [PubMed]

13. El-Setouhy, D.A.; Ibrahim, A.B.; Amin, M.M.; Khowessah, O.M.; Elzanfaly, E.S. Intranasal haloperidol-loaded miniemulsions for brain targeting: Evaluation of locomotor suppression and in-vivo biodistribution. Eur. J. Pharm. Sci. 2016, 92, 244-254. [CrossRef] [PubMed]

14. El-Zaafarany, G.M.; Soliman, M.E.; Mansour, S.; Awad, G.A.S. Identifying lipidic emulsomes for improved oxcarbazepine brain targeting: In vitro and rat in vivo studies. Int. J. Pharm. 2016, 503, 127-140. [CrossRef] 
15. Pires, P.C.; Santos, A.O. Nanosystems in nose-to-brain drug delivery: A review of non-clinical brain targeting studies. J. Control. Release 2018, 270, 89-100. [CrossRef]

16. Wang, Z.; Xiong, G.; Tsang, W.C.; Schätzlein, A.G.; Uchegbu, I.F. Nose-to-Brain Delivery. J. Pharmacol. Exp. Ther. 2019, 370, 593-601. [CrossRef]

17. Illum, L. Nasal drug delivery: New developments and strategies. Drug Discov. Today 2002, 7, 1184-1189. [CrossRef]

18. Gao, H. Progress and perspectives on targeting nanoparticles for brain drug delivery. Acta Pharm. Sin. B 2016, 6, 268-286. [CrossRef]

19. Trapani, A.; De Giglio, E.; Cometa, S.; Bonifacio, M.A.; Dazzi, L.; Di Gioia, S.; Hossain, M.N.; Pellitteri, R.; Antimisiaris, S.G.; Conese, M. Dopamine-loaded lipid based nanocarriers for intranasal administration of the neurotransmitter: A comparative study. Eur. J. Pharm. Biopharm. 2021, 167, 189-200. [CrossRef]

20. Bonferoni, M.C.; Rassu, G.; Gavini, E.; Sorrenti, M.; Catenacci, L.; Giunchedi, P. Nose-to-Brain Delivery of Antioxidants as a Potential Tool for the Therapy of Neurological Diseases. Pharmaceutics 2020, 12, 1246. [CrossRef]

21. Musumeci, T.; Bonaccorso, A.; Puglisi, G. Epilepsy Disease and Nose-to-Brain Delivery of Polymeric Nanoparticles: An Overview. Pharmaceutics 2019, 11, 118. [CrossRef] [PubMed]

22. Jnaidi, R.; Almeida, A.J.; Gonçalves, L.M. Solid Lipid Nanoparticles and Nanostructured Lipid Carriers as Smart Drug Delivery Systems in the Treatment of Glioblastoma Multiforme. Pharmaceutics 2020, 12, 860. [CrossRef] [PubMed]

23. de Barros, C.T.; Rios, A.C.; Alves, T.F.R.; Batain, F.; Crescencio, K.M.M.; Lopes, L.J.; Zielińska, A.; Severino, P.; Mazzola, P.; Souto, E.B.; et al. Cachexia: Pathophysiology and Ghrelin Liposomes for Nose-to-Brain Delivery. Int. J. Mol. Sci. 2020, $21,5974$. [CrossRef] [PubMed]

24. Chen, W.; Lu, F.; Chen, C.-C.V.; Mo, K.-C.; Hung, Y.; Guo, Z.-X.; Lin, C.-H.; Lin, M.-H.; Lin, Y.-H.; Chang, C.; et al. Manganeseenhanced MRI of rat brain based on slow cerebral delivery of manganese(II) with silica-encapsulated MnxFe1-xO nanoparticles. NMR Biomed. 2013, 26, 1176-1185. [CrossRef]

25. Ray, S.; Cheng, C.A.; Chen, W.; Li, Z.; Zink, J.I.; Lin, Y.Y. Magnetic Heating Stimulated Cargo Release with Dose Control using Multifunctional MR and Thermosensitive Liposome. Nanotheranostics 2019, 3, 166-178. [CrossRef]

26. Gadhave, D.G.; Tagalpallewar, A.A.; Kokare, C.R. Agranulocytosis-Protective Olanzapine-Loaded Nanostructured Lipid Carriers Engineered for CNS Delivery: Optimization and Hematological Toxicity Studies. AAPS PharmSciTech 2019, 20, 22. [CrossRef]

27. Uppuluri, C.T.; Ravi, P.R.; Dalvi, A.V. Design, optimization and pharmacokinetic evaluation of Piribedil loaded solid lipid nanoparticles dispersed in nasal in situ gelling system for effective management of Parkinson's disease. Int. J. Pharm. 2021, 606, 120881. [CrossRef]

28. Singh, S.K.; Dadhania, P.; Vuddanda, P.R.; Jain, A.; Velaga, S.; Singh, S. Intranasal delivery of asenapine loaded nanostructured lipid carriers: Formulation, characterization, pharmacokinetic and behavioural assessment. RSC Adv. 2016, 6, 2032-2045. [CrossRef]

29. Singh, S.K.; Hidau, M.K.; Gautam, S.; Gupta, K.; Singh, K.P.; Singh, S.K.; Singh, S. Glycol chitosan functionalized asenapine nanostructured lipid carriers for targeted brain delivery: Pharmacokinetic and teratogenic assessment. Int. J. Biol. Macromol. 2018, 108, 1092-1100. [CrossRef]

30. Cunha, S.; Almeida, H.; Amaral, M.H.; Lobo, S.J.M.; Silva, A.C. Intranasal Lipid Nanoparticles for the Treatment of Neurodegenerative Diseases. Curr. Pharm. Des. 2017, 23, 6553-6562. [CrossRef]

31. Ahmad, J.; Rizwanullah, M.; Amin, S.; Warsi, H.M.; Ahmad, Z.M.; Barkat, A.M. Nanostructured Lipid Carriers (NLCs): Nose-toBrain Delivery and Theranostic Application. Curr. Drug Metab. 2020, 21, 1136-1143. [CrossRef] [PubMed]

32. Costa, C.P.; Barreiro, S.; Moreira, J.N.; Silva, R.; Almeida, H.; Sousa Lobo, J.M.; Silva, A.C. In Vitro Studies on Nasal Formulations of Nanostructured Lipid Carriers (NLC) and Solid Lipid Nanoparticles (SLN). Pharmaceuticals 2021, 14, 711. [CrossRef] [PubMed]

33. Costa, C.P.; Moreira, J.N.; Sousa Lobo, J.M.; Silva, A.C. Intranasal delivery of nanostructured lipid carriers, solid lipid nanoparticles and nanoemulsions: A current overview of in vivo studies. Acta Pharm. Sin. B 2021, 11, 925-940. [CrossRef] [PubMed]

34. Dhuria, S.V.; Hanson, L.R.; Frey, W.H. Intranasal delivery to the central nervous system: Mechanisms and experimental considerations. J. Pharm. Sci. 2010, 99, 1654-1673. [CrossRef]

35. Ahmad, E.; Feng, Y.; Qi, J.; Fan, W.; Ma, Y.; He, H.; Xia, F.; Dong, X.; Zhao, W.; Lu, Y.; et al. Evidence of nose-to-brain delivery of nanoemulsions: Cargoes but not vehicles. Nanoscale 2017, 9, 1174-1183. [CrossRef]

36. Nair, S.C.; Vinayan, K.P.; Mangalathillam, S. Nose to Brain Delivery of Phenytoin Sodium Loaded Nano Lipid Carriers: Formulation, Drug Release, Permeation and In Vivo Pharmacokinetic Studies. Pharmaceutics 2021, 13, 1640. [CrossRef]

37. Feng, Y.; He, H.; Li, F.; Lu, Y.; Qi, J.; Wu, W. An update on the role of nanovehicles in nose-to-brain drug delivery. Drug Discov. Today 2018, 23, 1079-1088. [CrossRef]

38. Singh, A.P.; Saraf, S.K.; Saraf, S.A. SLN approach for nose-to-brain delivery of alprazolam. Drug Deliv. Transl. Res. 2012, 2, 498-507. [CrossRef]

39. Gänger, S.; Schindowski, K. Tailoring Formulations for Intranasal Nose-to-Brain Delivery: A Review on Architecture, PhysicoChemical Characteristics and Mucociliary Clearance of the Nasal Olfactory Mucosa. Pharmaceutics 2018, 10, 116. [CrossRef]

40. Kapoor, M.; Cloyd, J.C.; Siegel, R.A. A review of intranasal formulations for the treatment of seizure emergencies. J. Control. Release 2016, 237, 147-159. [CrossRef]

41. Mehnert, W.; Mäder, K. Solid lipid nanoparticles: Production, characterization and applications. Adv. Drug Deliv. Rev. 2001, 47, 165-196. [CrossRef]

42. Müller, R.H.; Mäder, K.; Gohla, S. Solid lipid nanoparticles (SLN) for controlled drug delivery-A review of the state of the art. Eur. J. Pharm. Biopharm. 2000, 50, 161-177. [CrossRef] 
43. Wissing, S.A.; Kayser, O.; Müller, R.H. Solid lipid nanoparticles for parenteral drug delivery. Adv. Drug Deliv. Rev. 2004, 56, 1257-1272. [CrossRef] [PubMed]

44. Tan, S.L.J.; Billa, N. Improved Bioavailability of Poorly Soluble Drugs through Gastrointestinal Muco-Adhesion of Lipid Nanoparticles. Pharmaceutics 2021, 13, 1817. [CrossRef] [PubMed]

45. Nguyen, T.-T.-L.; Duong, V.-A.; Maeng, H.-J. Pharmaceutical Formulations with P-Glycoprotein Inhibitory Effect as Promising Approaches for Enhancing Oral Drug Absorption and Bioavailability. Pharmaceutics 2021, 13, 1103. [CrossRef] [PubMed]

46. Dhiman, N.; Awasthi, R.; Sharma, B.; Kharkwal, H.; Kulkarni, G.T. Lipid Nanoparticles as Carriers for Bioactive Delivery. Front. Chem. 2021, 9, 580118. [CrossRef]

47. Abdel-Mageed, H.M.; Abd El Aziz, A.E.; Mohamed, S.A.; AbuelEzz, N.Z. The Tiny Big World of Solid Lipid Nanoparticles and Nanostructured Lipid Carriers: An Updated Review. J. Microencapsul. 2021, 39, 72-94. [CrossRef]

48. Tzanova, M.M.; Hagesaether, E.; Tho, I. Solid lipid nanoparticle-loaded mucoadhesive buccal films-Critical quality attributes and in vitro safety \& efficacy. Int. J. Pharm. 2021, 592, 120100. [CrossRef]

49. Qushawy, M.; Prabahar, K.; Abd-Alhaseeb, M.; Swidan, S.; Nasr, A. Preparation and Evaluation of Carbamazepine Solid Lipid Nanoparticle for Alleviating Seizure Activity in Pentylenetetrazole-Kindled Mice. Molecules 2019, 24, 3971. [CrossRef]

50. Joshi, M.D.; Müller, R.H. Lipid nanoparticles for parenteral delivery of actives. Eur. J. Pharm. Biopharm. 2009, 71, 161-172. [CrossRef]

51. Duong, V.-A.; Nguyen, T.-T.-L.; Maeng, H.-J.; Chi, S.-C. Nanostructured lipid carriers containing ondansetron hydrochloride by cold high-pressure homogenization method: Preparation, characterization, and pharmacokinetic evaluation. J. Drug Deliv. Sci. Technol. 2019, 53, 101185. [CrossRef]

52. Nasiri, F.; Faghfouri, L.; Hamidi, M. Preparation, optimization, and in-vitro characterization of $\alpha$-tocopherol-loaded solid lipid nanoparticles (SLNs). Drug Dev. Ind. Pharm. 2020, 46, 159-171. [CrossRef] [PubMed]

53. Duong, V.-A.; Nguyen, T.-T.-L.; Maeng, H.-J. Preparation of Solid Lipid Nanoparticles and Nanostructured Lipid Carriers for Drug Delivery and the Effects of Preparation Parameters of Solvent Injection Method. Molecules 2020, 25, 4781. [CrossRef] [PubMed]

54. Müller, R.H.; Radtke, M.; Wissing, S.A. Nanostructured lipid matrices for improved microencapsulation of drugs. Int. J. Pharm. 2002, 242, 121-128. [CrossRef]

55. Duong, V.-A.; Nguyen, T.-T.-L.; Maeng, H.-J.; Chi, S.-C. Preparation of Ondansetron Hydrochloride-Loaded Nanostructured Lipid Carriers Using Solvent Injection Method for Enhancement of Pharmacokinetic Properties. Pharm. Res. 2019, 36, 138. [CrossRef]

56. Duong, V.-A.; Nguyen, T.-T.-L.; Maeng, H.-J.; Chi, S.-C. Data on optimization and drug release kinetics of nanostructured lipid carriers containing ondansetron hydrochloride prepared by cold high-pressure homogenization method. Data Brief 2019, 26, 104475. [CrossRef]

57. Agbo, C.P.; Ugwuanyi, T.C.; Ugwuoke, W.I.; McConville, C.; Attama, A.A.; Ofokansi, K.C. Intranasal artesunate-loaded nanostructured lipid carriers: A convenient alternative to parenteral formulations for the treatment of severe and cerebral malaria. J. Control. Release 2021, 334, 224-236. [CrossRef]

58. Abourehab, M.A.S.; Khames, A.; Genedy, S.; Mostafa, S.; Khaleel, M.A.; Omar, M.M.; El Sisi, A.M. Sesame Oil-Based Nanostructured Lipid Carriers of Nicergoline, Intranasal Delivery System for Brain Targeting of Synergistic Cerebrovascular Protection. Pharmaceutics 2021, 13, 581. [CrossRef]

59. González-Mariscal, L.; Posadas, Y.; Miranda, J.; Uc, Y.P.; Ortega-Olvera, M.J.; Hernández, S. Strategies that Target Tight Junctions for Enhanced Drug Delivery. Curr. Pharm. Des. 2016, 22, 5313-5346. [CrossRef]

60. Fatouh, A.M.; Elshafeey, A.H.; Abdelbary, A. Agomelatine-based in situ gels for brain targeting via the nasal route: Statistical optimization, in vitro, and in vivo evaluation. Drug Deliv. 2017, 24, 1077-1085. [CrossRef]

61. Gabal, Y.M.; Kamel, A.O.; Sammour, O.A.; Elshafeey, A.H. Effect of surface charge on the brain delivery of nanostructured lipid carriers in situ gels via the nasal route. Int. J. Pharm. 2014, 473, 442-457. [CrossRef] [PubMed]

62. Agrawal, M.; Saraf, S.; Saraf, S.; Dubey, S.K.; Puri, A.; Gupta, U.; Kesharwani, P.; Ravichandiran, V.; Kumar, P.; Naidu, V.G.M.; et al. Stimuli-responsive In situ gelling system for nose-to-brain drug delivery. J. Control. Release 2020, 327, 235-265. [CrossRef] [PubMed]

63. Qureshi, M.; Aqil, M.; Imam, S.S.; Ahad, A.; Sultana, Y. Formulation and Evaluation of Neuroactive Drug Loaded Chitosan Nanoparticle for Nose to Brain Delivery: In-vitro Characterization and In-vivo Behavior Study. Curr. Drug Deliv. 2019, 16, 123-135. [CrossRef] [PubMed]

64. Kaur, R.; Gorki, V.; Singh, G.; Kaur, R.; Katare, O.P.; Nirmalan, N.; Singh, B. Intranasal delivery of polymer-anchored lipid nanoconstructs of artemether-lumefantrine in Plasmodium berghei ANKA murine model. J. Drug Deliv. Sci. Technol. 2021, 61, 102114. [CrossRef]

65. Pokharkar, V.; Patil-Gadhe, A.; Palla, P. Efavirenz loaded nanostructured lipid carrier engineered for brain targeting through intranasal route: In-vivo pharmacokinetic and toxicity study. Biomed. Pharmacother. 2017, 94, 150-164. [CrossRef]

66. Patel, S.; Chavhan, S.; Soni, H.; Babbar, A.K.; Mathur, R.; Mishra, A.K.; Sawant, K. Brain targeting of risperidone-loaded solid lipid nanoparticles by intranasal route. J. Drug Target. 2011, 19, 468-474. [CrossRef]

67. Fatouh, A.M.; Elshafeey, A.H.; Abdelbary, A. Intranasal agomelatine solid lipid nanoparticles to enhance brain delivery: Formulation, optimization and in vivo pharmacokinetics. Drug Des. Dev. Ther. 2017, 11, 1815-1825. [CrossRef]

68. Muntimadugu, E.; Dhommati, R.; Jain, A.; Challa, V.G.S.; Shaheen, M.; Khan, W. Intranasal delivery of nanoparticle encapsulated tarenflurbil: A potential brain targeting strategy for Alzheimer's disease. Eur. J. Pharm. Sci. 2016, 92, 224-234. [CrossRef] 
69. Patel, H.P.; Gandhi, P.A.; Chaudhari, P.S.; Desai, B.V.; Desai, D.T.; Dedhiya, P.P.; Maulvi, F.A.; Vyas, B.A. Clozapine loaded nanostructured lipid carriers engineered for brain targeting via nose-to-brain delivery: Optimization and in vivo pharmacokinetic studies. J. Drug Deliv. Sci. Technol. 2021, 64, 102533. [CrossRef]

70. Salem, L.H.; El-Feky, G.S.; Fahmy, R.H.; El Gazayerly, O.N.; Abdelbary, A. Coated Lipidic Nanoparticles as a New Strategy for Enhancing Nose-to-Brain Delivery of a Hydrophilic Drug Molecule. J. Pharm. Sci. 2020, 109, 2237-2251. [CrossRef]

71. Chandra Bhatt, P.; Srivastava, P.; Pandey, P.; Khan, W.; Panda, B.P. Nose to brain delivery of astaxanthin-loaded solid lipid nanoparticles: Fabrication, radio labeling, optimization and biological studies. RSC Adv. 2016, 6, 10001-10010. [CrossRef]

72. Kumar, M.; Kakkar, V.; Mishra, A.K.; Chuttani, K.; Kaur, I.P. Intranasal delivery of streptomycin sulfate (STRS) loaded solid lipid nanoparticles to brain and blood. Int. J. Pharm. 2014, 461, 223-233. [CrossRef] [PubMed]

73. Alam, M.I.; Baboota, S.; Ahuja, A.; Ali, M.; Ali, J.; Sahni, J.K.; Bhatnagar, A. Pharmacoscintigraphic evaluation of potential of lipid nanocarriers for nose-to-brain delivery of antidepressant drug. Int. J. Pharm. 2014, 470, 99-106. [CrossRef] [PubMed]

74. Gadhave, D.; Rasal, N.; Sonawane, R.; Sekar, M.; Kokare, C. Nose-to-brain delivery of teriflunomide-loaded lipid-based carbopolgellan gum nanogel for glioma: Pharmacological and in vitro cytotoxicity studies. Int. J. Biol. Macromol. 2021, 167, 906-920. [CrossRef] [PubMed]

75. Gadhave, D.; Choudhury, H.; Kokare, C. Neutropenia and leukopenia protective intranasal olanzapine-loaded lipid-based nanocarriers engineered for brain delivery. Appl. Nanosci. 2019, 9, 151-168. [CrossRef]

76. Gartziandia, O.; Herran, E.; Pedraz, J.L.; Carro, E.; Igartua, M.; Hernandez, R.M. Chitosan coated nanostructured lipid carriers for brain delivery of proteins by intranasal administration. Colloids Surf. B Biointerfaces 2015, 134, 304-313. [CrossRef]

77. Yasir, M.; Chauhan, I.; Zafar, A.; Verma, M.; Noorulla, K.M.; Tura, A.J.; Alruwaili, N.K.; Haji, M.J.; Puri, D.; Gobena, W.G.; et al Buspirone loaded solid lipid nanoparticles for amplification of nose to brain efficacy: Formulation development, optimization by Box-Behnken design, in-vitro characterization and in-vivo biological evaluation. J. Drug Deliv. Sci. Technol. 2021, 61, 102164. [CrossRef]

78. Sarma, A.; Das, M.K.; Chakraborty, T.; Das, S. Nanostructured lipid carriers (NLCs)-based intranasal Drug Delivery System of Tenofovir disoproxil fumerate (TDF) for brain targeting. Res. J. Pharm. Technol. 2020, 13, 5411-5424.

79. Deshkar, S.S.; Jadhav, M.S.; Shirolkar, S.V. Development of Carbamazepine Nanostructured Lipid Carrier Loaded Thermosensitive Gel for Intranasal Delivery. Adv. Pharm. Bull. 2021, 11, 150-162. [CrossRef]

80. Eskandari, S.; Varshosaz, J.; Minaiyan, M.; Tabbakhian, M. Brain delivery of valproic acid via intranasal administration of nanostructured lipid carriers: In vivo pharmacodynamic studies using rat electroshock model. Int. J. Nanomed. 2011, 6, 363-371. [CrossRef]

81. Alam, T.; Pandit, J.; Vohora, D.; Aqil, M.; Ali, A.; Sultana, Y. Optimization of nanostructured lipid carriers of lamotrigine for brain delivery: In vitro characterization and in vivo efficacy in epilepsy. Expert Opin. Drug Deliv. 2015, 12, 181-194. [CrossRef] [PubMed]

82. Sharma, N.; Bhandari, S.; Deshmukh, R.; Yadav, A.K.; Mishra, N. Development and characterization of embelin-loaded nanolipid carriers for brain targeting. Artif. Cells Nanomed. Biotechnol. 2017, 45, 409-413. [CrossRef] [PubMed]

83. Abbas, H.; Refai, H.; El Sayed, N. Superparamagnetic Iron Oxide-Loaded Lipid Nanocarriers Incorporated in Thermosensitive In Situ Gel for Magnetic Brain Targeting of Clonazepam. J. Pharm. Sci. 2018, 107, 2119-2127. [CrossRef] [PubMed]

84. Taymouri, S.; Minaiyan, M.; Ebrahimi, F.; Tavakoli, N. In-vitro and in-vivo evaluation of chitosan-based thermosensitive gel containing lorazepam NLCs for the treatment of status epilepticus. IET Nanobiotechnol. 2020, 14, 148-154. [CrossRef] [PubMed]

85. Rajput, A.; Bariya, A.; Allam, A.; Othman, S.; Butani, S.B. In situ nanostructured hydrogel of resveratrol for brain targeting: In vitro-in vivo characterization. Drug Deliv. Transl. Res. 2018, 8, 1460-1470. [CrossRef]

86. Rajput, A.P.; Butani, S.B. Resveratrol anchored nanostructured lipid carrier loaded in situ gel via nasal route: Formulation, optimization and in vivo characterization. J. Drug Deliv. Sci. Technol. 2019, 51, 214-223. [CrossRef]

87. Butani, S. Fabrication of an ion-sensitive in situ gel loaded with nanostructured lipid carrier for nose to brain delivery of donepezil. Asian J. Pharm. 2018, 12, 4.

88. Wavikar, P.; Pai, R.; Vavia, P. Nose to Brain Delivery of Rivastigmine by In Situ Gelling Cationic Nanostructured Lipid Carriers: Enhanced Brain Distribution and Pharmacodynamics. J. Pharm. Sci. 2017, 106, 3613-3622. [CrossRef]

89. Anand, A.; Arya, M.; Kaithwas, G.; Singh, G.; Saraf, S.A. Sucrose stearate as a biosurfactant for development of rivastigmine containing nanostructured lipid carriers and assessment of its activity against dementia in C. elegans model. J. Drug Deliv. Sci. Technol. 2019, 49, 219-226. [CrossRef]

90. Saini, S.; Sharma, T.; Jain, A.; Kaur, H.; Katare, O.P.; Singh, B. Systematically designed chitosan-coated solid lipid nanoparticles of ferulic acid for effective management of Alzheimer's disease: A preclinical evidence. Colloids Surf. B Biointerfaces 2021, 205, 111838. [CrossRef]

91. Hangargekar, S.R.; Mohanty, P.K.; Rai, J.P. Preclinical Screening of Antidepressant Activity of Formulated Sertraline HydrochlorideLoaded Solid Lipid Nanoparticles in Rats. J. Pharm. Res. Int. 2021, 33, 134-138. [CrossRef]

92. Alam, M.I.; Baboota, S.; Ahuja, A.; Ali, M.; Ali, J.; Sahni, J.K. Intranasal administration of nanostructured lipid carriers containing CNS acting drug: Pharmacodynamic studies and estimation in blood and brain. J. Psychiatr. Res. 2012, 46, 1133-1138. [CrossRef] [PubMed]

93. Vitorino, C.; Silva, S.; Gouveia, F.; Bicker, J.; Falcão, A.; Fortuna, A. QbD-driven development of intranasal lipid nanoparticles for depression treatment. Eur. J. Pharm. Biopharm. 2020, 153, 106-120. [CrossRef] 
94. Hernando, S.; Herran, E.; Figueiro-Silva, J.; Pedraz, J.L.; Igartua, M.; Carro, E.; Hernandez, R.M. Intranasal Administration of TAT-Conjugated Lipid Nanocarriers Loading GDNF for Parkinson's Disease. Mol. Neurobiol. 2018, 55, 145-155. [CrossRef] [PubMed]

95. Gartziandia, O.; Herrán, E.; Ruiz-Ortega, J.A.; Miguelez, C.; Igartua, M.; Lafuente, J.V.; Pedraz, J.L.; Ugedo, L.; Hernández, R.M. Intranasal Administration of Chitosan-Coated Nanostructured Lipid Carriers Loaded with GDNF Improves Behavioral and Histological Recovery in a Partial Lesion Model of Parkinson's Disease. J. Biomed. Nanotechnol. 2016, 12, 2220-2280. [CrossRef] [PubMed]

96. Pardeshi, C.V.; Rajput, P.V.; Belgamwar, V.S.; Tekade, A.R.; Surana, S.J. Novel surface modified solid lipid nanoparticles as intranasal carriers for ropinirole hydrochloride: Application of factorial design approach. Drug Deliv. 2013, 20, 47-56. [CrossRef]

97. Gautam, D.; Singh, S.; Maurya, P.; Singh, M.; Kushwaha, S.; Saraf, A.S. Appraisal of Nano-lipidic Astaxanthin Cum Thermoreversible Gel and its Efficacy in Haloperidol Induced Parkinsonism. Curr. Drug Deliv. 2021, 18, 1515-1527. [CrossRef]

98. Mishra, N.; Sharma, S.; Deshmukh, R.; Kumar, A.; Sharma, R. Development and Characterization of Nasal Delivery of Selegiline Hydrochloride Loaded Nanolipid Carriers for the Management of Parkinson's Disease. Cent. Nerv. Syst. Agents Med. Chem. 2019, 19, 46-56. [CrossRef]

99. Youssef, N.A.H.A.; Kassem, A.A.; Farid, R.M.; Ismail, F.A.; El-Massik, M.A.E.; Boraie, N.A. A novel nasal almotriptan loaded solid lipid nanoparticles in mucoadhesive in situ gel formulation for brain targeting: Preparation, characterization and in vivo evaluation. Int. J. Pharm. 2018, 548, 609-624. [CrossRef]

100. Gadhave, D.G.; Kokare, C.R. Nanostructured lipid carriers engineered for intranasal delivery of teriflunomide in multiple sclerosis: Optimization and in vivo studies. Drug Dev. Ind. Pharm. 2019, 45, 839-851. [CrossRef]

101. Page, M.J.; McKenzie, J.E.; Bossuyt, P.M.; Boutron, I.; Hoffmann, T.C.; Mulrow, C.D.; Shamseer, L.; Tetzlaff, J.M.; Akl, E.A.; Brennan, S.E.; et al. The PRISMA 2020 statement: An updated guideline for reporting systematic reviews. BMJ 2021, 372, n71. [CrossRef] [PubMed]

102. Alam, M.I.; Baboota, S.; Ahuja, A.; Ali, M.; Ali, J.; Sahni, J.K. Intranasal infusion of nanostructured lipid carriers (NLC) containing CNS acting drug and estimation in brain and blood. Drug Deliv. 2013, 20, 247-251. [CrossRef] [PubMed]

103. Yasir, M.; Sara, U.V.S.; Som, I. Development of a new HPLC method for in vitro and in vivo studies of haloperidol in solid lipid nanoparticles. Braz. J. Pharm. Sci. 2017, 53, e16047. [CrossRef]

104. Yasir, M.; Sara, U.V.S. Solid lipid nanoparticles for nose to brain delivery of haloperidol: In vitro drug release and pharmacokinetics evaluation. Acta Pharm. Sin. B 2014, 4, 454-463. [CrossRef]

105. Iqbal, M.A.; Md, S.; Sahni, J.K.; Baboota, S.; Dang, S.; Ali, J. Nanostructured lipid carriers system: Recent advances in drug delivery. J. Drug Target. 2012, 20, 813-830. [CrossRef]

106. Anton, N.; Benoit, J.-P.; Saulnier, P. Design and production of nanoparticles formulated from nano-emulsion templates-A review. J. Control. Release 2008, 128, 185-199. [CrossRef]

107. de Sousa Marcial, S.P.; Carneiro, G.; Leite, E.A. Lipid-based nanoparticles as drug delivery system for paclitaxel in breast cancer treatment. J. Nanoparticle Res. 2017, 19, 340. [CrossRef]

108. Jain, K.; Sood, S.; Gowthamarajan, K. Optimization of artemether-loaded NLC for intranasal delivery using central composite design. Drug Deliv. 2015, 22, 940-954. [CrossRef]

109. Yasir, M.; Chauhan, I.; Haji, M.J.; Tura, A.J.; Saxena, P.K. Formulation and evaluation of glyceryl behenate based solid lipid nanoparticles for the delivery of donepezil to brain through nasal route. Res. J. Pharm. Technol. 2018, 11, 2836-2844. [CrossRef]

110. Yasir, M.; Sara, U.V.S.; Chauhan, I.; Gaur, P.K.; Singh, A.P.; Puri, D.A. Solid lipid nanoparticles for nose to brain delivery of donepezil: Formulation, optimization by Box-Behnken design, in vitro and in vivo evaluation. Artif. Cells Nanomed. Biotechnol. 2018, 46, 1838-1851. [CrossRef]

111. Silva, S.; Bicker, J.; Fonseca, C.; Ferreira, N.R.; Vitorino, C.; Alves, G.; Falcão, A.; Fortuna, A. Encapsulated Escitalopram and Paroxetine Intranasal Co-Administration: In Vitro/In Vivo Evaluation. Front. Pharmacol. 2021, 12, 751321. [CrossRef] [PubMed]

112. Abdel Hady, M.; Sayed, O.M.; Akl, M.A. Brain uptake and accumulation of new levofloxacin-doxycycline combination through the use of solid lipid nanoparticles: Formulation; Optimization and in-vivo evaluation. Colloids Surf. B Biointerfaces 2020, 193, 111076. [CrossRef] [PubMed]

113. Devkar, T.B.; Tekade, A.R.; Khandelwal, K.R. Surface engineered nanostructured lipid carriers for efficient nose to brain delivery of ondansetron $\mathrm{HCl}$ using Delonix regia gum as a natural mucoadhesive polymer. Colloids Surf. B Biointerfaces 2014, 122, 143-150. [CrossRef] [PubMed]

114. Abd-algaleel, S.A.; Metwally, A.A.; Abdel-Bar, H.M.; Kassem, D.H.; Hathout, R.M. Synchronizing In Silico, In Vitro, and In Vivo Studies for the Successful Nose to Brain Delivery of an Anticancer Molecule. Mol. Pharm. 2021, 18, 3763-3776. [CrossRef]

115. Masjedi, M.; Azadi, A.; Heidari, R.; Mohammadi-Samani, S. Nose-to-brain delivery of sumatriptan-loaded nanostructured lipid carriers: Preparation, optimization, characterization and pharmacokinetic evaluation. J. Pharm. Pharmacol. 2020, 72, 1341-1351. [CrossRef]

116. Khan, A.; Imam, S.S.; Aqil, M.; Ahad, A.; Sultana, Y.; Ali, A.; Khan, K. Brain Targeting of Temozolomide via the Intranasal Route Using Lipid-Based Nanoparticles: Brain Pharmacokinetic and Scintigraphic Analyses. Mol. Pharm. 2016, 13, 3773-3782. [CrossRef]

117. Praveen, S.; Gowda, D.; Siddaramaiah, H.; Hemalatha, S. Ziprasidone hydrochloride loaded nanostructured lipid carriers (NLCS) for intranasal delivery: Optimization and in vivo studies. Int. J. Appl. Pharm. 2020, 12, 31-41. 
118. Noorulla, K.M.; Yasir, M.; Muzaffar, F.; Roshan, S.; Ghoneim, M.M.; Almurshedi, A.S.; Tura, A.J.; Alshehri, S.; Gebissa, T.; Mekit, S.; et al. Intranasal delivery of chitosan decorated nanostructured lipid carriers of Buspirone for brain targeting: Formulation development, optimization and In-Vivo preclinical evaluation. J. Drug Deliv. Sci. Technol. 2021, 67, 102939. [CrossRef]

119. Tripathi, D.; Sonar, P.K.; Parashar, P.; Chaudhary, S.K.; Upadhyay, S.; Saraf, S.K. Augmented Brain Delivery of Cinnarizine Through Nanostructured Lipid Carriers Loaded in situ Gel: In vitro and Pharmacokinetic Evaluation. BioNanoScience 2021, 11, 159-171. [CrossRef]

120. Madane, R.G.; Mahajan, H.S. Curcumin-loaded nanostructured lipid carriers (NLCs) for nasal administration: Design, characterization, and in vivo study. Drug Deliv. 2016, 23, 1326-1334. [CrossRef]

121. Fahmy, U.A.; Ahmed, O.A.A.; Badr-Eldin, S.M.; Aldawsari, H.M.; Okbazghi, S.Z.; Awan, Z.A.; Bakhrebah, M.A.; Alomary, M.N.; Abdulaal, W.H.; Medina, C.; et al. Optimized Nanostructured Lipid Carriers Integrated into In Situ Nasal Gel for Enhancing Brain Delivery of Flibanserin. Int. J. Nanomed. 2020, 15, 5253-5264. [CrossRef] [PubMed]

122. Jazuli, I.; Annu; Nabi, B.; Moolakkadath, T.; Alam, T.; Baboota, S.; Ali, J. Optimization of Nanostructured Lipid Carriers of Lurasidone Hydrochloride Using Box-Behnken Design for Brain Targeting: In Vitro and In Vivo Studies. J. Pharm. Sci. 2019, 108, 3082-3090. [CrossRef] [PubMed]

123. Palagati, S.; Sv, S.; Kesavan, B.R. Application of computational tools for the designing of Oleuropein loaded nanostructured lipid carrier for brain targeting through nasal route. DARU J. Pharm. Sci. 2019, 27, 695-708. [CrossRef] [PubMed]

124. Wang, L.; Zhao, X.; Du, J.; Liu, M.; Feng, J.; Hu, K. Improved brain delivery of pueraria flavones via intranasal administration of borneol-modified solid lipid nanoparticles. Nanomedicine 2019, 14, 2105-2119. [CrossRef] [PubMed]

125. Sivadasu, P.; Gowda, D.V.; Subramani, N.K.; Malgur, B.; Vishweshwaraiah, S.S.; Hatna, S. Direct brain targeted nanostructured lipid carriers for sustained release of schizophrenic drug: Formulation, characterization and pharmacokinetic studies. Brain 2020, 9, 12. [CrossRef]

126. Singh, A.; Ubrane, R.; Prasad, P.; Ramteke, S. Preparation and Characterization of Rizatriptan Benzoate Loaded Solid Lipid Nanoparticles for Brain Targeting. Mater. Today Proc. 2015, 2, 4521-4543. [CrossRef]

127. Pardeshi, C.V.; Belgamwar, V.S. Improved brain pharmacokinetics following intranasal administration of N,N,N-trimethyl chitosan tailored mucoadhesive NLCs. Mater. Technol. 2020, 35, 249-266. [CrossRef]

128. Gupta, S.; Kesarla, R.; Chotai, N.; Misra, A.; Omri, A. Systematic Approach for the Formulation and Optimization of Solid Lipid Nanoparticles of Efavirenz by High Pressure Homogenization Using Design of Experiments for Brain Targeting and Enhanced Bioavailability. BioMed Res. Int. 2017, 2017, 5984014. [CrossRef]

129. Jojo, G.M.; Kuppusamy, G.; De, A.; Karri, V.V.S.N.R. Formulation and optimization of intranasal nanolipid carriers of pioglitazone for the repurposing in Alzheimer's disease using Box-Behnken design. Drug Dev. Ind. Pharm. 2019, 45, 1061-1072. [CrossRef]

130. Esposito, E.; Ravani, L.; Drechsler, M.; Mariani, P.; Contado, C.; Ruokolainen, J.; Ratano, P.; Campolongo, P.; Trezza, V.; Nastruzzi, C.; et al. Cannabinoid antagonist in nanostructured lipid carriers (NLCs): Design, characterization and in vivo study. Mater. Sci. Eng. C 2015, 48, 328-336. [CrossRef]

131. Esposito, E.; Cortesi, R.; Drechsler, M.; Fan, J.; Fu, B.M.; Calderan, L.; Mannucci, S.; Boschi, F.; Nastruzzi, C. Nanoformulations for dimethyl fumarate: Physicochemical characterization and in vitro/in vivo behavior. Eur. J. Pharm. Biopharm. 2017, 115, 285-296. [CrossRef] [PubMed]

132. Hasan, N.; Imran, M.; Kesharwani, P.; Khanna, K.; Karwasra, R.; Sharma, N.; Rawat, S.; Sharma, D.; Ahmad, F.J.; Jain, G.K.; et al. Intranasal delivery of Naloxone-loaded solid lipid nanoparticles as a promising simple and non-invasive approach for the management of opioid overdose. Int. J. Pharm. 2021, 599, 120428. [CrossRef] [PubMed]

133. Li, J.-C.; Zhang, W.-J.; Zhu, J.-X.; Zhu, N.; Zhang, H.-M.; Wang, X.; Zhang, J.; Wang, Q.-Q. Preparation and brain delivery of nasal solid lipid nanoparticles of quetiapine fumarate in situ gel in rat model of schizophrenia. Int. J. Clin. Exp. Med. 2015, 8, 17590-17600. [PubMed]

134. de Oliveira Junior, E.R.; Truzzi, E.; Ferraro, L.; Fogagnolo, M.; Pavan, B.; Beggiato, S.; Rustichelli, C.; Maretti, E.; Lima, E.M.; Leo, E.; et al. Nasal administration of nanoencapsulated geraniol/ursodeoxycholic acid conjugate: Towards a new approach for the management of Parkinson's disease. J. Control. Release 2020, 321, 540-552. [CrossRef]

135. Khanna, K.; Sharma, N.; Rawat, S.; Khan, N.; Karwasra, R.; Hasan, N.; Kumar, A.; Jain, G.K.; Nishad, D.K.; Khanna, S.; et al. Intranasal solid lipid nanoparticles for management of pain: A full factorial design approach, characterization \& Gamma Scintigraphy. Chem. Phys. Lipids 2021, 236, 105060. [CrossRef]

136. Joshi, A.S.; Patel, H.S.; Belgamwar, V.S.; Agrawal, A.; Tekade, A.R. Solid lipid nanoparticles of ondansetron $\mathrm{HCl}$ for intranasal delivery: Development, optimization and evaluation. J. Mater. Sci. Mater. Med. 2012, 23, 2163-2175. [CrossRef]

137. Bhatt, R.; Singh, D.; Prakash, A.; Mishra, N. Development, characterization and nasal delivery of rosmarinic acid-loaded solid lipid nanoparticles for the effective management of Huntington's disease. Drug Deliv. 2015, 22, 931-939. [CrossRef]

138. Mostafa, D.A.E.; Khalifa, M.K.; Gad, S.S. Zolmitriptan Brain targeting via intranasal route using solid lipid nanoparticles for migraine therapy: Formulation, Characterization, in-vitro and In-vivo Assessment. Int. J. Appl. Pharm. 2020, 10, 86-93. [CrossRef]

139. Matarazzo, A.P.; Elisei, L.M.S.; Carvalho, F.C.; Bonfílio, R.; Ruela, A.L.M.; Galdino, G.; Pereira, G.R. Mucoadhesive nanostructured lipid carriers as a cannabidiol nasal delivery system for the treatment of neuropathic pain. Eur. J. Pharm. Sci. 2021, 159, 105698. [CrossRef] 
140. Du, W.; Li, H.; Tian, B.; Sai, S.; Gao, Y.; Lan, T.; Meng, Y.; Ding, C. Development of nose-to-brain delivery of ketoconazole by nanostructured lipid carriers against cryptococcal meningoencephalitis in mice. Colloids Surf. B Biointerfaces 2019, $183,110446$. [CrossRef]

141. Esposito, E.; Drechsler, M.; Mariani, P.; Carducci, F.; Servadio, M.; Melancia, F.; Ratano, P.; Campolongo, P.; Trezza, V.; Cortesi, R.; et al. Lipid nanoparticles for administration of poorly water soluble neuroactive drugs. Biomed. Microdevices 2017, 19, 44 . [CrossRef] [PubMed]

142. Soane, R.J.; Frier, M.; Perkins, A.C.; Jones, N.S.; Davis, S.S.; Illum, L. Evaluation of the clearance characteristics of bioadhesive systems in humans. Int. J. Pharm. 1999, 178, 55-65. [CrossRef]

143. Karmakar, A.; Zhang, Q.; Zhang, Y. Neurotoxicity of nanoscale materials. J. Food Drug Anal. 2014, 22, 147-160. [CrossRef] [PubMed]

144. Marttin, E.; Schipper, N.G.M.; Verhoef, J.C.; Merkus, F.W.H.M. Nasal mucociliary clearance as a factor in nasal drug delivery. Adv. Drug Deliv. Rev. 1998, 29, 13-38. [CrossRef]

145. Di Gioia, S.; Trapani, A.; Mandracchia, D.; De Giglio, E.; Cometa, S.; Mangini, V.; Arnesano, F.; Belgiovine, G.; Castellani, S.; Pace, L.; et al. Intranasal delivery of dopamine to the striatum using glycol chitosan/sulfobutylether- $\beta$-cyclodextrin based nanoparticles. Eur. J. Pharm. Biopharm. 2015, 94, 180-193. [CrossRef]

146. Cassano, R.; Trapani, A.; Di Gioia, M.L.; Mandracchia, D.; Pellitteri, R.; Tripodo, G.; Trombino, S.; Di Gioia, S.; Conese, M. Synthesis and characterization of novel chitosan-dopamine or chitosan-tyrosine conjugates for potential nose-to-brain delivery. Int. J. Pharm. 2020, 589, 119829. [CrossRef]

147. Sonvico, F.; Clementino, A.; Buttini, F.; Colombo, G.; Pescina, S.; Stanisçuaski Guterres, S.; Raffin Pohlmann, A.; Nicoli, S. Surface-Modified Nanocarriers for Nose-to-Brain Delivery: From Bioadhesion to Targeting. Pharmaceutics 2018, 10, 34. [CrossRef]

148. Ugwoke, M.I.; Agu, R.U.; Verbeke, N.; Kinget, R. Nasal mucoadhesive drug delivery: Background, applications, trends and future perspectives. Adv. Drug Deliv. Rev. 2005, 57, 1640-1665. [CrossRef]

149. Trapani, A.; Cometa, S.; De Giglio, E.; Corbo, F.; Cassano, R.; Di Gioia, M.L.; Trombino, S.; Hossain, M.N.; Di Gioia, S.; Trapani, G.; et al. Novel Nanoparticles Based on N,O-Carboxymethyl Chitosan-Dopamine Amide Conjugate for Nose-to-Brain Delivery. Pharmaceutics 2022, 14, 147. [CrossRef]

150. Sosnik, A.; das Neves, J.; Sarmento, B. Mucoadhesive polymers in the design of nano-drug delivery systems for administration by non-parenteral routes: A review. Prog. Polym. Sci. 2014, 39, 2030-2075. [CrossRef]

151. Vieira, A.C.C.; Chaves, L.L.; Pinheiro, S.; Pinto, S.; Pinheiro, M.; Lima, S.C.; Ferreira, D.; Sarmento, B.; Reis, S. Mucoadhesive chitosan-coated solid lipid nanoparticles for better management of tuberculosis. Int. J. Pharm. 2018, 536, 478-485. [CrossRef] [PubMed]

152. Trotta, V.; Pavan, B.; Ferraro, L.; Beggiato, S.; Traini, D.; Des Reis, L.G.; Scalia, S.; Dalpiaz, A. Brain targeting of resveratrol by nasal administration of chitosan-coated lipid microparticles. Eur. J. Pharm. Biopharm. 2018, 127, 250-259. [CrossRef] [PubMed]

153. Sabir, F.; Ismail, R.; Csoka, I. Nose-to-brain delivery of antiglioblastoma drugs embedded into lipid nanocarrier systems: Status quo and outlook. Drug Discov. Today 2020, 25, 185-194. [CrossRef] [PubMed]

154. Erdő, F.; Bors, L.A.; Farkas, D.; Bajza, Á.; Gizurarson, S. Evaluation of intranasal delivery route of drug administration for brain targeting. Brain Res. Bull. 2018, 143, 155-170. [CrossRef] [PubMed]

155. Lee, K.-R.; Maeng, H.-J.; Chae, J.-B.; Chong, S.; Kim, D.-D.; Shim, C.-K.; Chung, S.-J. Lack of a Primary Physicochemical Determinant in the Direct Transport of Drugs to the Brain after Nasal Administration in Rats: Potential Involvement of Transporters in the Pathway. Drug Metab. Pharmacokinet. 2010, 25, 430-441. [CrossRef] 